Fusão de informações obtidas a partir de múltiplas imagens visando à navegação autônoma de veículos inteligentes em ambiente agrícola 



\title{
Fusão de informações obtidas a partir de múltiplas imagens visando à navegação autônoma de veículos inteligentes em ambiente agrícola
}

\author{
Vítor Manha Utino
}

Orientador: Prof. Dr. Fernando Santos Osório

Dissertação apresentada ao Instituto de Ciências Matemáticas e de Computação - ICMC-USP, como parte dos requisitos para obtenção do título de Mestre em Ciências - Ciências de Computação e Matemática Computacional. EXEMPLAR DE DEFESA. 
Ficha catalográfica elaborada pela Biblioteca Prof. Achille Bassi e Seção Técnica de Informática, ICMC/USP, com os dados fornecidos pelo(a) autor(a)

Utino, Vítor Manha Fusão de informações obtidas a partir de múltiplas imagens visando à navegação autônoma de veículos inteligentes em ambiente agrícola / Vítor Manha Utino; orientador Fernando Santos Osório. -São Carlos, 2015. $80 \mathrm{p}$.

Tese (Doutorado - Programa de Pós-Graduação em Ciências de Computação e Matemática Computacional) -Instituto de Ciências Matemáticas e de Computação, Universidade de São Paulo, 2015.

1. Veículos Autônomos. 2. Detecção de Obstáculos. 3. Ambiente Rural. 4. Visão Computacional. 5. Fusão de Dados. I. Osório, Fernando Santos, orient. II. Título. 


\section{Resumo}

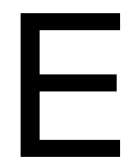

ste trabalho apresenta um sistema de auxilio à navegação autônoma para veículos terrestres com foco em ambientes estruturados em um cenário agrícola. É gerada a estimativa das posições dos obstáculos baseado na fusão das detecções provenientes do processamento dos dados de duas câmeras, uma estéreo e outra térmica. Foram desenvolvidos três módulos de detecção de obstáculos. O primeiro módulo utiliza imagens monoculares da câmera estéreo para detectar novidades no ambiente através da comparação do estado atual com o estado anterior. O segundo módulo utiliza a técnica Stixel para delimitar os obstáculos acima do plano do chão. Por fim, o terceiro módulo utiliza as imagens térmicas para encontrar assinaturas que evidenciem a presença de obstáculo. Os módulos de detecção são fundidos utilizando a Teoria de Dempster-Shafer que fornece a estimativa da presença de obstáculos no ambiente. Os experimentos foram executados em ambiente agrícola real. Foi executada a validação do sistema em cenários bem iluminados, com terreno irregular e com obstáculos diversos. O sistema apresentou um desempenho satisfatório tendo em vista a utilização de uma abordagem baseada em apenas três módulos de detecção com metodologias que não tem por objetivo priorizar a confirmação de obstáculos, mas sim a busca de novos obstáculos. Nesta dissertação são apresentados os principais componentes de um sistema de detecção de obstáculos e as etapas necessárias para a sua concepção, assim como resultados de experimentos com o uso de um veículo real.

Palavras-chave: Robôs Móveis Autônomos, Câmera Monocular, Câmera Estéreo, Câmera Térmica, Calibração de Câmeras, Fusão de sensores e Detecção de Obstáculos. 


\section{Abstract}

$\mathrm{T}$

his work presents a support system to the autonomous navigation for ground vehicles with focus on structured environments in an agricultural scenario. The estimated obstacle positions are generated based on the fusion of the detections from the processing of data from two cameras, one stereo and other thermal. Three modules obstacle detection have been developed. The first module uses monocular images of the stereo camera to detect novelties in the environment by comparing the current state with the previous state. The second module uses Stixel technique to delimit the obstacles above the ground plane. Finally, the third module uses thermal images to find signatures that reveal the presence of obstacle. The detection modules are fused using the Dempster-Shafer theory that provides an estimate of the presence of obstacles in the environment. The experiments were executed in real agricultural environment. System validation was performed in well-lit scenarios, with uneven terrain and different obstacles. The system showed satisfactory performance considering the use of an approach based on only three detection modules with methods that do not prioritize obstacle confirmation, but the search for new ones. This dissertation presents the main components of an obstacle detection system and the necessary steps for its design as well as results of experiments with the use of a real vehicle.

Keywords: Autonomous Mobile Robots, Monocular Camera, Stereo Camera, Thermal Camera, Camera Calibration, Sensor Fusion and Obstacle Detection. 


\section{Sumário}

Resumo

Abstract

iii

Sumário

Lista de Figuras

vii

Lista de Tabelas

xi

1. Introdução

1.1. Contextualização

1.2. Motivação 4

1.3. Objetivo 6

1.4. Estrutura da Dissertação 8

2. Robótica Móvel 9

2.1. Robôs Móveis Autônomos 9

2.2. Robótica na Agricultura 12

2.3. Sensores 12

2.3.1. Câmera de Vídeo Monocular 13

2.3.2. Câmera de Vídeo Estéreo 15

2.3.3. Câmera de Vídeo Termal 16

$\begin{array}{ll}\text { 2.4. Imagem } & 18\end{array}$

2.5. Segmentação de Imagem 20

2.6. Método de Otsu 21

2.7. Calibração 23

2.8. Mapa de Profundidade 24

2.9. Ferramentas de Software 26 
2.9.1. OpenCV 26

2.9.2. ROS 27

2.10. Fusão de Sensores $\quad 27$

2.11. Teoria de Dempster-Shafer 28

2.12. Considerações 29

3. Trabalhos Relacionados 31

3.1. Câmera de Vídeo Monocular 31

3.2. Câmera de Vídeo Estéreo 34

3.3. Câmera de Vídeo Térmica 37

3.4. Considerações 38

4. Metodologia $\quad \mathbf{4 0}$

4.1. Detecção de Obstáculos Utilizando Câmera de Vídeo Monocular 41

4.2. Detecção de Obstáculos Utilizando Câmera de Vídeo Estéreo 43

4.3. Calibração 44

4.4. Detecção de Obstáculos Utilizando Câmera de Vídeo Térmica 46

4.5. Fusão de Dados dos Sensores 47

4.6. Considerações 50

5. Experimentos e Resultados 51

5.1. Configuração dos Experimentos Realizados 51

5.2. Módulo de Detecção de Obstáculos Utilizando Câmera Monocular 54

5.3. Módulo de Detecção de Obstáculos Utilizando Câmera Estéreo 57

5.4. Calibração entre as Câmeras Térmica e Monocular 61

5.5. Módulo de Detecção de Obstáculos Utilizando Câmera Térmica 62

5.6. Detecção de Obstáculos Utilizando Câmera Térmica Durante a Noite 65

5.7. Fusão dos Módulos de Detecção de Obstáculos 68

5.8. Considerações 70

6. Conclusão $\quad 72$

6.1. Trabalhos Futuros $\quad 73$

Referências Bibliográficas $\quad 74$

Publicações Obtidas Como Resultado Deste Trabalho 80 


\section{Lista de Figuras}

Figura 1.1 - Veículo autônomo JAV I. Fonte:

http://www.edcentaurus.com.br/materias/granja.php?id=3782

Figura 1.2 - Veículo autônomo JAV II. Fonte:

http://www.edcentaurus.com.br/materias/granja.php?id=5406

Figura 1.3 - a) Projeto CaRINA I b) Projeto CaRINA II. Fonte: (LRM, 2014) 5

Figura 1.4 - Projeto NAV-AG. Fonte: (LRM, 2014) 5

Figura 1.5 - Projeto NAV-SEC. Fonte: (LRM, 2014) 5

Figura 1.6 - Imagens obtidas em uma plantação de laranja: a) Mapa de navegabilidade e obstáculos estimados, b) Imagem colorida do ambiente analisado, c) Mapa de profundidade obtido pela câmera estéreo. Fonte: (LRM, 2014)

Figura 1.7 - Citricultura estruturada. Fonte: (LRM, 2014) 7

Figura 2.1 - Roomba, Robô aspirador de pó. Fonte:

http://static.fiercemarkets.com/public/newsletter/dailytechrag/roomba_560.jpg 10

Figura 2.2 - Surveyor SRV. Fonte: (LRM, 2014) 10

Figura 2.3 - CaRINA II. Fonte: (LRM, 2014) 10

Figura 2.4 - Veículo autônomo "Boss", vencedor do DARPA 2007. Fonte:

http://www.autoline.tv/journal/?page_id=35

Figura 2.5 - Agribot, plataforma multifuncional para coleta de dados em agricultura de precisão. Fonte: http://www.nepas.eesc.usp.br/roboticaagricola/index.php/robosagricolas/agribot

Figura 2.6 - Carro autônomo da Google. Fonte: http://bgr.com/2012/08/07/google-selfdriving-car-accidents-300000-miles/ 
Figura 2.7 - a) Sensor CCD. b) Sensor CMOS. Fonte:

http://eletronicos.hsw.uol.com.br/cameras-digitais.htm

Figura 2.8 - Câmera estéreo Bumblebee2. Fonte:

http://www.ptgrey.com/products/bumblebee2/bumblebee2_stereo_camera.asp 15

Figura 2.9 - Nuvem de pontos gerada a partir de uma câmera estéreo . Fonte:

http://www.geometh.ethz.ch/research/range

Figura 2.10 - a) Imagem térmica em tons de cinza. b) Imagem térmica usando cores "quentes" e "frias". Fontes:

http://www.x2extreme.com/Thermal_Scopes/Thermal_Camera.jpg e http://hackedirl.files.wordpress.com/2011/07/epic-win-photos-thermal-elephantwin.jpg

Figura 2.11 - Câmera térmica FLIR PathFindlR. Fonte:

http://www. mitocorp.com/oem/flir-camera.jpg

Figura 2.12 - Visualização noturna de uma câmera de vídeo comum e de uma câmera termal. Fonte:

http://www.teakatoys.com/Hummer_Night_Vision_Package_by_MitoCorp_p/mitonightvision\%20pkg.html

Figura 2.13 - Representação de uma imagem através de pixels. Fonte: http://en.wikipedia.org/wiki/File:Dithering_example_undithered.png

Figura 2.14 - a) Visões da mesma cena pelos dois olhos. b) Superposição das imagens e a disparidade na retina. Fonte: (KIRNER, 2004)

Figura 2.15 - Resultado da aplicação do método de Otsu. Fonte: http://scipylectures.github.io/packages/scikit-image/

Figura 2.16 - Gabarito de calibração. Fonte (ALVES, 2007)

Figura 2.17 - (a) Mapa de profundidade de uma face. (b) Mapa de profundidade de latas. Fonte: http://jaredjared.com/chroma.html e

http://www.dofpro.com/cgigallery.html

Figura 2.18 - Diagrama de fusão de sensores. Fonte: Adaptado de http://www.ni.com/white-paper/8219/en

Figura 3.1 - (a) Cena do ambiente. (b) Subdivisão da cena em blocos a serem classificados pelo RNA. (c) Classificação das regiões quanto à navegabilidade. Fonte: (SHINZATO, 2010)

Figura 3.2 - a) Área de interesse da imagem. b) Remoção da área indesejada na imagem. Fonte: (LEE, 2005)

Figura 3.3 - a) Definição da área não navegável (vermelho) e navegável (azul). b) Resultado da classificação da cena (em branco a área navegável). Fonte (LEE, 2005) 
Figura 3.4 - Mapa de navegabilidade gerado e ilustração do método de desvio de obstáculos baseado no algoritmo VFH (Vector Field Histogram). Fonte: (MENDES, 2010)

Figura 3.5 - Técnica Stixel em dois diferentes cenários do mundo real. a) Estrada. b) Ambiente urbano. A cor dos stixels representa a distância lateral ao veículo. Fonte: (BADINO, 2009)

Figura 3.6 - Detecção de pedestres utilizando câmera estéreo. Linhas em tons de verde representam a estimação da técnica Stixel. Retângulos vermelhos representam a detecção dos pedestres. Fonte: (BENENSON, 2012)

Figura 3.7 - Segmentação da imagem utilizando a câmera térmica. Fonte: (NIN, 2011)

Figura 3.8 - a) Imagem capturada pela câmera térmica. b) Imagem pré-processada utilizando filtro de limiarização com o método de Otsu. Fonte: (CORREA, 2012)

Figura 4.1 - a) Ambiente sem obstáculos. b) Ambiente contendo obstáculos de cores e texturas contrastantes.

Figura 4.2 - Ambiente modificado com um retângulo alaranjado no horizonte.

Figura 4.3 - a) Histograma da imagem original. b) Histograma da imagem contendo o retângulo alaranjado, as setas indicam as alterações ocorridas.

Figura 4.4 - a) Estimação do plano do chão. b) Estimação da altura dos obstáculos. Fonte: (BADINO, 2009)

Figura 4.5 - Padrão xadrez utilizado na calibração das câmeras monocular e térmica.

Figura 4.6 - Detecção das features na imagem térmica a) e na imagem monocular b).

Figura 4.7 - a) Imagem térmica. b) Imagem térmica com a intensidade corrigida. Fonte: (JADIN, 2012)

Figura 4.8 - Resultado da fusão em 2D das informações dos módulos de detecção de obstáculos. As cores mais fortes representam uma probabilidade maior em existir um obstáculo.

Figura 5.1 - Fixação e disposição das câmeras estéreo e térmica durante os experimentos.

Figura 5.2 - Software de marcação manual de obstáculos.

Figura 5.3 - Remoção do céu da imagem com perda de informação de obstáculo. 55

Figura 5.4 - Remoção do céu da imagem sem perda de informações adicionais. 
Figura 5.5 - Resultado da redução da quantidade de cores da imagem.

Figura 5.6 - Resultado da detecção de obstáculos utilizando câmera monocular. 56

Figura 5.7 - Interface da aplicação rviz executando a técnica Stixel.

Figura 5.8 - Detecção de obstáculos em ambiente agrícola utilizando a técnica Stixel.

Figura 5.9 - Detecção de obstáculos em ambiente urbano com diferença de luminosidade utilizando a técnica Stixel.

Figura 5.10 - a) Padrão capturado pela câmera monocular. b) Padrão capturado pela câmera térmica. c) Imagem resultante da calibração.

Figura 5.11 - Imagem térmica com ajuste de intensidade.

Figura 5.12 - a) Imagem térmica. b) Imagem segmentada pelo método de Otsu.

Figura 5.13 - a) Imagem térmica com regiões expostas ao Sol. b) Imagem segmentada pelo método de Otsu.

Figura 5.14 - a) e d) Ambiente do experimento com iluminação artificial. b) e d) Ambiente do experimento sem iluminação artificial.

Figura 5.15 - Segmentação da imagem térmica em diferentes situações e distâncias.

Figura 5.16 - Fusão dos módulos de detecção.

Figura 5.17 - Resultado da fusão dos sensores com a presença de obstáculo a frente do veículo.

Figura 5.18 - Resultado da fusão de sensores sem a presença de obstáculos logo a frente do veículo. 


\section{Lista de Tabelas}

Tabela 5.1 - Resultados da detecção de obstáculos utilizando a câmera monocular. 57

Tabela 5.2 - Resultados da detecção de obstáculos utilizando a câmera estéreo. 61

Tabela 5.3 - Resultados da detecção de obstáculos utilizando a câmera térmica. 65

Tabela 5.4 - Resultados da detecção de obstáculos utilizando a câmera térmica durante a noite.

Tabela 5.5 - Resultados da fusão dos módulos de detecção. 
Este capítulo visa contextualizar a principal área abordada neste trabalho, a robótica móvel, e apresentar a motivação desta dissertação abordando seus objetivos e apresentando uma visão sucinta dos demais capítulos.

\subsection{Contextualização}

A constante evolução proporcionada pelas pesquisas em robótica móvel tem desenvolvido robôs cada vez mais eficientes para as mais variadas funções. Dotar robôs autônomos da capacidade de raciocínio inteligente e de interação com o meio em que estão inseridos é uma área de pesquisa que tem atraído à atenção de um grande número de pesquisadores (DUDEK e JENKIN, 2000).

Um Robô Móvel Autônomo (RMA) pode ser definido como um agente inteligente (GARCIA e SICHMAN, 2003). Móvel por poder se locomover pelo ambiente; autônomo por não necessitar ou ter a mínima interferência humana possível; e inteligente para, a partir de dados de sensores, conseguir atuar e se adaptar de maneira coerente ao ambiente ao qual foi inserido. A robótica móvel é uma área de pesquisa que lida com o controle de veículos autônomos ou semiautônomos (DUDEK e JENKIN, 2000; BEKEY, 2005).

Um dos objetivos primordiais do uso de sistemas robóticos é de que estes podem auxiliar em tarefas que exponham os seres humanos a algum tipo de risco, como limpeza e manipulação de resíduos tóxicos, inspeção de dutos, construção civil, agricultura, exploração de ambientes perigosos e segurança em áreas abertas e fechadas.

Um diferencial da robótica móvel comparado com outras áreas de pesquisa em robótica é sua ênfase nos problemas relacionados à operação (locomoção) em 
ambientes complexos, geralmente compostos de obstáculos estáticos e dinâmicos. Para operar neste tipo de ambiente o robô deve ser capaz de adquirir e utilizar conhecimento sobre o ambiente, possuir a habilidade de reconhecer obstáculos e responder em tempo real as diferentes situações que este possa encontrar. As tarefas de perceber, se localizar, e se mover pelo ambiente evitando colisões são problemas fundamentais no estudo dos robôs móveis autônomos (DUDEK e JENKIN, 2000; BEKEY, 2005).

A navegação é uma das importantes tarefas na área da robótica móvel, é o processo no qual o robô se move em um ambiente de trabalho, geralmente contendo obstáculos estáticos e/ou dinâmicos, de uma posição e orientação inicial para uma posição e orientação destino (SIEGWART e NOURBAKHSH, 2004). Ir de um lugar para outro depende de três aspectos fundamentais: localização, orientação, percepção/decisão e controle. Para conhecer tanto sua localização como sua orientação, um RMA deve possuir sensores adequados (GPS, bússola, etc.). Para o controle, um RMA deve possuir um número adequado de motores (um veículo autônomo, por exemplo, usualmente possui um motor angular, para o controle da direção das rodas e um motor linear, para tração). Para poder se deslocar de modo seguro, um RMA deve possuir sensores que permitam detectar obstáculos, e assim poder decidir como agir, fazendo uso de conhecimentos sobre o ambiente (p.ex. mapas e trajetórias) ou não. Normalmente sensores e atuadores são sujeitos a erros e interferências, assim o controle das ações de um robô deve sempre levar em conta a imprecisão dos sensores e motores envolvidos. Um sistema robusto deve permitir que, mesmo com sensores e atuadores imprecisos, 0 agente cumpra adequadamente com o seu objetivo.

Como resultado da evolução das pesquisas em robótica móvel, o futuro de aplicações robotizadas na agricultura é promissor. Hoje, veículos autônomos são grandes candidatos como alternativa para a escassa mão de obra qualificada no campo e, em propriedades de grande porte onde a agricultura de precisão deve dominar o cenário. $O$ uso de sistemas robotizados para atividades de monitoramento, coleta de amostras, colheita, entre outras, deve crescer muito nas próximas décadas.

Não restritos apenas ao ambiente terrestre, os robôs móveis aéreos tem também ganhado espaço na área agrícola por permitirem manobras de maior complexidade, alcançando locais de difícil acesso, com menor consumo de energia. Além disto, é uma excelente fonte de coleta de dados e diagnósticos minimamente invasivos, pois muitas vezes, no campo, a detecção precoce de uma infestação pode permitir um controle e reduzir drasticamente os prejuízos para o agricultor.

$\mathrm{Na}$ agricultura, a automação de veículos já é uma realidade. A chamada agricultura de precisão (AP) vem ganhando adeptos principalmente nas principais áreas produtoras do país. O uso de tecnologias de ponta como GPS RTK (Real Time Kinematic), sensoriamento remoto, piloto automático, etc. integrado as máquinas 
permitiu uma grande redução de custo somado ao aumento da produtividade. Apesar do auxilio de toda a tecnologia, ainda é necessário que um ser humano opere o maquinário, o que gera muitas vezes erros que impedem que o agricultor maximize ao máximo seu lucro.

Tendo como inevitável a automação total da frota agrícola em um futuro próximo, a empresa Máquinas Agrícolas Jacto (JACTO, 2014) deu inicio ao desenvolvimento de veículos autônomos agrícolas, tendo sua primeira geração conceitual denominada JAV I (Jacto Autonomous Vehicle I) (ver Figura 1.1) e sua segunda geração, capaz de ir a campo devido a sua maior autonomia e velocidade de operação, o JAV II (Jacto Autonomous Vehicle II) (ver Figura 1.2).

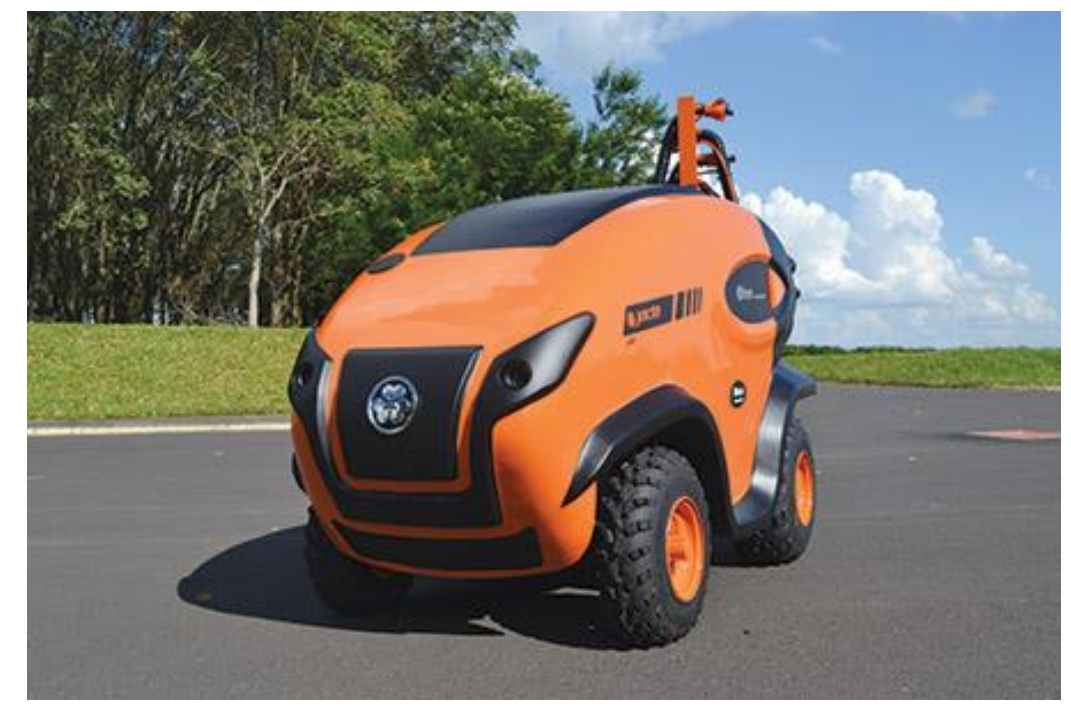

Figura 1.1 - Veículo autônomo JAV I. Fonte:

http://www.edcentaurus.com.br/materias/granja.php?id=3782

O projeto JAV nasceu com o objetivo de gerar tecnologias, conhecimentos e experiências para futuros produtos que necessitem de especificidades na realização de tarefas em campo com pouca ou sem a presença humana. O conceito do veículo autônomo é de um pulverizador autopropelido capaz de, em um primeiro momento, realizar tarefas em ambientes controlados (JAV I), tais como estufas; em um segundo, trabalhar em culturas perenes (JAV II) e, em um último estágio, em culturas extensivas, como soja, milho e cana. 


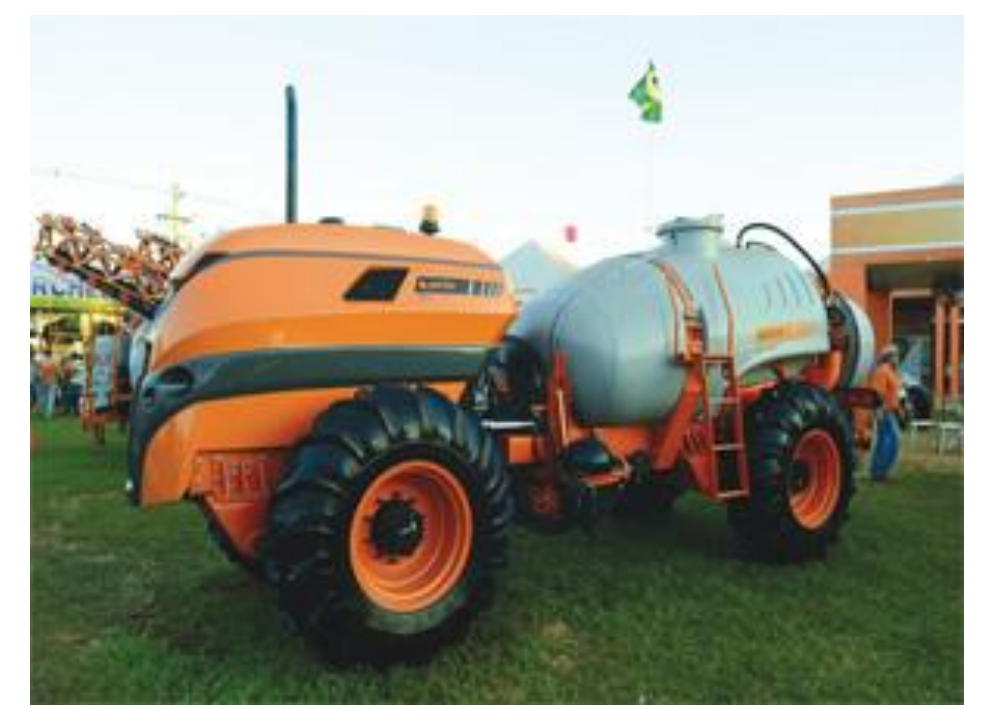

Figura 1.2 - Veículo autônomo JAV II. Fonte:

http://www.edcentaurus.com.br/materias/granja.php?id=5406

O equipamento está dotado de sensores que monitoram todos os obstáculos e atividades do ambiente e o guiam por uma rota pré-estabelecida por GPS ou, em casos de manobras fora de operação, por telecomando. Tendo embarcado uma câmera estéreo e sensores de proximidade, o JAV II também está apto a identificar, desviar e até mesmo parar em casos de emergência e informar a base de controle a cerca de obstáculos que podem ser estáticos ou dinâmicos. Este projeto que já está quase em fase comercial é apenas um exemplo entre muitos outros (LI, 2009), porém é um exemplo importante dos trabalhos de pesquisa e desenvolvimento que vêm sendo realizados atualmente no Brasil por empresas privadas atuantes na área agrícola.

\subsection{Motivação}

Esta dissertação de mestrado se insere no contexto de pesquisas que já vem sendo desenvolvidas no LRM (Laboratório de Robótica Móvel) (LRM, 2014) junto ao INCT-SEC (Instituto Nacional de Ciência e Tecnologia em Sistemas Embarcados Críticos) (INCT-SEC, 2014) e mais recentemente junto ao CROB-SC/USP (Centro de Robótica de São Carlos) (CROB, 2014). O LRM-ICMC/USP com o apoio do INCTSEC estabeleceu em 2012 uma parceria com a empresa privada Máquinas Agrícolas Jacto.

O LRM-ICMC/USP desenvolve pesquisas em diversas áreas relacionadas à robótica, dentre elas destacam-se: visão computacional, sistemas inteligentes, computação evolutiva, aprendizado de máquina, sistemas computacionais reconfiguráveis, robôs e veículos autônomos. Atualmente, grande parte da pesquisa desenvolvida no laboratório está relacionada ao desenvolvimento de veículos inteligentes para ambientes urbanos (projetos CaRINA e S-TRUCK) (ver Figura 1.3), 
agrícolas (projeto NAV-AG) (ver Figura 1.4) e de segurança (projeto SEC-BOT) (ver Figura 1.5).

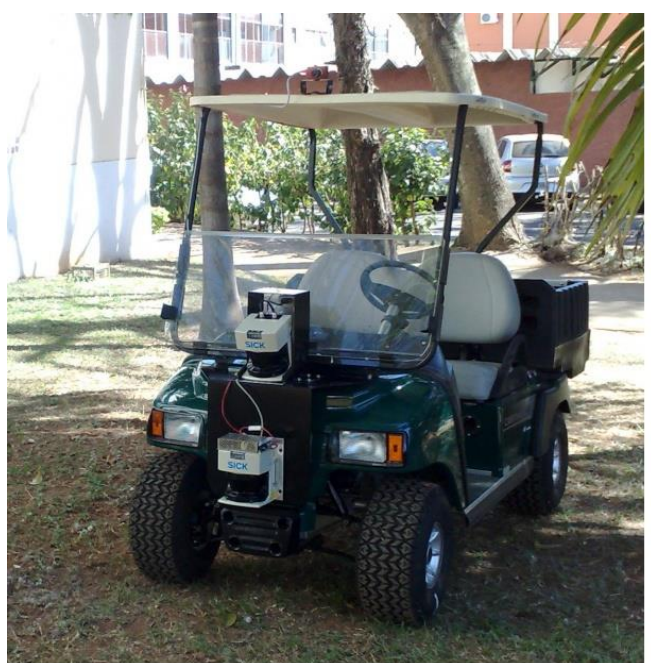

a)

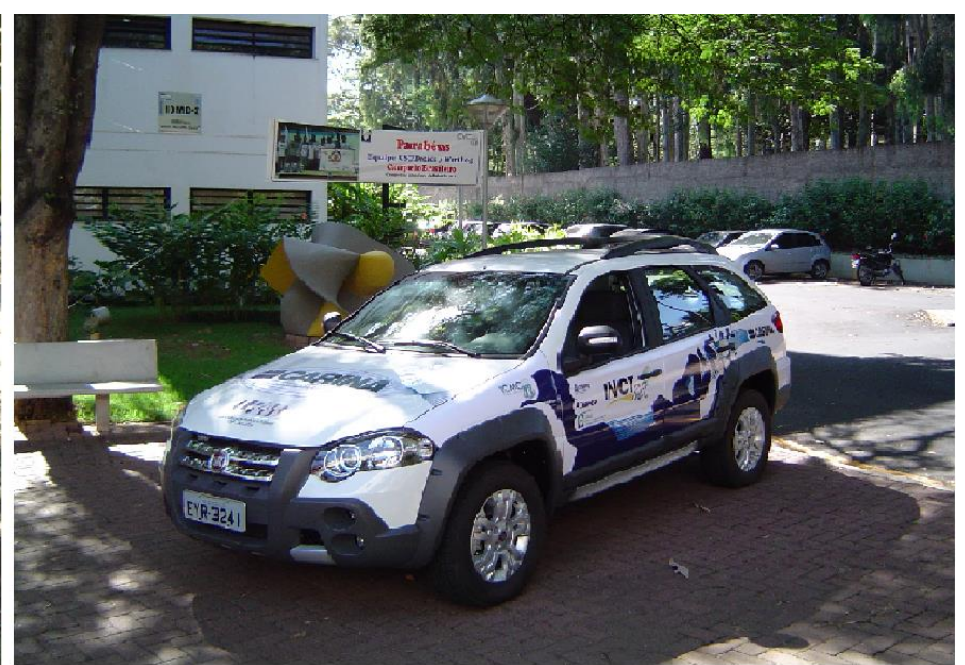

b)

Figura 1.3 - a) Projeto CaRINA I b) Projeto CaRINA II. Fonte: (LRM, 2014)
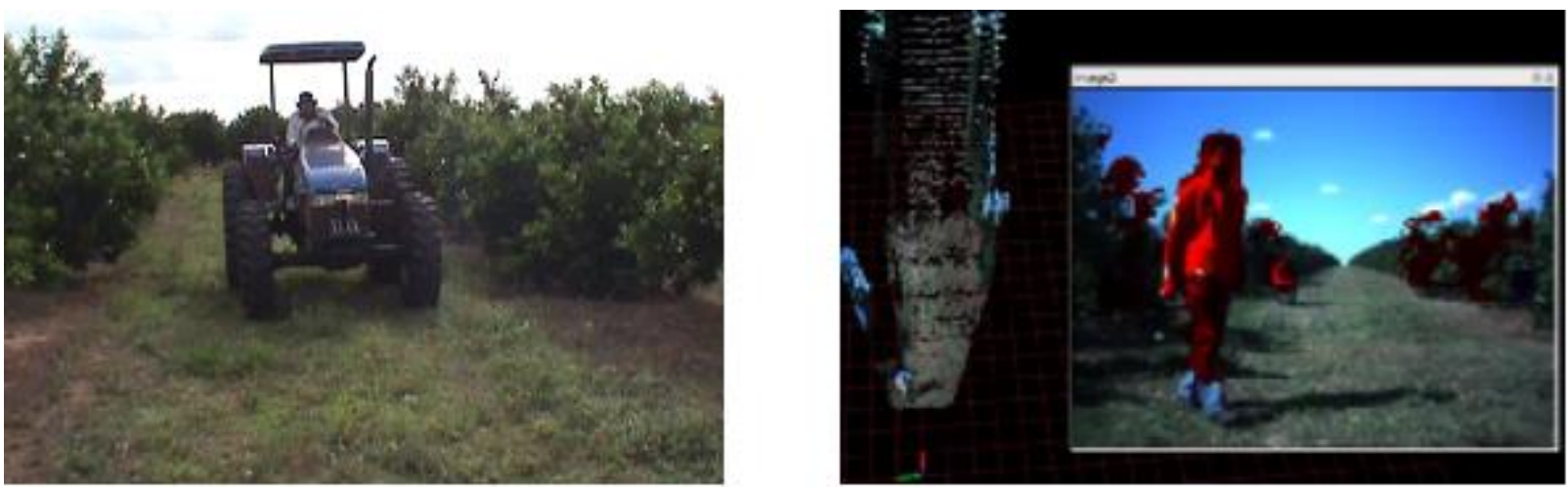

Figura 1.4 - Projeto NAV-AG. Fonte: (LRM, 2014)
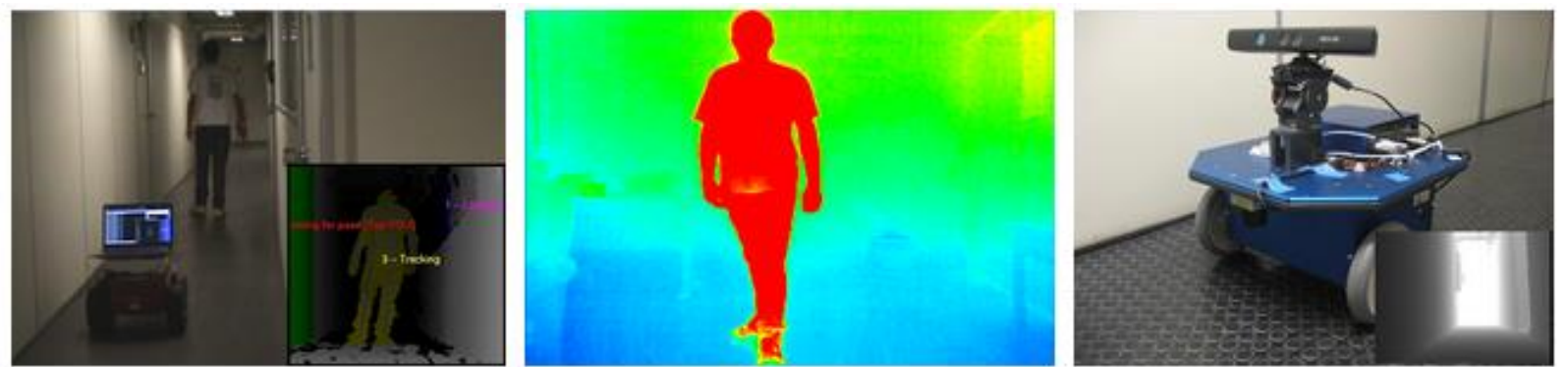

Figura 1.5 - Projeto NAV-SEC. Fonte: (LRM, 2014)

O projeto NAV-AG (Navegação na Agricultura), ao qual este trabalho está relacionado, tem como objetivo o desenvolvimento de algoritmos inteligentes para aplicações robóticas na área agrícola. Através da automação, é buscada uma diminuição de custos e aumento da eficácia na prática da agricultura, esta necessária para que seus produtos sejam competitivos dentro e fora do mercado nacional. Uma 
das principais linhas de pesquisa nesse projeto é a detecção de obstáculos por máquinas agrícolas em linhas de plantio.

Cabe destacar que o presente projeto visa dar continuidade aos trabalhos em desenvolvimento junto ao LRM-ICMC/USP e INCT-SEC, focados no estudo e desenvolvimento de métodos e algoritmos para a detecção de obstáculos visando à navegação autônoma de robôs móveis, onde podemos destacar três dissertações de mestrado defendidas recentemente (HATA, 2010; SHINZATO, 2010; MENDES, 2012; KLASER, 2013) que deram origem a diversas publicações importantes e novos projetos.

Esta dissertação visa contribuir de modo importante e significativo para o desenvolvimento de um sistema inteligente de detecção de obstáculos voltado à navegação de robôs móveis autônomos para aplicações agrícolas, tema este relevante no cenário das pesquisas nacionais e internacionais em robótica móvel, bem como foco central de parcerias como a que foi estabelecida entre o LRM e a empresa Jacto, visando o desenvolvimento de soluções para veículos autônomos como o do projeto JAV.

\subsection{Objetivo}

Esta dissertação de mestrado visa alcançar como principal resultado o desenvolvimento de um sistema capaz de detectar em tempo real a presença de obstáculos estáticos e dinâmicos através da fusão de diferentes imagens obtidas através de diferentes tipos de câmeras de vídeo (monocular, estéreo e térmica). 0 trabalho desenvolvido será parte fundamental de um sistema de navegação de um veículo autônomo utilizado na pulverização de culturas permanentes. É importante destacar que o produto deste trabalho poderá ser também implantado em diversos tipos de aplicações utilizando robôs autônomos.

Através da fusão das imagens capturadas através das diferentes câmeras de vídeo, procuramos obter a classificação dos elementos da cena por diferentes técnicas e desta forma poder detectar objetos intransponíveis, pessoas e animais. Vale a pena ressaltar que essa classificação levará em consideração que pequenos objetos ou irregularidades do terreno que não atrapalhem a navegação do veículo não sejam considerados como verdadeiros obstáculos. Pela Figura 1.6 pode ser vista a imagem de uma plantação de laranja obtida através de diferentes tipos de câmeras. 


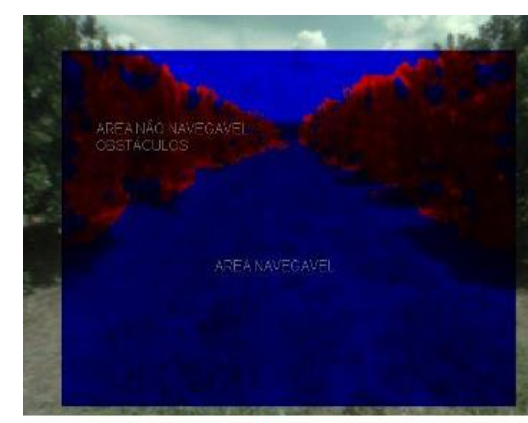

(a)

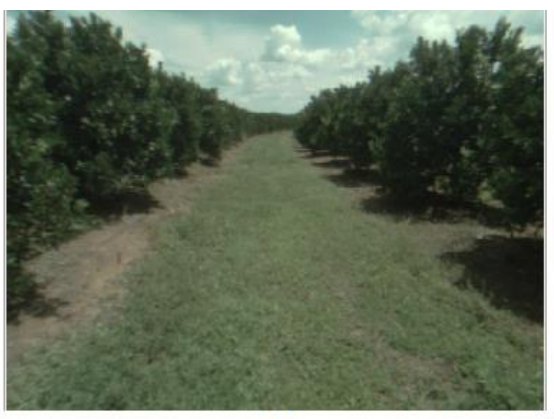

(b)

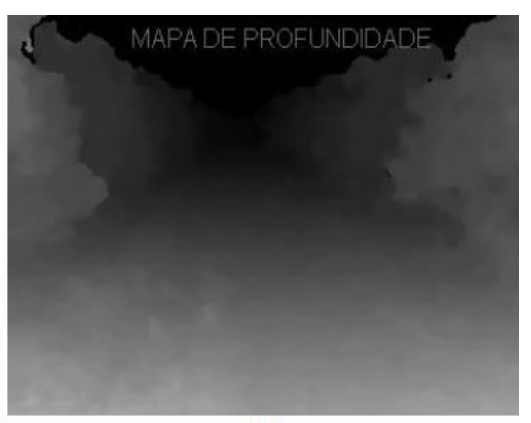

(c)

Figura 1.6 - Imagens obtidas em uma plantação de laranja: a) Mapa de navegabilidade e obstáculos estimados, b) Imagem colorida do ambiente analisado,

c) Mapa de profundidade obtido pela câmera estéreo. Fonte: (LRM, 2014)

O sistema que buscamos desenvolver deve ter a capacidade de detectar obstáculos intransponíveis, bem como pessoas e animais e permitir que o veículo autônomo se locomova em um ambiente outdoor, caracterizado por uma plantação estruturada como mostrada na Figura 1.7 e pela possível presença de diversos obstáculos estáticos (árvores, estruturas, etc.) e móveis (maquinário agrícola, seres humanos, animais, etc.).

O veículo deverá atuar, a princípio, em um ambiente controlado, ou seja, deve possuir uma boa iluminação (períodos da manhã e tarde), ausência de chuva ou condições que atrapalhem a visibilidade, veículo em baixa velocidade (por volta de $5,0 \mathrm{~km} / \mathrm{h}$ ) e obstáculos preferencialmente sinalizados (por exemplo, funcionários com vestimentas de cores que chamem a atenção). O sistema deve auxiliar a navegação do veículo através de um mapa probabilístico que informará possíveis obstáculos que possam colidir com o veículo e causar danos, seja ao veículo ou aos elementos pertencentes ao próprio ambiente.

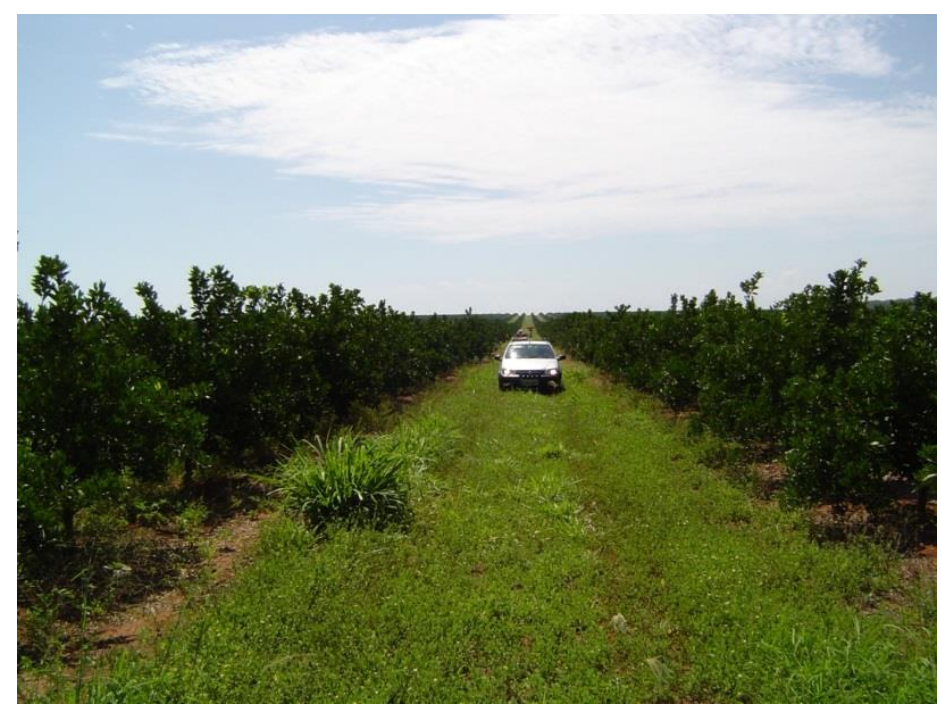

Figura 1.7 - Citricultura estruturada. Fonte: (LRM, 2014) 
Como objetivo secundário esperamos obter bons resultados nos seguintes itens:

- Detecção de obstáculos por cor em imagens RGB;

- Detecção de obstáculos com câmera estéreo;

- Detecção de obstáculos com câmera termal;

- Calibração das câmeras visando à fusão dos dados;

- Fusão de sensores representados em um mapa de probabilístico de ocupação;

- Detecção de obstáculos e de zona livre para navegação.

\subsection{Estrutura da Dissertação}

Este projeto está organizado em 6 Capítulos cuja estrutura e os conteúdos abordados em cada capítulo deste documento estão descritos resumidamente abaixo:

- O Capítulo 2 tem como objetivo descrever um panorama geral da robótica móvel, abordar alguns conceitos de visão computacional, apresentar os sensores e ferramentas utilizadas neste projeto de mestrado e introduzir um método de fusão de sensores.

- O Capítulo 3 tem como objetivo descrever brevemente os trabalhos relacionados a este projeto de mestrado.

- O Capítulo 4 tem como objetivo descrever a metodologia utilizada e descrever os objetivos gerais deste projeto de mestrado.

- O Capítulo 5 tem como objetivo descrever os trabalhos desenvolvidos e os resultados obtidos.

- O Capítulo 6 tem como objetivo apresentar a conclusão do trabalho e propor sugestões para futuros trabalhos. 


Capítulo

Robótica Móvel

O projeto, pesquisa e desenvolvimento de um sistema de detecção de obstáculos envolve a integração de hardwares (câmeras) e softwares (sistemas de percepção e controle), a fim de criar um sistema inteligente com capacidade de auxilio na navegação autônoma. Este capítulo descreve os conceitos de base sobre a robótica móvel, dando ênfase aos robôs autônomos. Será apresentada uma introdução a alguns conceitos de visão computacional, os sensores e ferramentas utilizados neste trabalho de mestrado e será introduzido um método muito conhecido para a fusão de sensores.

\subsection{Robôs Móveis Autônomos}

Os veículos autônomos ou também chamados robôs móveis autônomos (RMA) fazem parte de uma classe de robôs os quais possuem mecanismos que lhe permitem se movimentar em um ambiente de forma autônoma ou semiautônoma (WOLF, 2009). São sistemas capazes de operar em ambientes reais, sem qualquer forma de controle externo por longos períodos de tempo (BEKEY, 2005). Na Figura 2.1 e na Figura 2.2 são apresentados robôs móveis autônomos (RMAs) de pequeno porte geralmente utilizados em ambientes internos. Nas figuras abaixo, Figura 2.4, Figura 2.3, Figura 2.5 e Figura 2.6 são apresentados veículos autônomos de grande porte utilizados em pesquisas acadêmicas, competições de robótica promovidas pela 
DARPA (Defense Advanced Research Projects Agency), agricultura e iniciativas de empresas privadas.

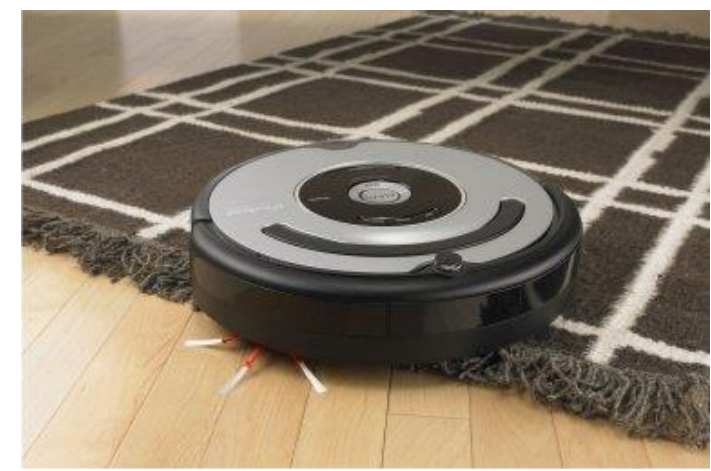

Figura 2.1 - Roomba, Robô aspirador de pó. Fonte:

http://static.fiercemarkets.com/public/ne wsletter/dailytechrag/roomba_560.jpg

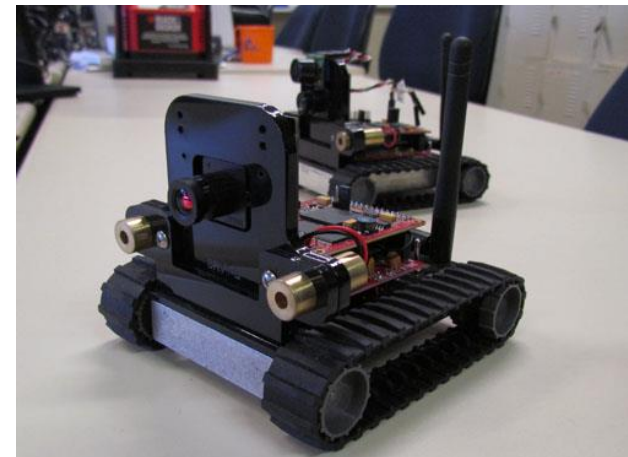

Figura 2.2 - Surveyor SRV. Fonte: (LRM, 2014)

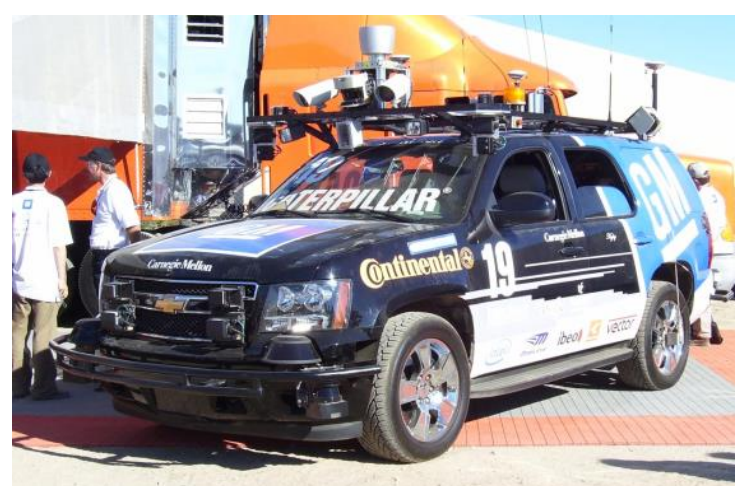

Figura 2.3 - Veículo autônomo "Boss", vencedor do DARPA 2007. Fonte: http://www.autoline.tv/journal/?page_id $=35$

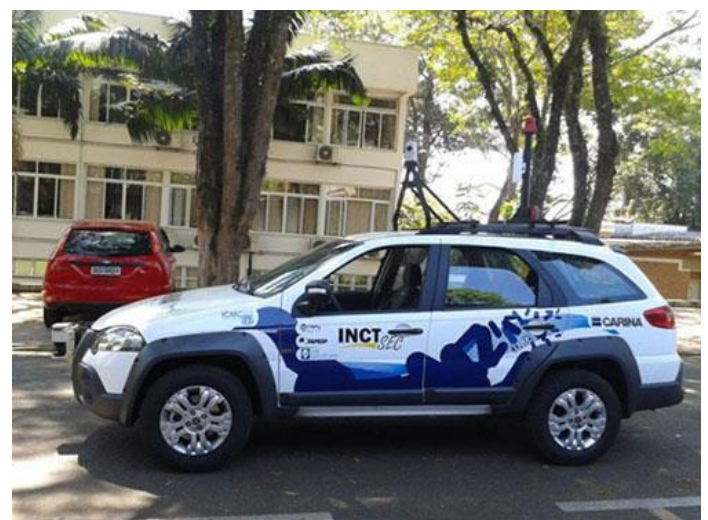

Figura 2.4 - CaRINA II. Fonte: (LRM, 2014)

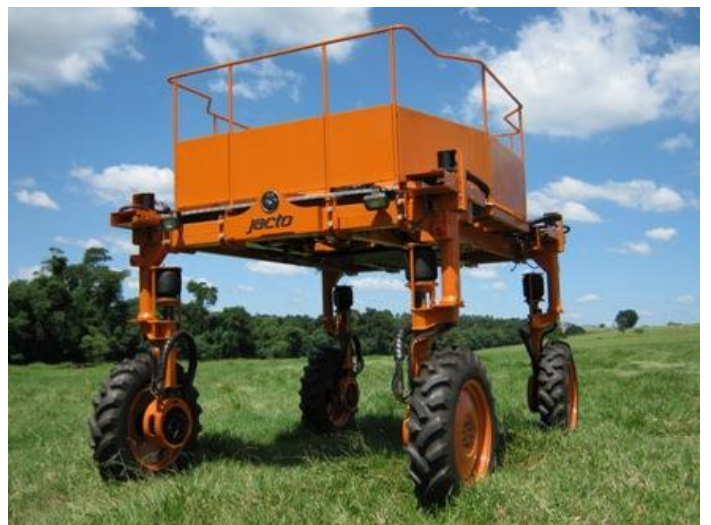

Figura 2.5 - Agribot, plataforma multifuncional para coleta de dados em agricultura de precisão. Fonte:

http://www.nepas.eesc.usp.br/roboticaa gricola/index.php/robosagricolas/agribot

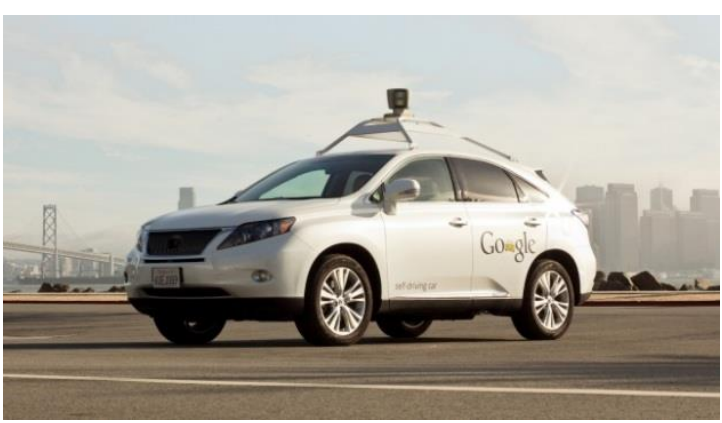

Figura 2.6 - Carro autônomo da Google. Fonte:

http://bgr.com/2012/08/07/google-selfdriving-car-accidents-300000-miles/ 
Um veículo autônomo deve ser dotado de sensores, atuadores, e possuir um mecanismo de controle inteligente (BECKEY, 2005; MATARIĆ, 2007). Os sensores fazem parte do hardware do robô e permitem que seja feita a captura de dados do próprio robô e do ambiente no qual ele está inserido. Os atuadores também constituem o hardware e permitem que o robô modifique o ambiente e/ou efetue 0 seu deslocamento no mesmo. O controle inteligente, por sua vez, constitui o software e provê a inteligência do robô. O controle é responsável por obter os dados dos sensores, processar e planejar possíveis ações para os atuadores (DUDEK, 2000). Na robótica móvel podemos considerar três importantes linhas de pesquisa que são 0 mapeamento de ambientes, a localização e a navegação do robô (WOLF, 2009).

O mapeamento utiliza sensores para a obtenção de dados do ambiente onde o robô está inserido. A partir deste passo é possível criar um mapa que representa a visão que o robô tem do ambiente (WOLF 2009). Existem diversos tipos de mapas, como por exemplo, mapas métricos e de ocupação, mapas topológicos, e mapas de navegabilidade. Um mapa de navegabilidade deve permitir definir as zonas nas quais o robô móvel poderá se locomover, indicando e diferenciando zonas navegáveis de zonas não navegáveis.

A localização na robótica móvel é a temática onde são pesquisadas técnicas precisas para identificar a localização do robô, ou seja, usualmente buscamos identificar da forma mais precisa possível sua posição, indicada pelas suas coordenadas no plano cartesiano ou em coordenadas geodésicas, e sua orientação. Para a localização, da mesma forma que no mapeamento, o robô utiliza os sensores juntamente com um mapa ou sistema de referência (SIEGWART e NOURBAKHSH, 2004; WOLF 2009).

A navegação utiliza os atuadores para fazer o deslocamento do veículo autônomo no ambiente, para isso, deve ser definida uma trajetória onde usualmente busca-se saber a sua localização e ter um mapa do ambiente para poder planejar qual caminho seguir (DUDEK, 2000; WOLF, 2009). Durante sua movimentação, o veículo deve ser capaz de se deslocar evitando colisões com obstáculos, selecionando um caminho adequado para uma navegação segura.

O programa de controle inteligente do veículo autônomo é o responsável pelo processamento das informações para o mapeamento, a localização, e a navegação, realizando o planejamento das ações que ele deverá efetuar (MATARIĆ, 2007). Algumas ações e tarefas típicas dos veículos autônomos incluem: navegar de um ponto a outro no seu ambiente de modo seguro; seguir um ponto móvel no seu ambiente, como por exemplo, seguir outro veículo (comboio); monitorar um ambiente externo ou interno detectando intrusos e incidentes. Para todas estas e muitas outras tarefas é necessário que o RMA tenha autonomia na tomada de decisões para desviar de obstáculos, saber sua localização e traçar trajetórias de sua posição atual até a meta. 


\subsection{Robótica na Agricultura}

A idéia da aplicação robótica na agricultura (ambiente agrícola atendido por máquinas inteligentes) não é nova. No passado muitos engenheiros desenvolveram tratores sem condutor, mas não foram bem sucedidos uma vez que não tinham a capacidade de abraçar a complexidade do mundo real. A maioria deles assumiu um estilo de agricultura industrial, onde tudo era conhecido de antemão e as máquinas poderiam funcionar de maneira inteiramente pré-definidas. Hoje em dia a abordagem é desenvolver máquinas que são inteligentes o suficiente para trabalhar em um ambiente estático ou seminatural. Estas máquinas devem apresentar um comportamento sensato em contextos reconhecidos durante longos períodos de tempo e sem assistência (BLACKMORE, 2005).

Veículos autônomos têm sido amplamente utilizados na produção industrial e em armazéns, onde um ambiente controlado pode ser garantido. Na Agricultura, a pesquisa em veículos autônomos sempre foi um sonho. Nos últimos anos, o desenvolvimento desses veículos teve um crescente interesse e o conceito de que múltiplos pequenos veículos autónomos seria mais eficiente do que os tradicionais tratores de grandes dimensões está sendo estudado. Este estudo considera que pequenos veículos produzem uma menor compactação do solo, menor gasto de combustível, conseguem cobrir uma maior área em um tempo menor e em caso de quebra podem ser substituídos rapidamente e com um menor custo (BLACKMORE, 2004; YAGHOUBI, 2013; EMMI, 2014).

Portanto, considerando a importância dos veículos autônomos em diversas aplicações como, por exemplo, na Agricultura, os mesmos a fim de poderem ter um comportamento inteligente devem ser dotados de sistemas de percepção do ambiente. Um dos sensores mais amplamente difundidos na atualidade são as câmeras de vídeo usadas para a aquisição de imagens.

\subsection{Sensores}

Um sensor é um dispositivo que mede o valor de uma grandeza física, como por exemplo, a temperatura, a velocidade, a distância, a pressão, etc. Sistemas automatizados, como os robôs, trabalham inseridos em ambientes reais, estáticos ou dinâmicos e estão dotados de sensores que lhes permitem adquirir informação sobre o modo como interagem com o mundo em que operam e sobre o seu próprio estado interno. De um modo geral, os sensores são componentes chave que possibilitam os robôs a perceberem o ambiente ao qual estão inseridos e cumprir com êxito seu objetivo, desta forma, é muito importante saber quais os tipos e configurações (modelos) de sensores que devem ser utilizados em uma determinada aplicação (SCARAMUZZA, 2011). 
Os sensores podem ser classificados do ponto de vista da origem de sensoriamento como proprioceptivos e exteroceptivos (BECKEY, 2005; SIEGWART e NOURBAKHSH, 2004). Os sensores proprioceptivos medem informações do próprio robô, como temperatura, deslocamento, velocidade e posição. Os sensores exteroceptivos recebem informações do meio em que o robô está inserido, como por exemplo, sensores que detectam obstáculos à frente do robô, tal como sensores laser (LIDAR), sonares e sensores infravermelhos (FACELI, 2001; MATARIĆ, 2007; MURPHY, 2000; SCARAMUZZA, 2011).

Os sensores podem ainda ter outra classificação, esta com relação ao tipo de medição. Podem ser passivos, neste caso possuem um detector que apenas recebe informações do ambiente, a exemplo das câmeras de vídeo. Quando são ativos, os sensores tem um emissor para gerar um sinal e enviar ao ambiente e logo após recebem a reflexão deste sinal por um detector. (FACELI, 2001; MATARIĆ, 2007).

\subsubsection{Câmera de Vídeo Monocular}

As câmeras de vídeo são mecanismos que procuram uma aproximação e imitação do olho biológico, buscando ter uma percepção visual mais completa do mundo (MATARIĆ, 2007). Alguns sensores captam apenas a intensidade de luz, outros são capazes de captar informações de cor, e outros ainda percebem o calor através de sensores infravermelhos.

As câmeras são dotadas de uma série de lentes que focalizam a luz sobre um dispositivo semicondutor que registra os sinais eletronicamente (ondas eletromagnéticas), criando a imagem de uma cena. Então, um computador armazena e processa essas informações eletrônicas em dados digitais, ou seja, a imagem capturada.

O sensor de imagem utilizado pela maioria das câmeras de vídeo digitais é um $\mathrm{CCD}$, charge coupled device. Alternativamente, algumas câmeras usam a tecnologia de CMOS, complementary metal oxide semiconductor. Os sensores de imagem CCD e CMOS, representados abaixo na Figura 2.7 (a) e Figura 2.7 (b) respectivamente, convertem luz em elétrons. Uma maneira simplificada de pensar a respeito destes sensores é imaginar uma matriz bidimensional de milhares ou mesmo milhões de minúsculas células solares (fotoelétricas). 


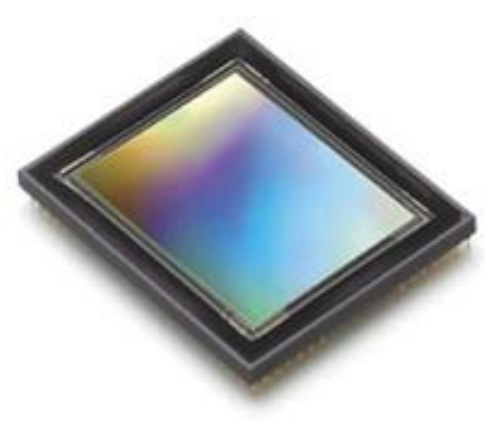

(a)

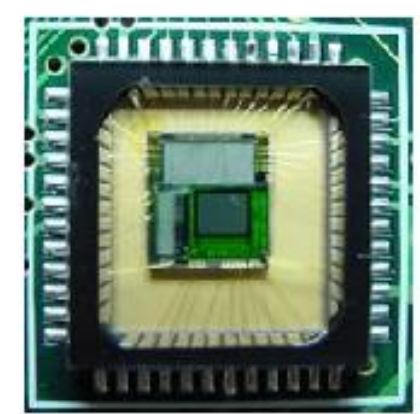

(b)

Figura 2.7 - a) Sensor CCD. b) Sensor CMOS. Fonte: http://eletronicos.hsw.uol.com.br/cameras-digitais.htm

Assim que o sensor converte a luz em elétrons, é registrado o valor (a carga acumulada) de cada célula na imagem. No sensor CCD a carga é transportada através do chip e lida em um canto da matriz. Um conversor analógico para digital (conversor $A / D$ ) transforma o valor de cada pixel em um valor digital por meio da medição da quantidade de carga de cada photosite (diodo fotossensível) e converte essa medição para a forma binária. Já em um sensor CMOS, são usados diversos transistores em cada pixel para amplificar e mover a carga usando fios tradicionais. $O$ sinal de CMOS é digital, assim ele não necessita do conversor A/D.

A intensidade de luz pode ser representada na escala de cinza (tonalidades), neste caso, usualmente, será utilizado um byte para representar a intensidade de um pixel. Chama-se este modelo de imagem monocromática de 8-bits. 0 valor armazenado zero significa preto e o valor armazenado 255 significa branco (intensidade máxima). Os valores intermediários são os tons de cinza.

Um dos esquemas utilizados para representação de imagens coloridas é o RGB (do inglês red, green, blue). Este modelo de cor é chamado de 24-bits, pois usualmente se utiliza três bytes para representar a cor de um pixel, com seus componentes vermelho, verde e azul. Desta forma o preto é representado pelos três bytes com valor zero e o branco é obtido quando os três bytes de cor possuem o valor 255. Com as possíveis combinações de valores para cada byte de cor obtêm-se pixels coloridos (MURPHY, 2000), podendo representar até 16 milhões de cores com o uso destes 24 bits.

As câmeras de vídeo utilizadas na robótica móvel para ambientes internos podem ser câmeras simples, é comum o uso das chamadas Webcams pelo baixo custo e simplicidade de uso. Sua resolução é baixa, geralmente $320 \times 240$ ou $640 \times 480$ o que facilita o processamento da matriz de pixels. Já em aplicações para ambientes externos, câmeras de melhor resolução são necessárias para que seja possível ter uma melhor visão a longas distâncias e fazer detecções ou identificações de pessoas ou objetos, por exemplo. 


\subsubsection{Câmera de Vídeo Estéreo}

Um tipo particular de câmera é a câmera de vídeo estéreo (ver Figura 2.8). Neste projeto de mestrado será utilizada a câmera estéreo Bumblebee2 (BUMBLEBEE2, 2014) da fabricante PointGray. Através dela é feita a aquisição simultânea de duas imagens por um conjunto binocular de câmeras, no entanto, este tipo de câmeras além de obter imagens em duas dimensões, é usado também para a aquisição de informações em três dimensões obtidas pela combinação das duas imagens, criando assim um mapa de profundidade (também chamado de mapa de disparidade) que é uma imagem de duas dimensões com informação de profundidade. O conceito teórico e exemplos de mapa de profundidade são detalhados na seção 2.8 deste capítulo.
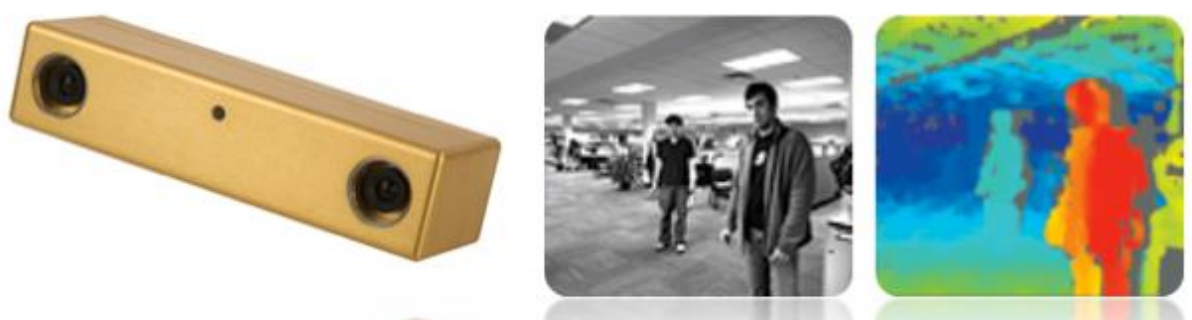

Figura 2.8 - Câmera estéreo Bumblebee2. Fonte:

http://www.ptgrey.com/products/bumblebee2/bumblebee2_stereo_camera.asp

Outra forma de representar o ambiente utilizando a informação proveniente deste tipo de câmera é utilizando uma nuvem de pontos. Na Figura 2.9 pode ser visualizada uma nuvem de pontos $3 \mathrm{D}$ da mesma cena, mas em ângulos diferentes. Nesta representação é utilizado o sistema de coordenadas ( $x, y, z)$ no qual cada ponto do ambiente tem sua posição neste sistema. Quando a informação de cor é adicionada na nuvem de pontos então se tem uma nuvem de pontos 4D (coordenadas $x, y$ e $z$ e cor) (PCL, 2012) que também pode ser chamada de informação RGB-D (do inglês red, green, blue, depth) que é a informação de cor adicionada de profundidade. 

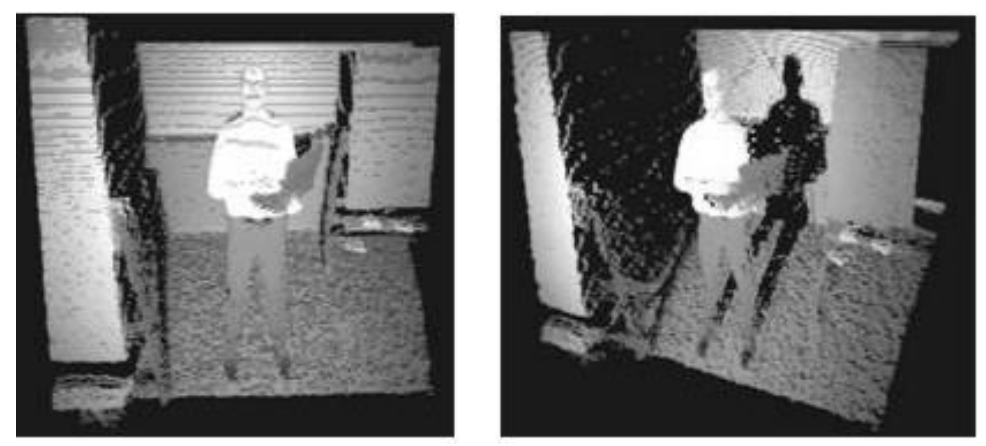

Figura 2.9 - Nuvem de pontos gerada a partir de uma câmera estéreo . Fonte: http://www.geometh.ethz.ch/research/range

Para que a aquisição das imagens ocorra apropriadamente, as câmeras devem ser colocadas lado a lado com eixos ópticos paralelos, distâncias focais iguais com eixo horizontal e escala coincidentes. Através da combinação das duas imagens é possível obter a profundidade dos objetos capturados pela câmera.

\subsubsection{Câmera de Vídeo Termal}

Existem câmeras capazes de capturar imagens além do espectro visível, como é o caso de sensores usados em satélites de monitoramento. A radiação infravermelha é um espectro de luz não visível para o ser humano, onde sensores específicos podem ser capazes de perceber este tipo de radiação e podendo indicar também a presença de calor, uma vez que são emitidas radiações infravermelha junto a este.

As câmeras termais (ou térmicas) são câmeras de vídeo que utilizam estes sensores infravermelhos (near/far infrared) para perceber o calor do ambiente e representar em forma de imagens a temperatura dos elementos presentes em uma cena. Estas imagens podem ser em tons de cinza (ver Figura 2.10 (a)), ou utilizar falsas cores para destacar mais os elementos da imagem, usando uma palette com cores "frias" e "quentes" (ver Figura 2.10 (b)). Para as regiões mais quentes do ambiente são usualmente representadas com cores mais claras e regiões mais frias são representadas com cores mais escuras (BRÄUNL, 2008). 


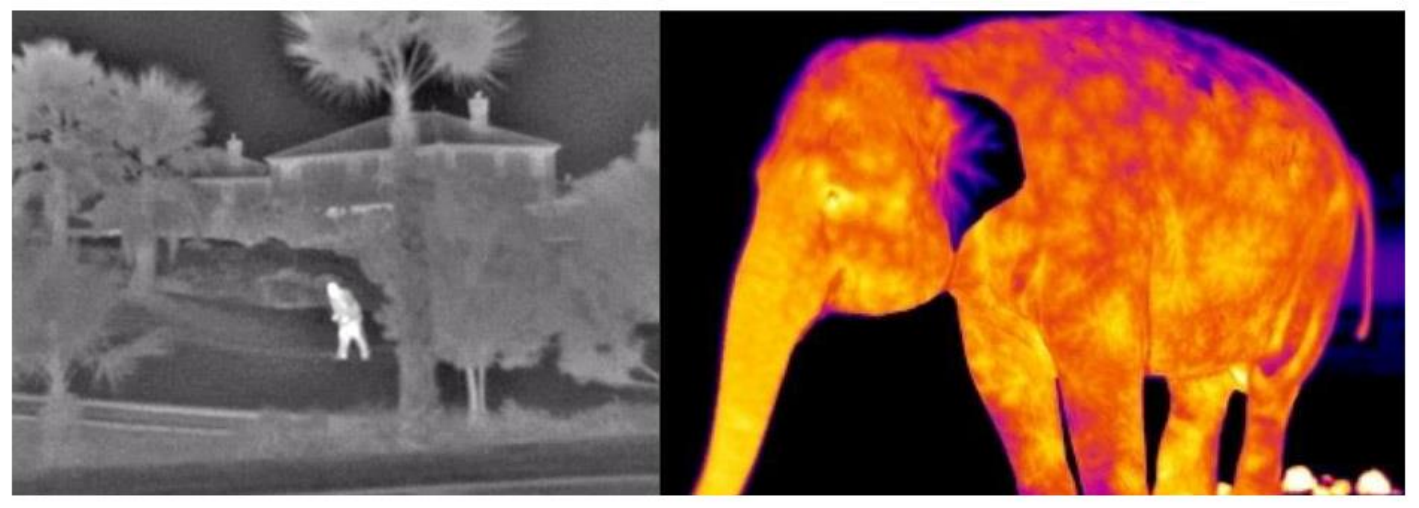

(a)

(b)

Figura 2.10 - a) Imagem térmica em tons de cinza. b) Imagem térmica usando cores "quentes" e "frias". Fontes:

http://www.x2extreme.com/Thermal_Scopes/Thermal_Camera.jpg e http://hackedirl.files.wordpress.com/2011/07/epic-win-photos-thermal-elephant-win.jpg

A câmera termal que vem sendo utilizada em aplicações de robótica junto ao LRM e será utilizada neste projeto de mestrado é a câmera térmica FLIR PathFindIR (ver Figura 2.11), um dispositivo de relativo baixo custo e pequeno porte que é utilizado também para aplicações de visão noturna (FLIR, 2014). Na área da robótica é muito importante poder verificar se um obstáculo à frente é um ser humano, animal, ou objeto móvel (objetos de temperatura quente), ou apenas um objeto estático (elemento frio).

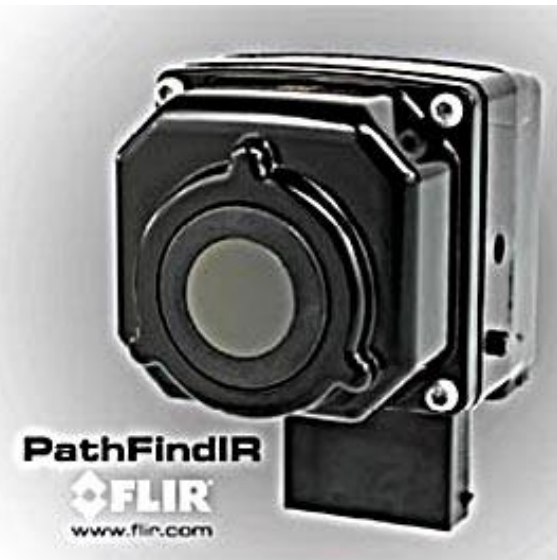

Figura 2.11 - Câmera térmica FLIR PathFindIR. Fonte:

http://www.mitocorp.com/oem/flir-camera.jpg

Na Figura 2.12 pode ser visualizada à esquerda uma imagem gerada por uma câmera de vídeo comum e a direita uma imagem gerada por uma câmera térmica. Não seria possível ou seria muito difícil visualizar um pedestre e o animal na câmera de vídeo comum nestas condições de luminosidade, porém com o uso da câmera térmica o pedestre e o animal são facilmente identificados, pois suas temperaturas os diferem do ambiente onde estão. 

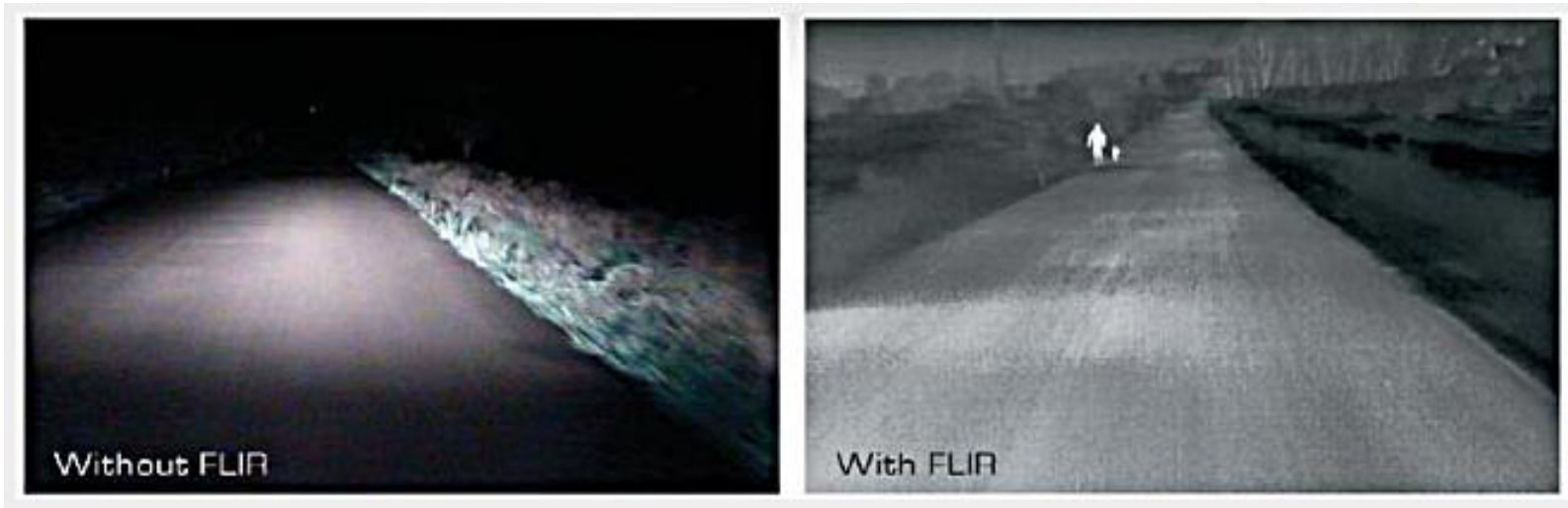

Figura 2.12 - Visualização noturna de uma câmera de vídeo comum e de uma câmera termal. Fonte:

http://www.teakatoys.com/Hummer_Night_Vision_Package_by_MitoCorp_p/mitonightvision\%20pkg.html

Nas seções seguintes serão descritos conceitos referentes às imagens (sua representação e processamento), visto que este será um dos elementos de destaque em relação a este trabalho.

\subsection{Imagem}

Uma imagem é uma grade de duas dimensões formada por elementos de mesmos tamanhos chamados de pixel (do inglês picture element) (MURPHY, 2000). O pixel é considerado o menor componente de uma imagem digital. Cada pixel contém uma série de atributos que descrevem a sua cor ou intensidade. A precisão com a qual cada pixel pode especificar sua cor é chamada de "profundidade de bit" ou "profundidade de cor". Quanto maior a quantidade de pixels que uma imagem possui, maior a capacidade de representar detalhes nesta imagem. Através da Figura 2.13 pode ser vista uma ampliação de uma imagem digital. 


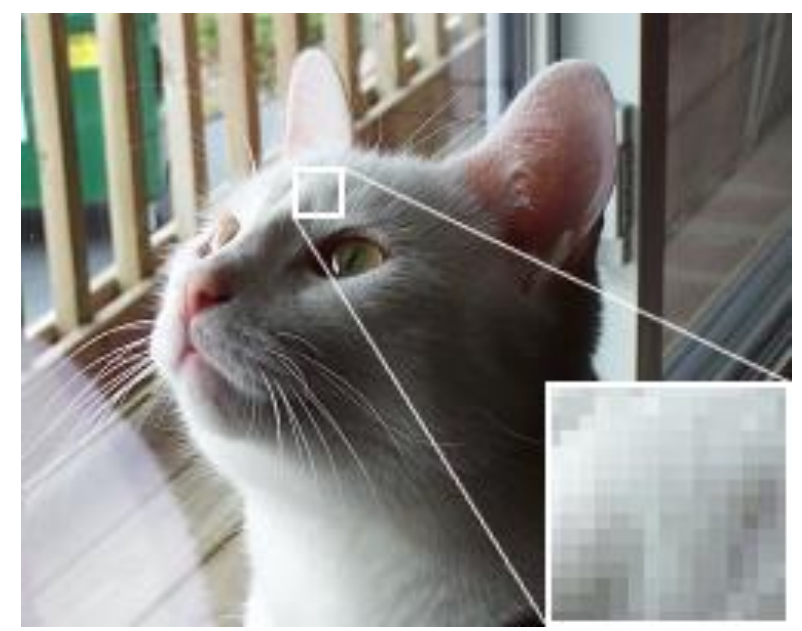

Figura 2.13 - Representação de uma imagem através de pixels. Fonte: http://en.wikipedia.org/wiki/File:Dithering_example_undithered.png

A imagem é produzida junto a dispositivos como olho, câmeras e espelhos. Podemos classificar as imagens em dois principais tipos, em relação ao que será tratado neste trabalho, monoculares (duas dimensões) e estereoscópicas (três dimensões). As imagens monoculares, também chamadas de static depth cues, contam com elementos para uma percepção rudimentar da profundidade, valendo-se apenas das leis da perspectiva, onde o tamanho aparente dos objetos diminui à medida que esses se afastam do observador (AZEVEDO, 2003). Assim, os objetos mais próximos acabam escondendo os objetos mais distantes que se encontram sobre o mesmo eixo de perspectiva. Esse efeito visual é classificado como passivo, pois está presente diretamente na imagem.

Através de uma imagem monocular é possível extrair características tridimensionais da cena, estes efeitos são chamados de efeitos passivos. Eles são inerentes à aparência do mundo externo e independem dos nossos olhos. Alguns desses efeitos são: perspectiva (distância dos objetos), iluminação (melhor visualização da forma dos objetos), oclusão (ordem dos objetos), sombra (distância do objeto ao plano de apoio) e textura (noção de profundidade, rugosidade e/ou combinação de cores do objeto).

Já as imagens estereoscópicas permitem obter a distância relativa dos objetos. Essa imagem é formada através da fusão de imagens tiradas de pontos de observação ligeiramente diferentes e nesse processo, obtêm-se informações quanto à profundidade, distância, posição e tamanho dos objetos, gerando uma sensação de visão em 3D (AZEVEDO, 2003). Este tipo de imagem é capturada através de uma câmera estéreo.

A estereoscopia é classificada como efeito ativo, pois não está presente diretamente em uma imagem, sendo interpretada pelo nosso cérebro. Uma consequência imediata da diferença das imagens capturadas pelos dois olhos é o espaçamento entre o mesmo ponto projetado nas duas retinas, chamado de 
disparidade na retina. Por exemplo, na Figura 2.14 (a) o olho esquerdo vê a árvore à esquerda do pinheiro, enquanto o olho direito a vê à direita. Estas duas imagens chegam ao cérebro onde é feita uma superposição, resultando na Figura 2.14 (b) (KIRNER, 2004).

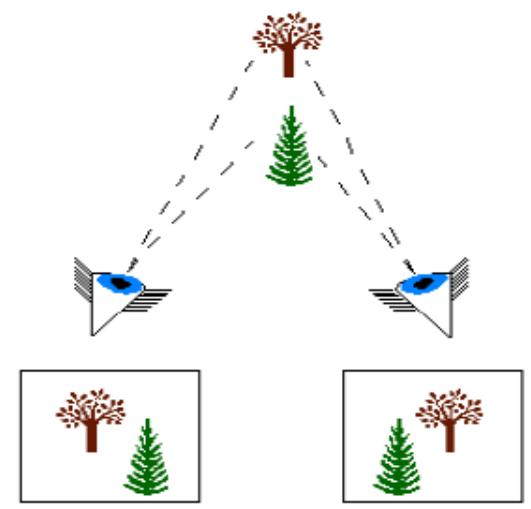

(a)

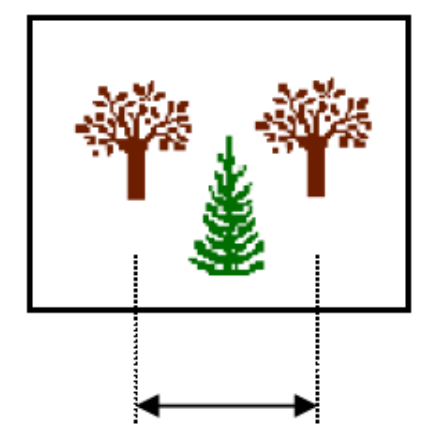

disparidade na retina

(b)

Figura 2.14 - a) Visões da mesma cena pelos dois olhos. b) Superposição das imagens e a disparidade na retina. Fonte: (KIRNER, 2004)

Na robótica, o uso de imagens obtidas através de câmeras é amplamente utilizado para classificar os elementos da cena. Estes elementos podem ser classificados quanto a sua temperatura, textura, distância em relação aos outros elementos, cor, etc. Desta forma, é possível realizar uma segmentação dos elementos que compõem uma cena, e baseando-se pela classificação, pode-se definir e distinguir assim áreas navegáveis de áreas não navegáveis. O processamento de imagens permite identificar obstáculos e reconhecer padrões, e inclusive determinar a posição destes elementos na cena.

Sabendo da importância e benefícios que a análise de uma imagem pode fornecer, este trabalho visa à fusão de diferentes tipos de imagens (monocular, estéreo e termal) com o intuito de fortalecer a precisão na detecção de elementos que impeçam a navegação segura do veículo autônomo no ambiente onde este será inserido.

\subsection{Segmentação de Imagem}

A segmentação de imagem é usualmente um dos primeiros processos para a extração de informação de mais alto nível a partir de uma imagem, neste processo é extraída, do domínio da imagem, uma ou mais regiões conectadas que satisfaçam o critério de uniformidade (homogeneidade), o qual é baseado em características derivadas de componentes do espectro. $O$ processo de segmentação pode ser 
melhorado através de alguns conhecimentos adicionais sobre os objetos em cena tais como as suas propriedades ópticas e geométricas (GONÇALVES, 2007).

Uma região na imagem pode ser definida de quatro formas: componente conectado de um grupo de pixels especificado por uma função de pertinência de classes definida num espaço de cores; grupo (maximal) de pixels conectados para cada condição de uniformidade que é satisfeita; grupo de pixels conectados unidos por uma borda de pixels criando um contorno colorido; superfície ou objeto de material homogêneo. Ou seja, podemos definir região como sendo baseada em pixel, área, borda e fisicamente baseada (por exemplo, baseada na textura).

No campo da segmentação de imagem, a segmentação por regiões distingue as diferentes áreas presentes numa mesma imagem, já a segmentação por contornos delimita os diferentes objetos presentes na imagem pela identificação de sua fronteira. Outro aspecto importante dos métodos de segmentação é o espaço de cor do qual as características da cor são computadas (por exemplo, o espaço RGB com distância Euclidiana de cor) (BOVIK, 2000).

Cada técnica de segmentação é normalmente baseada em alguns modelos matemáticos (teoria) e/ou abordagens algorítmicas (como agrupamentos fuzzy, campos aleatórios Markov, procedimento recursivo, algoritmo bottom-up, etc.). Além disso, são especificadas através de categorias comuns de métodos matemáticos básicos (BOVIK, 2000). A maioria das técnicas de segmentação leva em consideração algo sobre a cena que é visto na imagem, este é um conhecimento adicional atribuído ao método de segmentação determinado.

Em resumo, os seguintes atributos são avaliados pelas técnicas de segmentação: definição de região, método matemático básico, espaço de cor, conhecimentos adicionais e aplicações. O método de Otsu (OTSU, 1979), explorado por este projeto, é um exemplo de método de limiarização não assistida que utiliza o espaço de cor (tons de cinza). Este método possibilita a segmentação de imagens em dois grupos, pixels pertencentes e não pertencentes ao fundo da imagem.

\subsection{Método de Otsu}

Esse método de limiarização baseia-se na análise discriminante, caracterizando-se por sua natureza não paramétrica e não supervisionada de seleção de limiar. A operação de limiarização é considerada como sendo o particionamento dos pixels de uma imagem com I níveis de cinza em duas classes $c_{1}$ e $c_{2}$, que 
representam o objeto e o fundo, ou vice-versa, sendo que esta partição se dará no nível de cinza $t$. Desta forma teremos:

$$
\begin{aligned}
& c_{1}=\{1,2,3,4, \ldots, t\} \\
& c_{2}=\{t+1, t+2, t+3, t+4, \ldots, l\}
\end{aligned}
$$

Seja $\sigma_{w}^{2}$ variância dentro da classe, $\sigma_{b}^{2}$ variância entre as classes e $\sigma_{t}^{2}$ variância total. Um limiar ótimo pode ser obtido através da maximização de umas das seguintes funções critérios:

$$
\begin{gathered}
\gamma=\frac{\sigma_{b}^{2}}{\sigma_{w}^{2}} \\
\eta=\frac{\sigma_{b}^{2}}{\sigma_{t}^{2}} \\
\varphi=\frac{\sigma_{t}^{2}}{\sigma_{w}^{2}}
\end{gathered}
$$

Das três funções critérios acima, $\eta$ é a mais simples, logo, o limiar ótimo pode ser obtido encontrando o valor de $t$ que maximiza a função $\eta$. $O$ valor máximo de $\eta$ pode ser utilizado como medida de separabilidade das classes $c_{1}$ e $c_{2}$ na imagem original ou na bimodalidade. O limite inferior é obtido quando e somente quando uma dada imagem tenha um único e constante nível de cinza, e o limite superior é obtido quando e somente quando a imagem apresenta apenas dois valores. A Figura 2.15 mostra o resultado da limiarização de uma imagem através do método de Otsu. A linha tracejada no histograma da imagem indica o limitante ótimo.
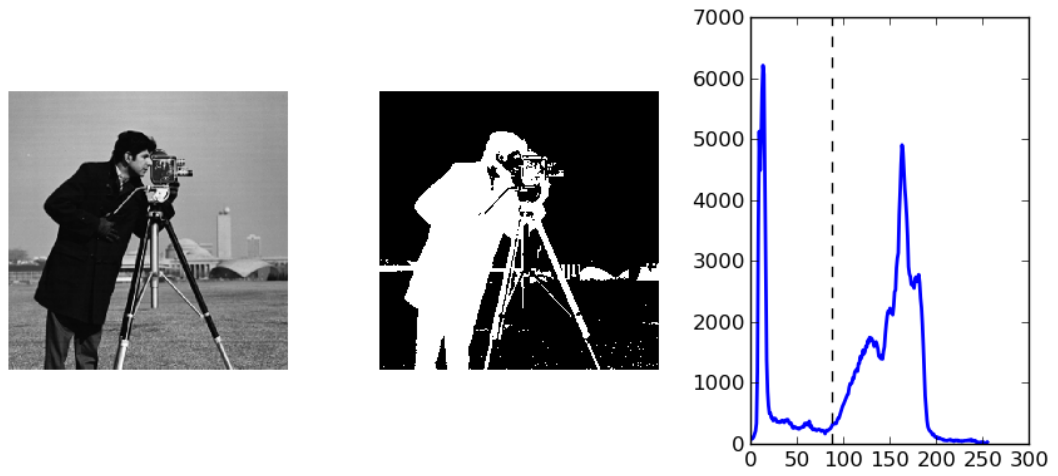

Figura 2.15 - Resultado da aplicação do método de Otsu. Fonte: http://scipylectures.github.io/packages/scikit-image/

A maioria dos algoritmos de processamento de imagens trabalha no plano da imagem, ou seja, uma projeção 2D. Podemos segmentar os elementos por atributos diversos (cor, textura, bordas na imagem), uma alternativa ao tratamento de imagens 2D é o uso de informações que estimem a profundidade dos elementos da cena. 
Para que seja possível obter uma estimativa de profundidade, é necessário entender como a câmera forma a imagem. Isto pode ser entendido conhecendo-se os parâmetros intrínsecos e extrínsecos da câmera, através de um processo chamado calibração.

\subsection{Calibração}

A Calibração de câmeras é um procedimento para a determinação de parâmetros internos geométricos e óticos da câmera (parâmetros intrínsecos), incluindo a posição e orientação da câmera em relação a um sistema de coordenadas globais (parâmetros extrínsecos) (TSAI 1987). Os métodos de calibração podem ser classificados em lineares e não lineares.

Os métodos lineares são mais rápidos porque não empregam iterações, entretanto a precisão dos resultados é menor devido a simplificações feitas no modelo de câmera. A rigor, esses métodos não consideram as distorções das lentes das câmeras (SALVI 2002). Os métodos não lineares não restringem o modelo de câmera, e mesmo que a câmera empregada seja de alta resolução e baixa distorção, os resultados dos métodos podem ser bem próximos. Porém, métodos não lineares necessitam de um grande número de iterações para o seu sucesso, resultando em maior custo computacional e a necessidade de um gabarito de calibração (ver Figura 2.16) onde dois ou três planos ortogonais, cujas formas e dimensões são bem conhecidos, são utilizados para formar um sistema de coordenadas "imaginário". Logo, a exatidão das coordenadas depende apenas do processo de manufatura do gabarito de calibração que em geral são conhecidas com extrema precisão.

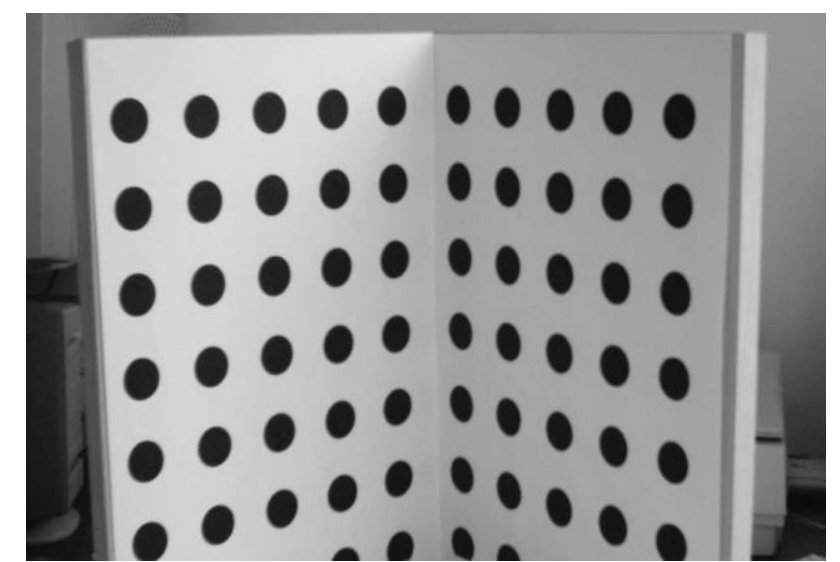

Figura 2.16 - Gabarito de calibração. Fonte (ALVES, 2007)

Em algumas aplicações, a utilização do gabarito é inconveniente, pois a calibração não pode ser realizada durante a operação normal do sistema. Por exemplo, caso haja uma mudança na distância focal das câmeras (um zoom), a inspeção visual deve ser interrompida e o gabarito posto a frente das câmeras. Em 
vista disso, Maybank e Faugeras (MAYBANK e FAUGERAS, 1992) propuseram uma nova teoria que permite que a calibração seja realizada de forma automática, durante a operação normal do sistema. Infelizmente, o processo de calibração automática possui um custo computacional bastante elevado.

Uma alternativa para não se ter este custo da calibração, é o uso de uma câmera estéreo pré-calibrada, como é o caso da câmera estéreo Bumblebee 2 que é uma das câmeras utilizada por este projeto. Por ter uma montagem fixa, a matriz de calibração é previamente calculada pelo fabricante, assim, o processo de calibração manual não é necessário. Tendo a câmera estéreo perfeitamente calibrada, é possível obter com exatidão informações que estimem a profundidade dos elementos da cena. Estas estimações compõem o mapa de profundidade.

\subsection{Mapa de Profundidade}

Para permitir que um robô possa navegar através de dados visuais capturados a partir de uma câmera estéreoscópica é necessario ter alguma forma de representação adequada do mundo observado. Utilizando como base imagens bidimensionais obtidas através de um sistema de duas ou mais câmeras de vídeo, é possível combinar as informações obtidas a partir das imagens de modo a auferir uma representação tridimensional da cena.

A imagem tridimensional obtida a partir das imagens bidimensionais é chamada de mapa de profundidade ou mapa de disparidade. Essa imagem é representada através de tons de cinza (adotando uma determinada representação, como por exemplo, onde os objetos distantes são representados por tons mais escuros) (ver Figura 2.17 (b)) ou através da adição de uma paleta de cores, ou falsas cores, associando-se um sentido as cores (ver Figura 2.17 (a)). Usualmente adotamse cores "quentes" (avermelhadas/claras) e cores "frias" (azuladas/escuras) para representar os objetos mais próximos (quentes) e mais distantes (frios), respectivamente. Este tipo de representação ajuda na percepção e interpretação de uma cena e da profundidade dos elementos presentes nesta cena, quando analisada por uma pessoa. 


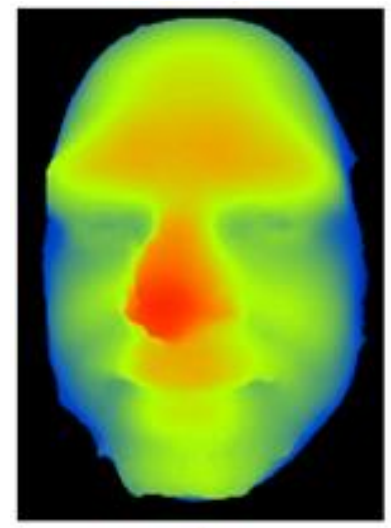

a)

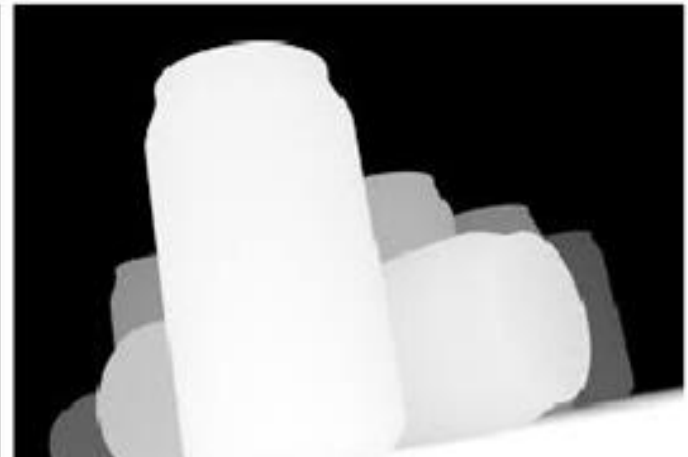

b)

Figura 2.17 - (a) Mapa de profundidade de uma face. (b) Mapa de profundidade de latas. Fonte: http://jaredjared.com/chroma.html e http://www.dofpro.com/cgigallery.html

O cálculo do mapa de profundidade é comumente realizado através de duas técnicas principais, as técnicas baseadas em áreas (MARAPANE, 1989; LI, 2002) e as técnicas baseadas em características (GOULERMAS, 1999). As técnicas baseadas em áreas utilizam a correlação entre os valores de intensidade de uma janela na imagem da esquerda, e outra na imagem da direita, produzindo um mapa de disparidades denso. O tamanho da janela, bem como a área de busca na imagem, influenciam a exatidão da correspondência, e também, a complexidade do processamento (SUNYOTO, 2004).

As técnicas baseadas em características baseiam-se no uso de características retiradas das imagens, tais como segmentos de borda, gradientes, e etc., realizando comparações simples entre atributos dessas características. Tais técnicas possuem maior velocidade e exatidão do que as técnicas baseadas em área, todavia, possuem a desvantagem da geração de um mapa de disparidade esparso, sendo necessário o uso de técnicas de interpolação para gerar mapas densos (FERNANDES, 2004).

Além dessas duas técnicas, se mostram como técnicas poderosas para solucionar o problema da correspondência às baseadas em Redes Neurais Artificiais. Neste campo de atuação podemos citar o trabalho do Wang (WANG, 1999), que faz uso de uma Rede Neural de Múltiplas Camadas de Perceptrons (MLP) com treinamento supervisionado para encontrar os pontos correspondentes.

Portanto, o ideal de um algoritmo de visão estéreo consiste na capacidade de obter, a partir de um par de imagens em alta resolução, uma malha densa de pontos correspondentes estruturados de tal forma que essa malha seja a representação mais exata possível da cena real, podendo essa informação ser obtida no menor espaço de tempo possível, e assim podendo ser utilizada em aplicações práticas. No entanto, sabe-se que grande parte das técnicas atuais não são adequadas aos sistemas de tempo real, já que os algoritmos de correlação desse par de imagens tem um peso computacional bem elevado. 
Atualmente encontramos pesquisas em desenvolvimento que buscam se utilizar do processamento paralelo, seja através de um hardware dedicado (por exemplo, usando FPGAs) (DIAS, 2011), ou através do uso de hardwares específicos como é o caso das GPUS (por exemplo, usando a arquitetura CUDA presente nas placas de vídeo da empresa NVidia) (GIBSON, 2008).

\subsection{Ferramentas de Software}

Do ponto de vista da Ciência da Computação (e consequentemente de software) o projeto de um robô móvel autônomo envolve a implementação/utilização de várias técnicas de aprendizado de máquina, processamento de imagens, visão computacional, busca em grafos, programação dinâmica, entre outras. Além disso, é importante que sejam feitas simulações para validar os projetos de robôs, bem como utilizar drivers para a comunicação de computadores com os robôs e com os sensores. Felizmente existem várias bibliotecas, ferramentas e drivers disponíveis atualmente (muitos destes são open source) para a criação e manutenção de sistemas robóticos. Algumas destas bibliotecas e ferramentas utilizadas neste projeto serão vistas nas próximas subseções.

\subsubsection{OpenCV}

Com o advento e a acessibilidade de computadores com cada vez maior poder de processamento, várias áreas da computação tem usufruído deste desenvolvimento. Entre elas estão as áreas de visão computacional e de processamento de imagens. Áreas estas que estão envolvidas com a captura de imagens a partir de sensores, o seu processamento e a extração de informações importantes para a aplicação.

A OpenCV (OPENCV, 2014) é uma biblioteca de visão computacional que surgiu em 1999 na Intel Research (hoje é mantida pela instituição de pesquisa Willow Garage) e conta com mais de 2500 algoritmos otimizados para execução em tempo real. Suas aplicações expandem-se em várias áreas, como inspeção de produtos em uma fábrica, análise de imagens médicas, vigilância, interface de usuário, calibração de câmeras, visão estereoscópica e várias áreas da robótica (BRADSKI e KAEHLER, 2008; OPENCV, 2014).

Na robótica o uso da biblioteca OpenCV vai desde a captura dos dados dos sensores, até a extração de características (encontrar pontos de interesse na imagem, por exemplo) e aplicação de técnicas de aprendizado de máquina que o OpenCV possui. Além disso, há rotinas de aplicação de filtros e segmentação de imagens (pré-processamento), úteis para facilitar o processamento das imagens ao longo de todo o processo de sensoriamento do robô. 
Cada vez mais, buscando alto desempenho no processamento de imagens, modelos de computação paralelos (CUDA e OpenCL) vem sendo inseridos na biblioteca OpenCV, permitindo que muitas técnicas precisas, mas consideradas "pesadas", agora possam ser utilizadas em tempo real. São estes e outros avanços proporcionados pela biblioteca OpenCV que tornam possível o desenvolvimento de sistemas sofisticados de Visão, com baixo investimento e custo de operação. A utilização de câmeras pode inclusive substituir outros sensores e sistemas mais caros, complexos e menos genéricos. Isso evidencia não só o crescimento desta área, mas também a tendência de aproximação dos computadores à forma como os humanos entendem o ambiente ao seu redor.

\subsubsection{ROS}

Com o grande número de drivers e bibliotecas surgiu a necessidade de um sistema que fizesse a integração destas ferramentas para facilitar o desenvolvimento de aplicações para robótica. Neste contexto surgiu o ROS (Robot Operating System), o qual foi criado e é mantido pela empresa Willow Garage. O ROS é, portanto, um sistema distribuído com uma arquitetura orientada a serviços que permite a comunicação entre os diferentes módulos e também entre os diferentes agentes.

O ROS é uma estrutura que fornece uma arquitetura distribuída dedicado para aplicações robóticas, fornecendo muitos recursos básicos, funcionalidades e serviços que permitem a composição de uma arquitetura de sistema híbrido de controle de robôs móveis autônomos. Aplicações que fazem uso da plataforma ROS devem ser projetadas de forma modular, com partes do sistema que interagem uns com os outros através de mensagens e trocas de serviços.

Pesquisas na área de percepção robótica são, em sua maioria, feitas através de logs das informações dos sensores, permitindo assim realizar comparações entre diferentes algoritmos e simplificar o procedimento experimental. A plataforma ROS apoia essa abordagem provendo funcionalidades de registro de logs e reprodução destes. Quaisquer mensagens enviadas através do ROS, seja ela proveniente de um hardware (por exemplo, sensores) ou de uma aplicação, podem ser gravadas e reproduzida quantas vezes forem necessárias.

Algumas de suas características incluem abstração de hardware, drivers de dispositivos, bibliotecas, passagem de mensagens entre processos e visualizadores (imagens, nuvem de pontos, etc.) (ROS, 2014).

\subsection{Fusão de Sensores}

Fusão de sensores é a técnica de combinação de dados sensoriais de várias fontes a fim de reduzir o grau de incerteza que um robô possa experimentar. Isso 
permite que um robô possa construir um modelo de mundo mais preciso, a fim de navegar e se comportar de forma mais segura (CIFTCIOGLU, 2007; KAM, 1997). Fusão de sensores combina dados sensoriais de uma das três formas básicas:

- Sensores redundantes: Fornece a mesma percepção do meio ambiente.

- Sensores complementares: Fornece tipos disjuntos de informações sobre o meio ambiente.

- Sensores coordenados: Trabalham em seqüência para reunir informações sobre o meio ambiente.

Depois que os dados sensoriais são combinados, o robô deve perceber ou entender os dados e baseado nisso agir sobre o ambiente (ver Figura 2.18).

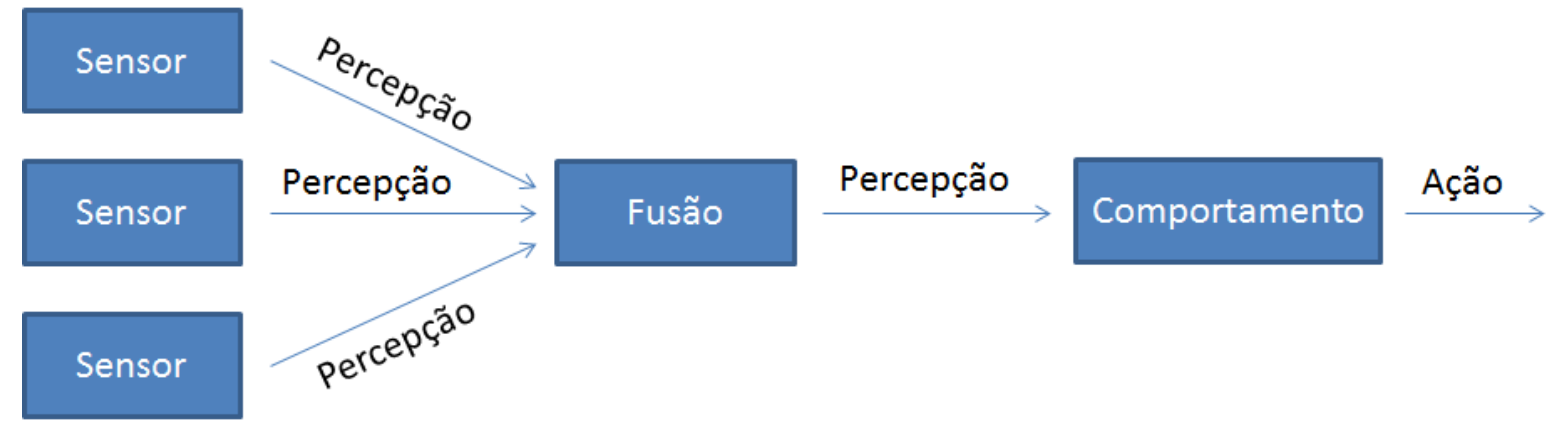

Figura 2.18 - Diagrama de fusão de sensores. Fonte: Adaptado de http://www.ni.com/white-paper/8219/en

Sistemas que trabalham com conhecimento devem ter a capacidade de manipular, transportar e modelar dados para sua representação. Um dos grandes problemas desses sistemas baseados em conhecimento é como lidar com dados imprecisos, incompletos ou inconsistentes. As técnicas de fatores de certeza e redes bayesianas consideram proposições isoladas e atribuem a cada uma delas uma estimativa de ponto (um único valor) do grau de crença garantido, face às evidências observadas.

Dentro dos diversos métodos de fusão de sensores o uso da Teoria de Dempster-Shafer aparece como uma abordagem interessante e que foi adotada a este projeto de mestrado.

\subsection{Teoria de Dempster-Shafer}

A Teoria de Dempster-Shafer (TDS) se originou com o trabalho de Dempster sobre probabilidades inferior e superior (DEMPSTER, 1967a; DEMPSTER, 1967b) e teve continuidade com os trabalhos de Shafer (SHAFER, 1976), que refinou e 
estendeu as ideias de Dempster. A TDS considera grupos de proposições que chamamos de evidências $(A)$ e atribui a cada uma delas um intervalo no qual está o grau de crença, como demostrado em (2.6). Ela foi projetada para lidar com a distinção entre incerteza e ignorância, sendo que permite representar a ignorância sobre uma proposição. Ao invés de calcular a probabilidade de uma proposição, ela calcula a probabilidade das evidências suportarem a proposição (2.7). A crença em $A$ (Belief $\operatorname{Bel}(A)$ ) é definida pela massa $m(B)$, que expressa a probabilidade de todas as provas pertinentes e disponíveis que apoiam a alegação de que o estado atual pertence a $A$, mas não a um subconjunto específico de $B$.

$$
\begin{aligned}
& \operatorname{Bel}(A)=\sum_{B \ni A} m(B) \\
& \operatorname{pl}(A)=\sum_{B \mid B \cap A \neq \varnothing} m(B)
\end{aligned}
$$

Muitas vezes utilizada como um método de fusão de sensores, a TDS permite que evidências provindas de diferentes sensores do sistema possam ser somadas visando à obtenção de uma crença total que pode aumentar ou diminuir o grau de crença sobre uma determinada hipótese (como: detecção de obstáculos, navegação em um ambiente, deteç̧ão de seres humanos, etc.).

\subsection{Considerações}

Este capítulo apresentou os conceitos básicos de robótica móvel autônoma e sua crescente importância para a área agrícola, também foram apresentados alguns sensores e ferramentas de softwares utilizados ao longo deste projeto. Importantes conceitos relacionados à visão computacional foram apresentados e discutidos, pois neste trabalho será necessária a escolha de métodos de segmentação de imagens, filtros, calibração de câmeras e estimação do mapa de profundidade que permitam um alto desempenho da aplicação, visto que é necessário seu uso em tempo real.

Em relação às ferramentas apresentadas, a plataforma ROS possibilitou com que os dados gerados por um sensor pudessem ser publicados e facilmente utilizados, tornando possível a execução das diversas aplicações (por exemplo, diferentes detectores de obstáculos) em diferentes computadores. Além disso, o ROS possibilita a abstração do hardware e a comunicação entre processos.

Através do uso do software OpenCV integrado a plataforma ROS e dos dados dos sensores gravados e armazenados no formato ".bag" (formato ROS destinado ao armazenamento de mensagens, que permite a criação de "logs" sincronizados dos dados capturados), será possível desenvolver e testar diferentes algoritmos de detecção de obstáculos que servirão para o desenvolvimento deste trabalho. No capítulo a seguir serão apresentados trabalhos que utilizam os sensores descritos 
neste capitulo e métodos que estão relacionados com as pesquisas deste projeto de mestrado. 


\begin{tabular}{c|c|} 
Capítulo \\
3
\end{tabular}

\section{Trabalhos Relacionados}

Neste capítulo serão apresentados trabalhos relacionados a esta dissertação de mestrado. Dentre eles, alguns desenvolvidos neste laboratório (LRM-ICMC/USP), visto que o trabalho proposto engloba sensores comumente utilizados na área da robótica e abordagens inspiradas em outros trabalhos previamente desenvolvidos e/ou em desenvolvimento junto ao nosso grupo de pesquisa.

Uma vez que o tema principal deste trabalho é a detecção de obstáculos utilizando três sensores do tipo câmera de vídeo, serão apresentados alguns trabalhos na seção 3.1 que utilizam a cor e a textura das imagens da câmera monocular para segmentar da cena os obstáculos. Na seção 3.2 serão apresentados alguns trabalhos relevantes sobre detecção de obstáculos utilizando imagens da câmera estéreo. Por fim, na seção 3.3 serão apresentados alguns trabalhos sobre detecção de obstáculos utilizando imagens da câmera térmica.

\subsection{Câmera de Vídeo Monocular}

Este projeto de pesquisa visa a implementação de um sistema que dará suporte à navegação autônoma e segura a um robô de uso externo em um ambiente agrícola estruturado. É necessário, portanto, considerar alguns métodos de detecção de obstáculos para que não haja colisões com os elementos do ambiente, sejam eles estáticos ou dinâmicos. 
Nesta seção serão apresentados dois trabalhos que utilizam uma câmera de vídeo monocular para extrair informações de cores e texturas e a partir delas realizar a segmentação dos objetos de interesse na cena, classificando-os de acordo com o desejado.

O trabalho de Shinzato (SHINZATO, 2010), desenvolvido junto ao LRMICMC/USP, propõe o reconhecimento de superfícies navegáveis (estradas bem estruturadas, pavimentadas e bem conservadas) usando a informação visual do ambiente urbano (cores dos elementos e textura). Este sistema de deteç̧ão visual baseado em múltiplas Redes Neurais Artificiais (RNAs) treinadas para reconhecer um padrão de superfície navegável, tendo como entrada diferentes características de uma mesma imagem como: proporção, entropia, energia e a variância de canais de cores diferentes (RGB, HSV, YUV). Através desse conjunto de atributos extraídos de subimagens (blocos com cerca de 10x10 pixels) a RNA tem a capacidade de estimar a classificação destes blocos de pixels de tamanho fixo em regiões navegáveis ou não navegáveis, além de fornecer um fator de confiança de cada parte do ambiente detectada pela câmera monocular fixada ao RMA.

O sistema visual do trabalho desenvolvido consiste em duas etapas principais. A primeira etapa é gerar todas as imagens com diferentes características da mesma cena. A Segunda etapa é a classificação dessas imagens geradas, onde um conjunto de RNA que recebe as imagens como entrada decide se as regiões da imagem são navegáveis ou não. Combinadas todas as regiões das imagens, é assim obtida uma matriz com o mapa de navegação visual da cena. A Figura 3.1 (a) ilustra uma cena do ambiente, sua segmentação em regiões (ver Figura 3.1 (b)) e na Figura 3.1 (c) sua classificação quanto à área navegável (regiões na cor vermelha) e não navegável, onde neste caso o padrão de imagem classificado como região navegável corresponde ao da textura do asfalto (os demais elementos da cena são classificados como não navegáveis).

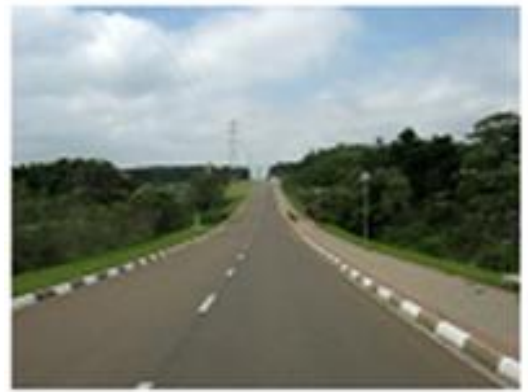

a)

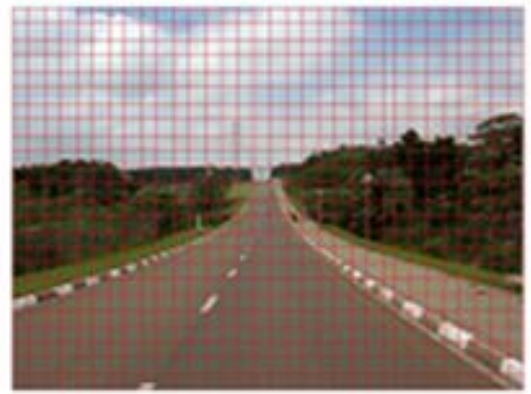

b)

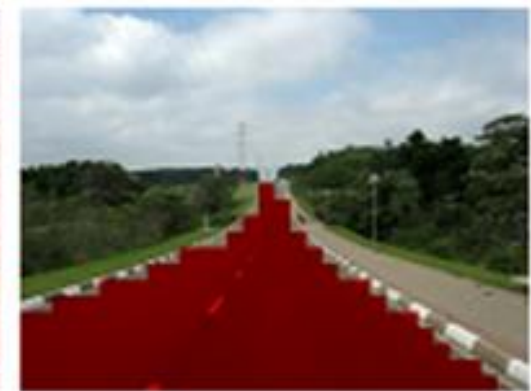

c)

Figura 3.1 - (a) Cena do ambiente. (b) Subdivisão da cena em blocos a serem classificados pelo RNA. (c) Classificação das regiões quanto à navegabilidade. Fonte: (SHINZATO, 2010) 
Este sistema foi testado exaustivamente com veículos em ambientes externos e em vias bem definidas (ruas pavimentadas e estradas de terra bem delimitadas). Além dos testes em ambientes abertos, alguns testes também foram feitos em robôs móveis em ambientes fechados, ambos os resultados foram satisfatórios (SALES, 2010; SOUZA, 2013).

O trabalho de (LEE, 2005), desenvolvido pelo Centro de Máquinas e Robôs Inteligentes na Universidade da Florida, propõe o desenvolvimento de um veículo autônomo chamado NaviGator que teve como objetivo participar do evento DARPA Grand Challenge. O veículo é composto de diversos sensores (LIDAR, câmera estéreo, radar, etc.), entre eles uma câmera monocular, utilizada para detectar e manter o veículo na estrada.

O processamento realizado nas imagens capturadas pela câmera monocular se inicia com a remoção de áreas indesejadas (por exemplo, céu), mantendo apenas as áreas de interesse (ver Figura 3.2). Utilizando a representação das cores em RGB, são definidos conjuntos de imagens que definem as áreas navegáveis e não navegáveis do ambiente onde o veículo irá atuar (ver Figura 3.3 (a)), através de um classificador de Bayes o sistema classifica os pixels da imagem em navegáveis ou não navegáveis, gerando uma grade que é posteriormente utilizada pelo sistema de navegação do veículo. O resultado da classificação dos pixels pode ser visto na Figura 3.3 (b).
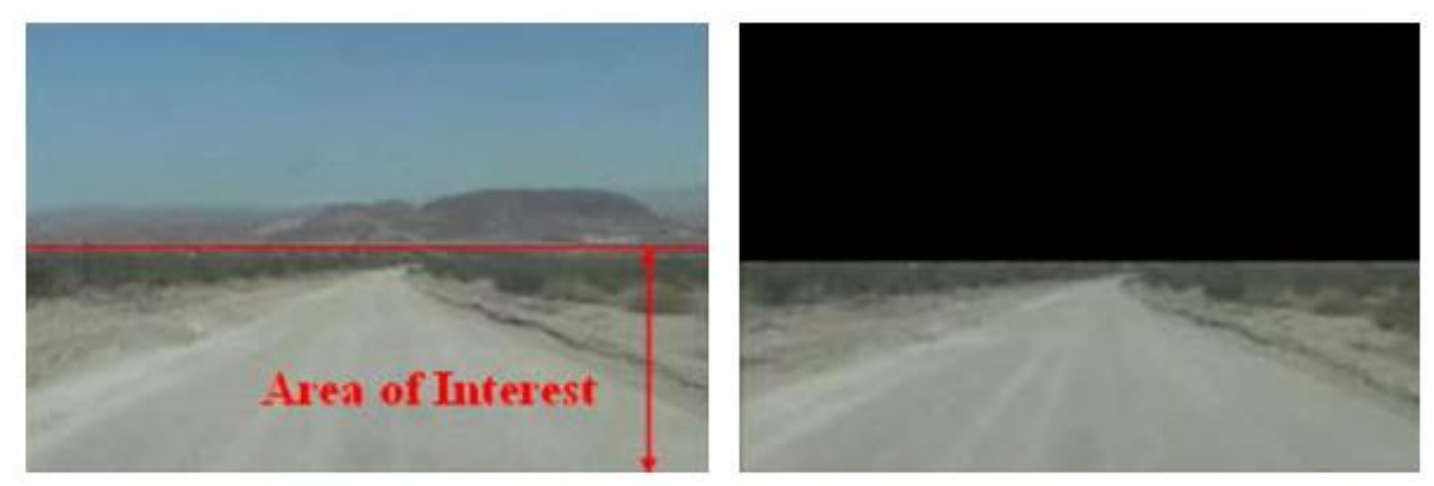

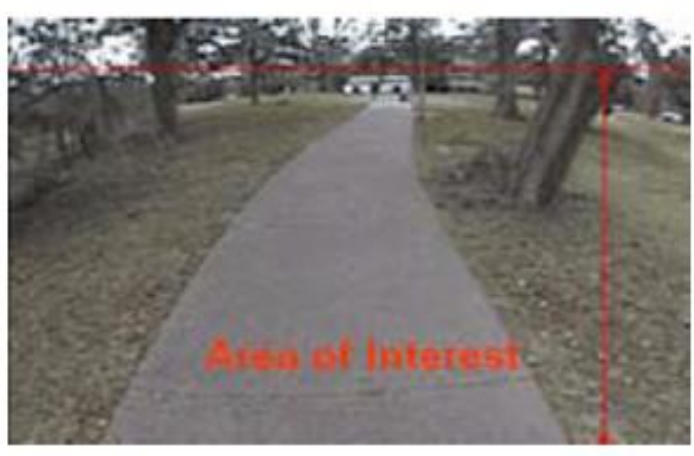

a)

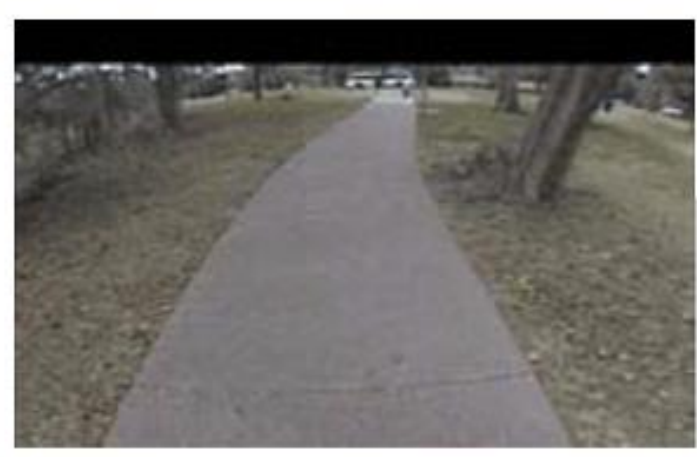

b)

Figura 3.2 - a) Área de interesse da imagem. b) Remoção da área indesejada na imagem. Fonte: (LEE, 2005) 


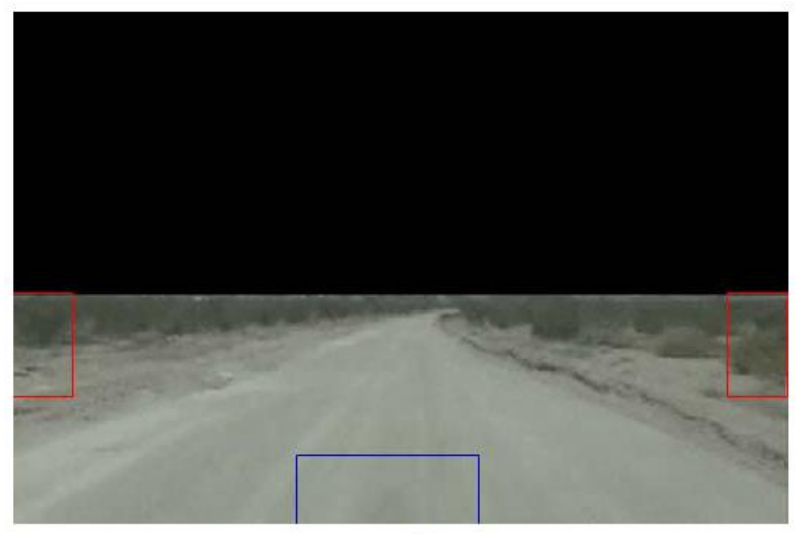

a)

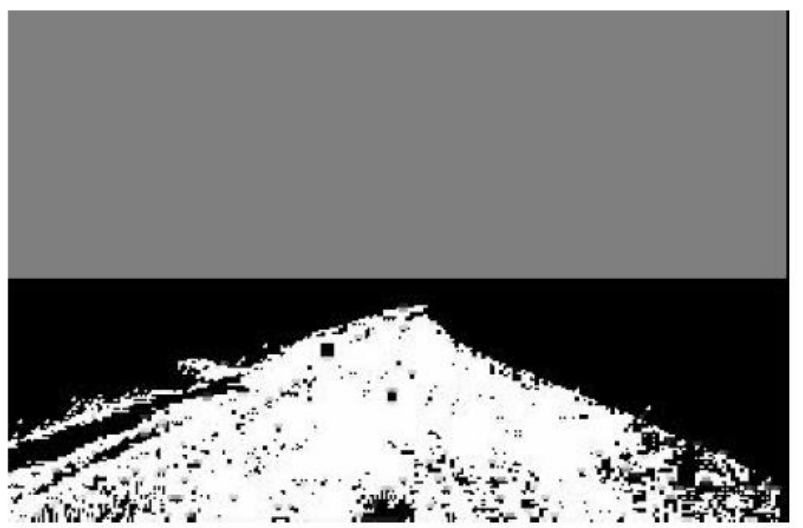

b)

Figura 3.3 - a) Definição da área não navegável (vermelho) e navegável (azul). b) Resultado da classificação da cena (em branco a área navegável). Fonte (LEE, 2005)

\subsection{Câmera de Vídeo Estéreo}

Nesta seção serão apresentados quatro trabalhos que utilizam uma câmera de vídeo estéreo para extrair informações tridimensionais do ambiente, possibilitando estimar a posição e aproximação de obstáculos do veículo, permitindo que este desvie ou tome alguma ação pré-programada.

A utilização de uma câmera de vídeo estéreo é muito adotada na detecção de obstáculos por RMAs, um exemplo disto é o trabalho (MENDES, 2012). Este trabalho implementado com o uso da plataforma CaRINA I pertencente ao laboratório LRM/ICMC-USP propõe um método robusto de navegação autônoma em tempo real evitando obstáculos na rota programada.

O trabalho consiste no fornecimento de um par de imagens capturadas através de uma camera de vídeo estéreo que é processada pelo método estéreo semiglobal para obter um mapa de profundidade. Este é convertido para uma nuvem de pontos 3D. O paradigma RANdom SAmple Consensus (RANSAC) (FISCHLER, 1981) é então utilizado para estimar os parâmetros do plano onde o veículo está ligado. Através de Figura 3.4 é possivel ver o mapa de navegabilidade gerado por este trabalho. 


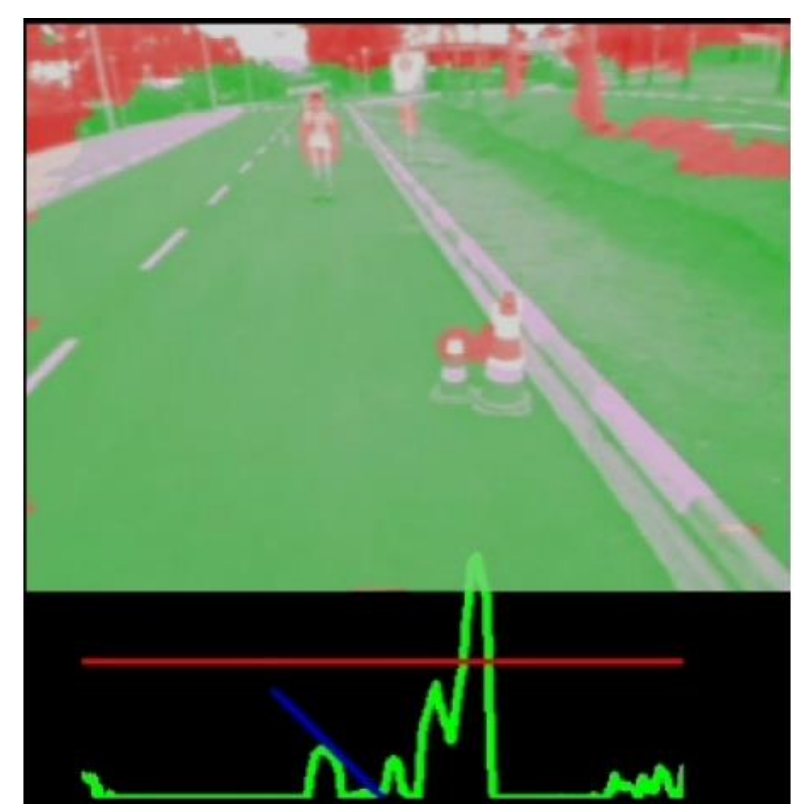

Figura 3.4 - Mapa de navegabilidade gerado e ilustração do método de desvio de obstáculos baseado no algoritmo VFH (Vector Field Histogram). Fonte: (MENDES, 2010)

Ao contrário do sistema de navegação desenvolvido por (SHINZATO, 2010), o qual é baseado no uso de imagens obtidas por câmeras monoculares, este sistema usa uma câmera estéreo que permite obter informações mais precisas da estrutura tridimensional do ambiente e, portanto, é possível identificar de uma forma mais precisa os obstáculos e sua posição no ambiente.

O método de detecção de obstáculos classifica os pontos com base na sua altura em relação ao plano calculado. Essas informações servem como entrada para o algoritmo de desvio de obstáculos que orienta o veículo a um ponto de GPS predefinido.

Em (MURARKA, 2008) foi utilizado um método estéreo global baseado em segmentação por cores e enquadramento de planos para gerar o mapa de disparidades. Em conjunto com um método baseado em movimento para detecção de quedas, o trabalho construiu um mapa bidimensional discreto onde cada célula poderia possuir valores indicando a altura do chão. Apesar da inviabilidade deste método em sistema de tempo real (devido à demora no cálculo do mapa de disparidade), o método fornece uma boa precisão em se tratando de câmera de vídeo estéreo.

A técnica denominada "stixels", introduzida pelo trabalho de Badino (BADINO, 2009), consiste em um conjunto de varetas retangulares como mostrado na Figura 3.5. Assume que todos os objetos partem do plano do chão e possui um limitante superior, desta forma, cada stixel é definido pela sua posição $3 \mathrm{D}$ em relação à câmara estéreo e localiza-se verticalmente no solo com uma altura determinada. 
Cada stixel simplifica a imagem, limitando o espaço livre e aproximando dos limites do objeto.

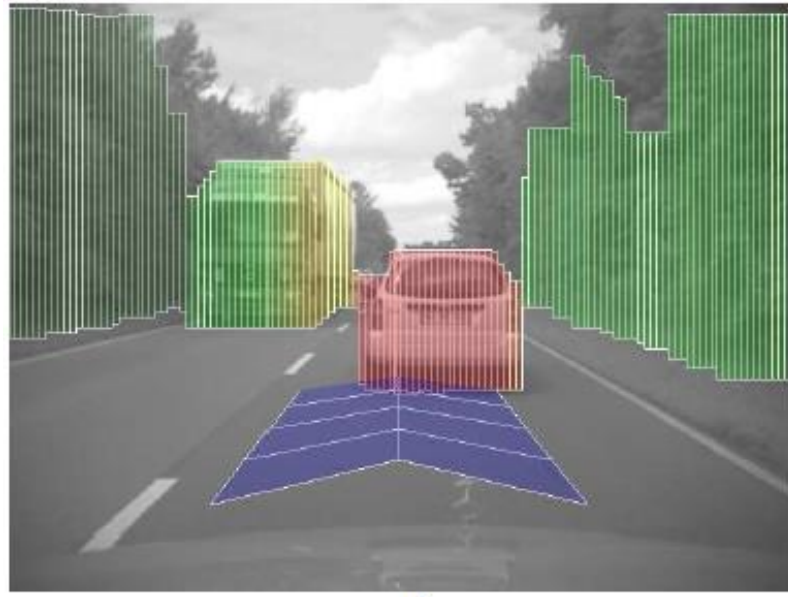

a)

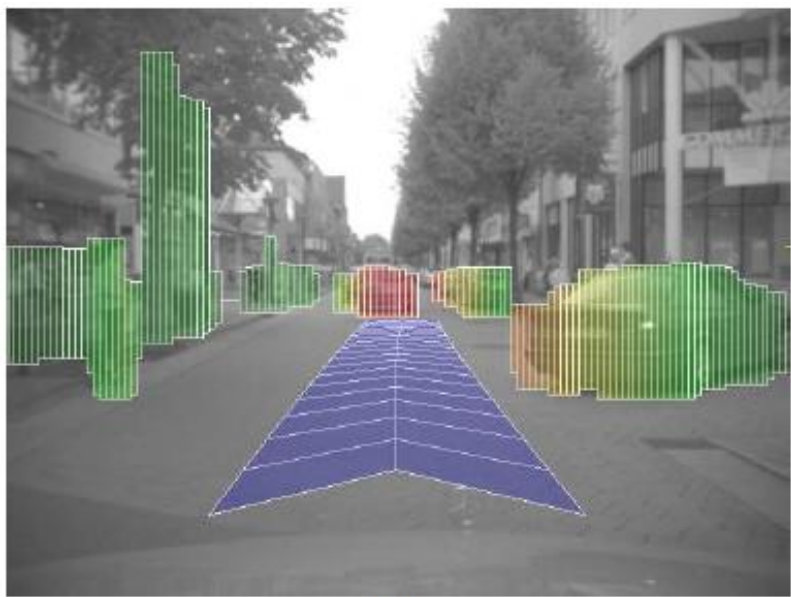

b)

Figura 3.5 - Técnica Stixel em dois diferentes cenários do mundo real. a) Estrada. b) Ambiente urbano. A cor dos stixels representa a distância lateral ao veículo. Fonte:

(BADINO, 2009)

O trabalho de Benenson, baseado na técnica desenvolvida por Badino, aperfeiçoou a técnica dos stixels permitindo estima-los diretamente sem necessitar do mapa de disparidade, com isto houve um grande ganho de velocidade, permitindo que grandes porções das imagens sejam descartadas sem prejuízo para o detector de pedestres implementado no trabalho (BENENSON, 2011). Recentemente, novas melhorias permitiram que fosse possível realizar a detecção de pedestres a uma taxa de $200 \mathrm{~Hz}$ (BENENSON, 2012). Esta alta taxa de detecção deve-se principalmente a técnica Stixel, que limita a imagem apenas às áreas de interesse. Pela imagem Figura 3.6 pode ser vista a detecção de pedestres utilizando a técnica Stixel.

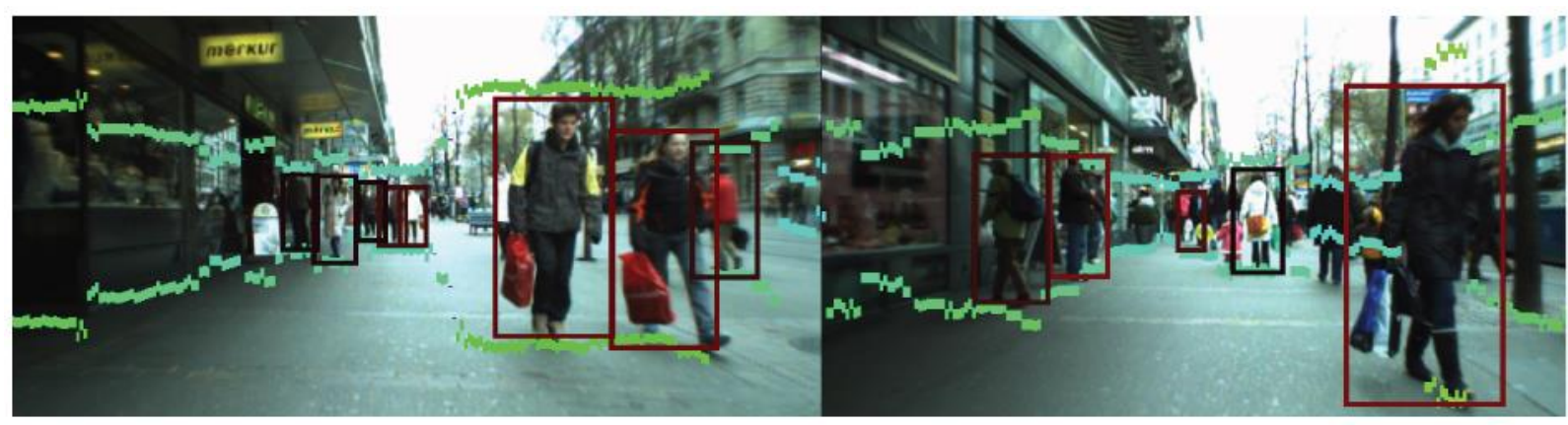

Figura 3.6 - Detecção de pedestres utilizando câmera estéreo. Linhas em tons de verde representam a estimação da técnica Stixel. Retângulos vermelhos representam a detecção dos pedestres. Fonte: (BENENSON, 2012) 


\subsection{Câmera de Vídeo Térmica}

Nesta seção serão apresentados três trabalhos que utilizam uma câmera de vídeo térmica para extrair informações de calor do ambiente e assim realizar a segmentação dos objetos de interesse na cena, classificando-os em possíveis humanos (objetos quentes) e objetos do ambiente (objetos frios).

O trabalho desenvolvido por Matheus Nin (NIN, 2011) junto ao laboratório LRM/ICMC, utiliza o processamento de imagens (histogramas e segmentação de imagens) para a segmentação de pessoas a partir dos dados provenientes da câmera térmica FLIR PathFindIR em um ambiente indoor. Na Figura 3.7 o resultado da segmentação de uma imagem térmica. Durante a segmentação as regiões mais escuras (regiões frias do ambiente) têm seus pixels igualados a zero a fim de focar o processamento apenas nas regiões de maior calor e que potencialmente representam humanos. Objetos que emitem calor e possuem uma superfície relativamente grande podem ser detectados como humanos neste trabalho.
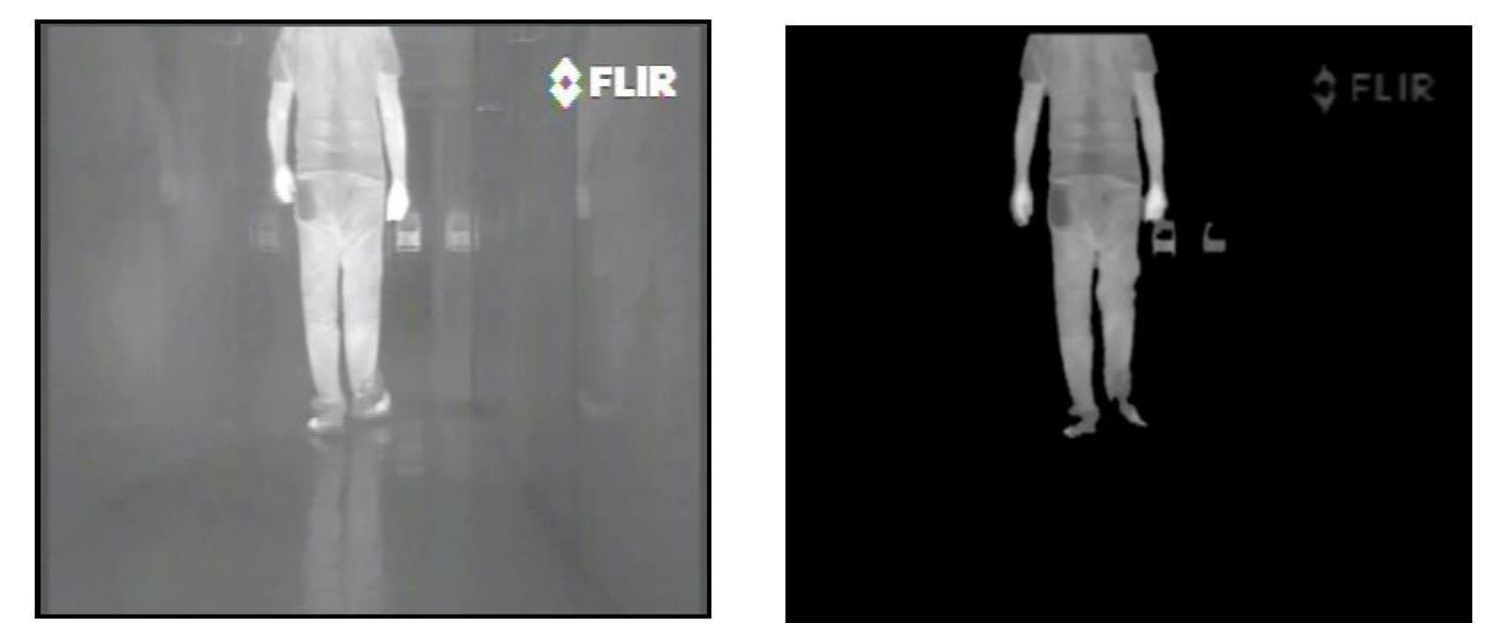

Figura 3.7 - Segmentação da imagem utilizando a câmera térmica. Fonte: (NIN, 2011)

Em (DICKENS, 2011) é proposto um veículo autônomo que pode ser utilizado em minas subterrâneas para aumentar a produtividade, segurança e diminuir os custos da extração dos materiais. O veículo, capaz de trabalhar em conjunto com seres humanos, percebe 0 ambiente através das informações tridimensionais capturadas por uma câmera de vídeo estéreo fundidas com as informações capturadas por uma câmera térmica.

O sistema extrai regiões de interesse e as classifica como sendo ser humano (elementos dinâmicos) ou objeto de fundo (elementos estáticos). As decisões tomadas pelo veículo autônomo são baseadas na informação resultante da fusão das duas câmeras e no uso de uma rede neural, fornecendo em tempo real e com 
precisão as ações que devem ser tomadas pelos atuadores do veículo autônomo, desviando de obstáculos estáticos e móveis que estejam em seu caminho.

O trabalho desenvolvido em (CORREA, 2012) propõe o desenvolvimento de um sistema robusto de percepção do ambiente visando à navegação de robôs móveis autônomos em ambientes internos para a execução de tarefas de monitoramento, vigilância, detecção da presença de pessoas e de situações anômalas (por exemplo, incêndios). Para tal, são utilizados o sensor 3D Kinect da Microsoft e uma câmera térmica.

Os dados do sensor Kinect são utilizados durante a navegação para que o robô possa se locomover de maneira segura e evitando colisões. Durante a navegação um mapa de navegabilidade local é criado permitindo assim o desvio de obstáculos. Durante a navegação o robô utiliza técnicas de inteligência artificial juntamente com processamento de imagens para se localizar no ambiente. A câmera térmica é utilizada em conjunto com os dados do Kinect com a finalidade de aumentar a confiabilidade e robustez durante a detecção de seres humanos.

As imagens da câmera térmica são pré-processadas gerando uma imagem contendo apenas a região de interesse, descartando o que não é considerado um humano/intruso (regiões mais frias). Após este processo, é aplicado o filtro de limiar pelo método Otsu (OTSU, 1979). A segmentação da imagem capturada pela câmera térmica e pré-processada pode ser vista na Figura 3.8.

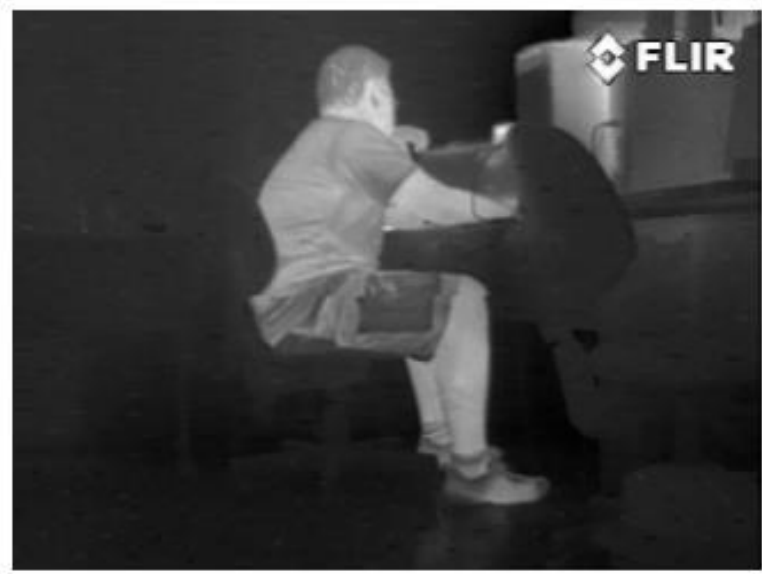

(a)

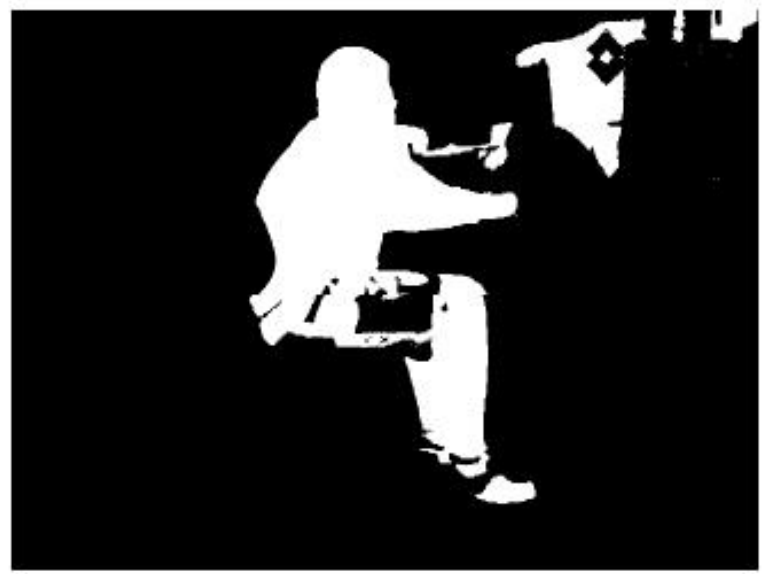

(b)

Figura 3.8 - a) Imagem capturada pela câmera térmica. b) Imagem pré-processada utilizando filtro de limiarização com o método de Otsu. Fonte: (CORREA, 2012)

\subsection{Considerações}

A pesquisa aqui tratada envolve o desenvolvimento de um sistema computacional usado como suporte à navegação autônoma de um robô que será 
utilizado em um ambiente agrícola. O sistema deverá ser capaz de informar sobre qualquer obstáculo relevante, estático ou dinâmico, que esteja na rota do robô. Neste capítulo foram apresentados trabalhos que utilizam sensores e métodos que foram estudados e que contribuíram significativamente durante o desenvolvimento deste projeto de mestrado.

Os sensores que fazem parte deste projeto foram escolhidos devido ao seu baixo custo, ao crescente número de pesquisadores que os utilizam com sucesso em suas pesquisas e seus bons desempenhos comparados com sensores de alto custo e precisão (por exemplo, LIDAR). Além disto, tais sensores apresentam uma complementariedade que permite que cada um possa capturar elementos importantes e distintos de uma mesma cena.

Os métodos aqui propostos buscam sempre o melhor desempenho do hardware (alta taxa de frames/segundo) com uma alta taxa de detecção dos obstáculos. No capítulo 4 serão apresentados detalhes da metodologia de desenvolvimento do sistema proposto que está baseada nas ferramentas e métodos que foram estudados previamente e nos trabalhos apresentados neste capítulo. 


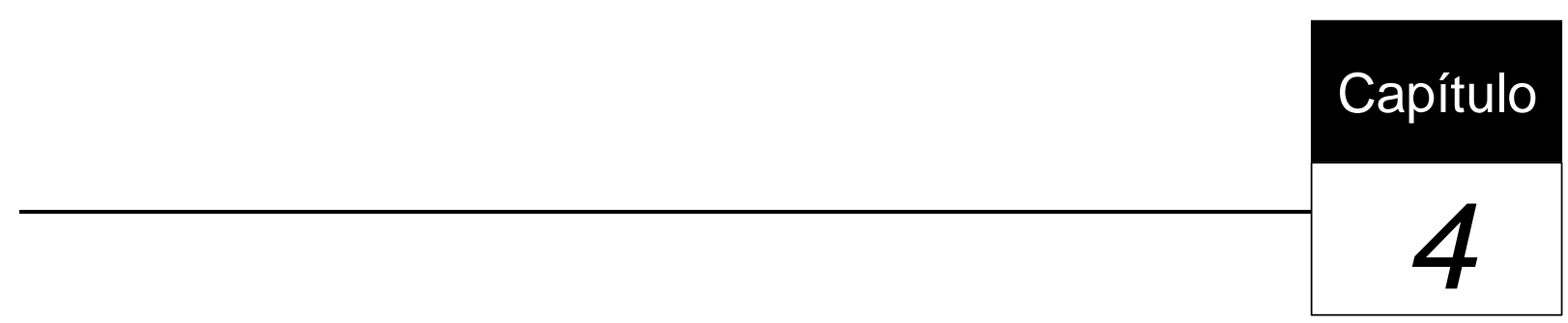

Metodologia

Buscando uma maior precisão na detecção de obstáculos presentes no meio onde o veículo autônomo será inserido, serão utilizados no projeto três tipos de câmeras de relativo baixo custo, todas já utilizadas em trabalhos anteriormente desenvolvidos no LRM. Através deste projeto de mestrado será feito o aperfeiçoamento e a adaptação dos trabalhos desenvolvidos no LRM buscando extrair informações das diferentes câmeras e fundi-las, criando assim um mapa de navegabilidade tridimensional (nuvem de pontos).

Os trabalhos anteriormente desenvolvidos junto ao LRM estão focados no desenvolvimento de aplicações para veículos autônomos em ambientes urbanos, neste trabalho um dos objetivos é considerar as particularidades de ambientes pouco estruturados (por exemplo, plantações) a fim de testar novas técnicas e aperfeiçoar algoritmos utilizados em ambientes urbanos para detectar obstáculos, passando a serem adotados em ambientes agrícolas.

Este capítulo apresenta os métodos de detecção de obstáculos de cada sensor e o método de fusão de sensores proposto para realizar a detecção de obstáculos que dará suporte ao sistema de navegação de um veículo autônomo agrícola. O sistema de detecção de obstáculos é composto por cinco fases. Na seção 4.1 será descrito o método de detecção de obstáculos que utilizará a câmera de vídeo monocular. A seção 4.2 apresentará o método de detecção de obstáculos que usa a câmera de vídeo estéreo. A seção 4.3 explicará o método de calibração 
utilizado para correlacionar a imagem gerada pela câmera térmica com as imagens geradas pela câmera estéreo. Na seção 4.4 será apresentado o método de detecção de obstáculos utilizando a câmera de vídeo térmica. Por fim, a seção 4.5 trata o método de fusão dos sensores.

\subsection{Detecção de Obstáculos Utilizando Câmera de Vídeo Monocular}

A fim de desenvolver este módulo de detecção, utilizaremos a câmera estéreo Bumblebee2 para capturar imagens RGB do ambiente. Para este módulo será apenas utilizada a câmera esquerda do par de câmeras. A escolha da câmera esquerda dá-se pelo fato de que o mapa de profundidade é gerado baseado nas imagens capturadas desta câmera, utilizando estas mesmas imagens não é necessário fazer a correspondência dos pixels com o mapa de profundidade, desta forma, não precisamos utilizar nenhum método adicional de calibração para poder fundir os resultados deste módulo com o módulo que será descrito na próxima seção.

A utilização da câmera monocular neste projeto de mestrado deve-se as informações de cores e textura que esta pode nos fornecer do ambiente. Apesar de serem muito dependentes de alguns fatores (por exemplo, iluminação), em um ambiente agrícola onde cores como tons de verde, marrom e amarelo estão muito presentes, um tom diferente destes ficará muito evidente na imagem, sugerindo a presença de algo incomum no ambiente.

Partindo desta motivação, um dos métodos de detecção de obstáculos proposto neste projeto de mestrado baseia-se na detecção de cores "anormais" que apareçam na cena. O inconveniente deste método é que obstáculos que estejam camuflados (pouca variação de cor e textura entre eles e o ambiente) não serão detectados. Um ambiente onde a variação das cores entre um frame e seu subsequente esteja abaixo de certo limiar é tido como um ambiente livre de obstáculos. Através da Figura 4.1 (a) pode ser visto um ambiente livre de obstáculos detectáveis através da cor e textura e na Figura 4.1 (b) um ambiente contendo pessoas com roupas coloridas que se destacam no ambiente. 


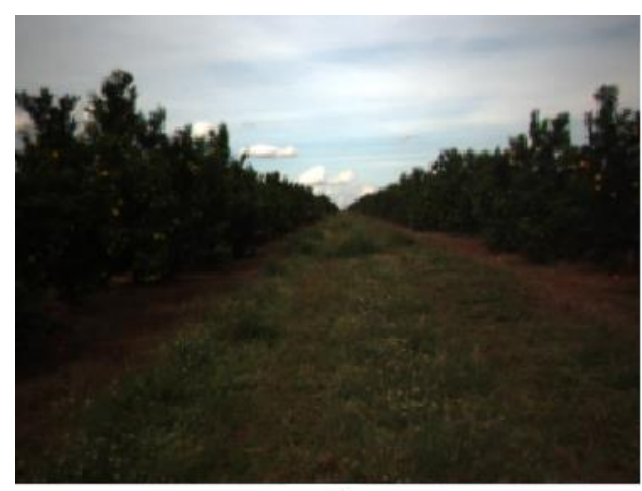

a)

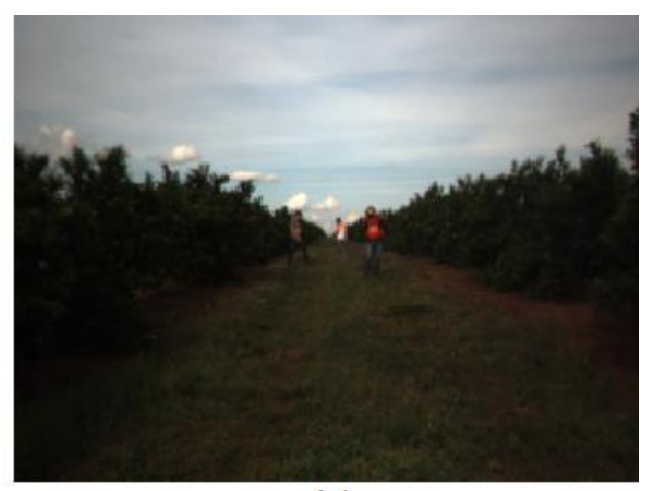

b)

Figura 4.1 - a) Ambiente sem obstáculos. b) Ambiente contendo obstáculos de cores e texturas contrastantes.

A quantização das cores presentes na cena é feita baseada no histograma HSV da imagem. A cada frame capturado um histograma será gerado e comparado com o histograma do frame anterior, através desta comparação é possível identificar novas cores que possam estar surgindo (detecção de novidade na cena) e evitar que pequenas mudanças no ambiente afetem a detecção. A fim de exemplificar o funcionamento do método, um retângulo de cor alaranjado (composto pelas componentes RGB vermelho e verde) foi adicionado ao próximo frame da sequência a qual o frame da Figura 4.1 (a) foi retirado (ver Figura 4.2). Ao gerarmos os histogramas das imagens Figura 4.1(a) e Figura 4.2, podemos notar variação nas componentes vermelho e verde da imagem, evidenciando que alguma novidade apareceu na cena, esta novidade será classificada como um possível obstáculo. Os histogramas RGB das imagens podem ser vistos através da Figura 4.3.

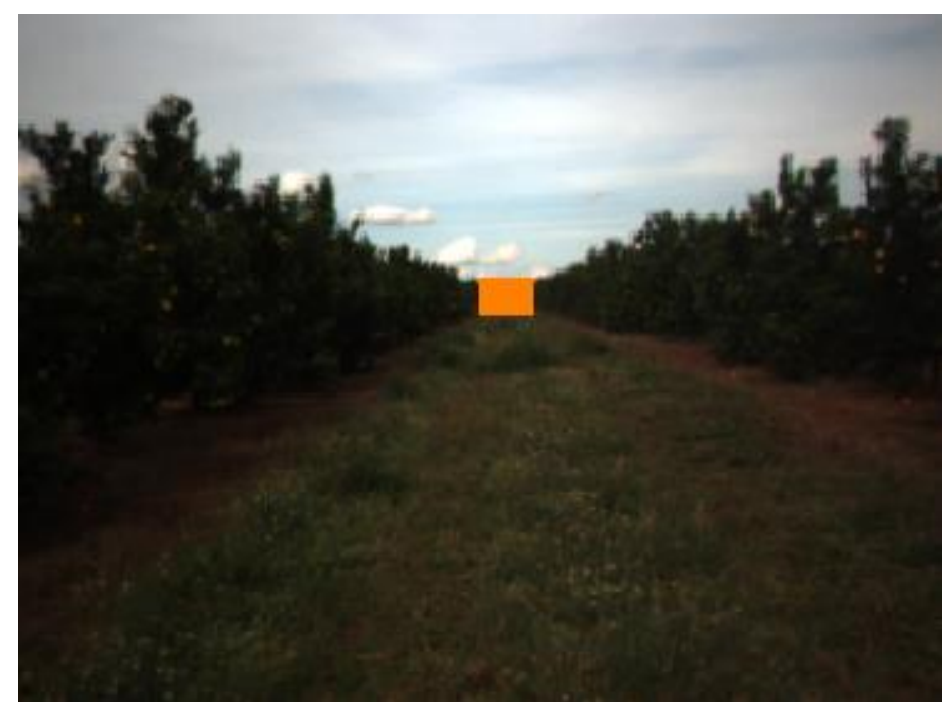

Figura 4.2 - Ambiente modificado com um retângulo alaranjado no horizonte. 


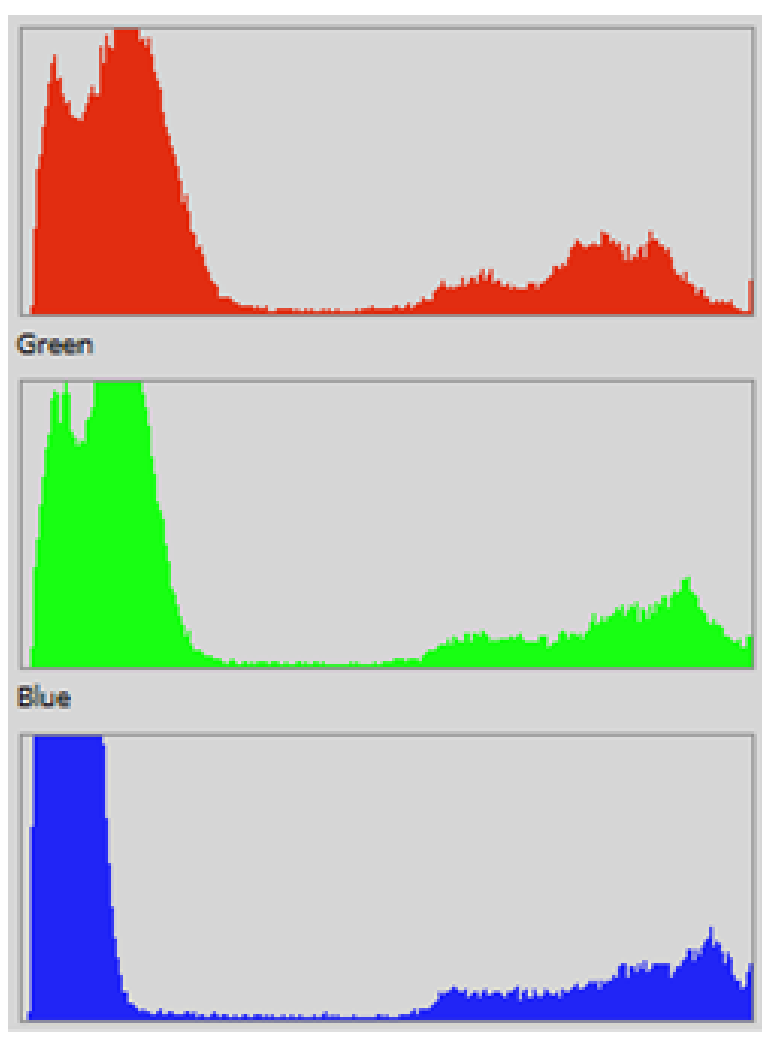

a)

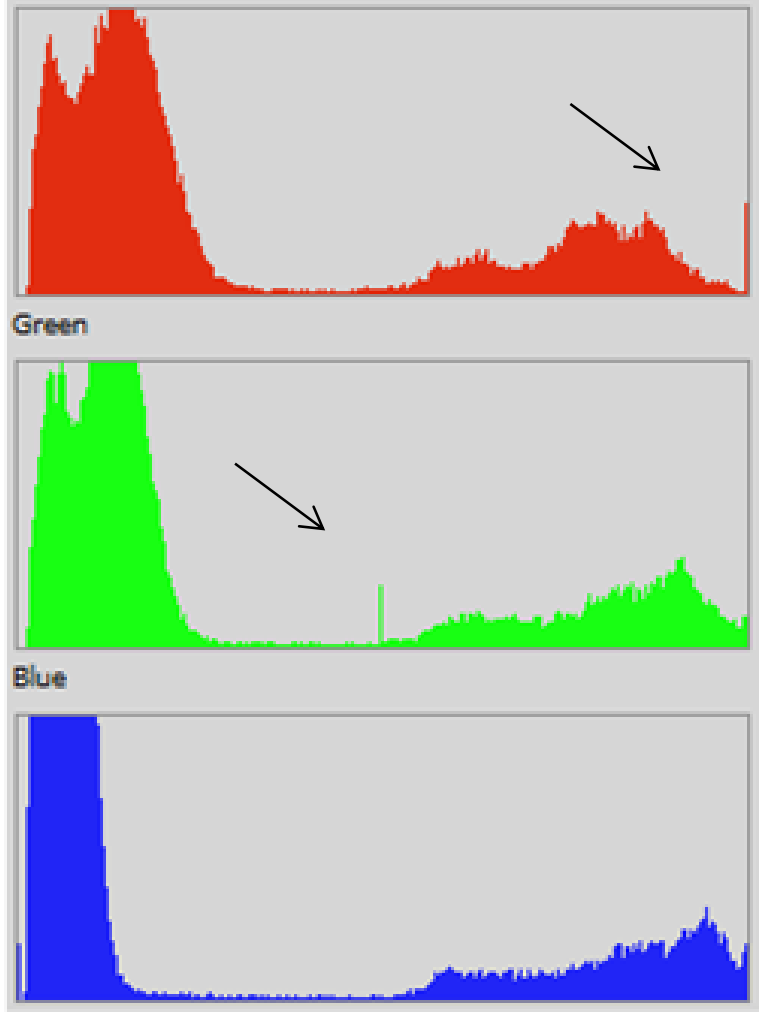

b)

Figura 4.3 - a) Histograma da imagem original. b) Histograma da imagem contendo o retângulo alaranjado, as setas indicam as alterações ocorridas.

É importante salientar que para facilitar a exemplificação utilizamos o histograma RGB das imagens por ser mais conhecido, o método escolhido utiliza o histograma HSV por ser de simples implementação, baixo custo computacional e principalmente a possibilidade de ser aplicado com êxito em um ambiente agrícola, visto que em ambientes contendo muitas novidades visuais (novas cores e texturas) seu índice de acerto seria inferior ao necessário.

\subsection{Detecção de Obstáculos Utilizando Câmera de Vídeo Estéreo}

Inspirado pelo trabalho de (MENDES, 2010), neste módulo de detecção de obstáculos foi utilizada a câmera de vídeo estéreo Bumblebee2 para buscar objetos que se elevam a partir do chão e que estejam na rota do veículo. Diferentemente do trabalho de Mendes que utiliza diretamente o mapa de profundidade para estimar a posição dos obstáculos, foi proposto o uso da técnica Stixel devido ao seu bom resultado mesmo em situações de baixa luminosidade.

Em sua mais nova versão (BENENSON, 2012), a técnica Stixel não utiliza mapa de profundidade para estimar a altura dos objetos que se elevam do plano do chão, utiliza a altura estimada dos objetos, parâmetro este definido a priori de acordo com o ambiente onde o veículo será inserido. Estimado primeiramente o plano do 
chão (ver Figura 4.4 (a)), para a estimação de cada stixel é verificado se existe algum objeto que parta do plano do chão e que seja menor ou próximo da altura especificada, caso exista, este é marcado como um possível obstáculo. Pela Figura 4.4 (b) pode ser vista a estimação dos stixels.

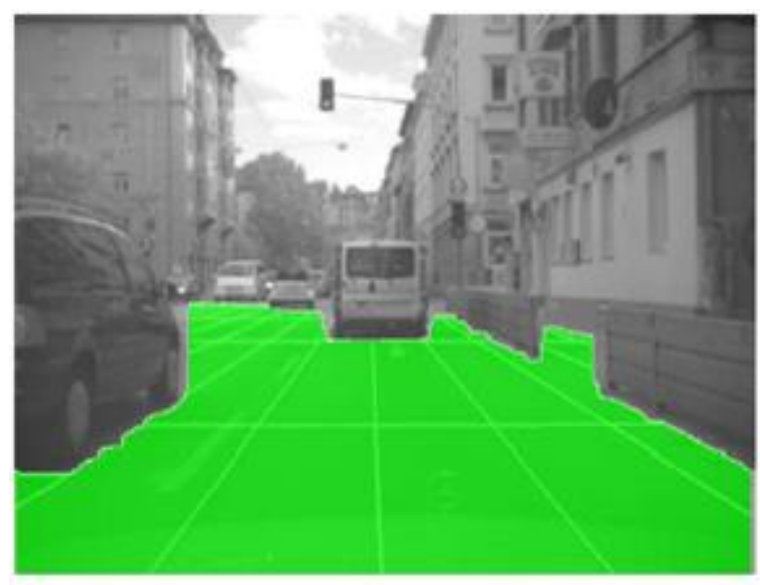

a)

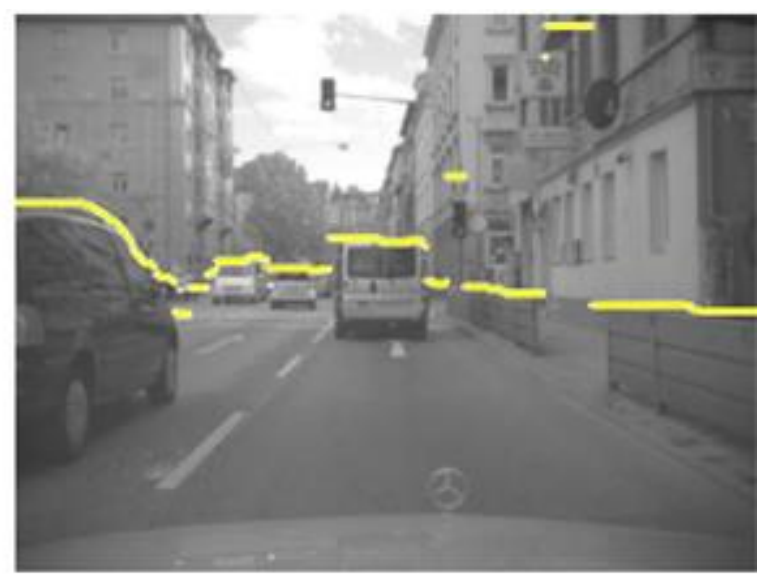

b)

Figura 4.4 - a) Estimação do plano do chão. b) Estimação da altura dos obstáculos. Fonte: (BADINO, 2009)

Através desta técnica diminuímos a área de interesse da imagem, sendo possível aplicar até mesmo um classificador de pessoas, veículos ou animais em tempo real. Neste módulo de detecção utilizando câmera estéreo será testado inicialmente apenas o uso da técnica Stixel, visto que é de interesse a detecção de todos os tipos de obstáculo. Espera-se deste módulo, além da detecção de possíveis obstáculos que venham a colidir com o veículo, a confirmação das estimativas realizadas pelos outros módulos.

\subsection{Calibração}

A calibração entre a câmera estéreo e a câmera térmica é um procedimento executado antes dos módulos de detecção serem iniciados. Ela é necessária, pois diferente do que ocorre entre as imagens monoculares e o mapa de profundidade (ambos gerados pela mesma câmera), a correlação entre pixels das imagens térmicas e o mapa de profundidade não acontece de forma direta, pois os parâmetros intrínsecos e extrínsecos das câmeras são diferentes, podemos dizer de forma simplificada que as câmeras "enxergam" de forma diferente.

Devido ao ambiente e a falta de recursos em que o procedimento de calibração, a principio, iria ocorrer (ambiente agrícola), foi desenvolvido um método considerando como requisitos importantes sua simplicidade e rapidez. A implementação do método aproveitou o fato de que não seria necessário o cálculo do mapa de profundidade entre as câmeras monocular e térmica, visto que este é obtido 
pela câmera estéreo. Assim, considerando os parâmetros intrínsecos das câmeras a perspectiva da imagem térmica foi alterada para a perspectiva da imagem monocular, obtemos desta forma uma correlação aproximada entre os pixels das imagens.

Para que fosse possível alterar a perspectiva de uma imagem ajustando para "encaixar" com a perspectiva de outra imagem, foi preciso encontrar features capturados por ambas as câmeras que pudessem ser correlacionados. Foi utilizado para tal, um padrão xadrez (ver Figura 4.5) que pudesse ser visualizado pelas duas câmeras. $O$ padrão foi construído utilizando materiais que ao serem aquecidos ou resfriados apresentassem uma diferença de temperatura visível pela câmera térmica e apresentassem uma diferença visual de cor ao serem vistos pela câmera monocular. Os materiais utilizados para a confecção do padrão foram papel chumbo na cor verde e espuma vinílica acetinada (EVA).

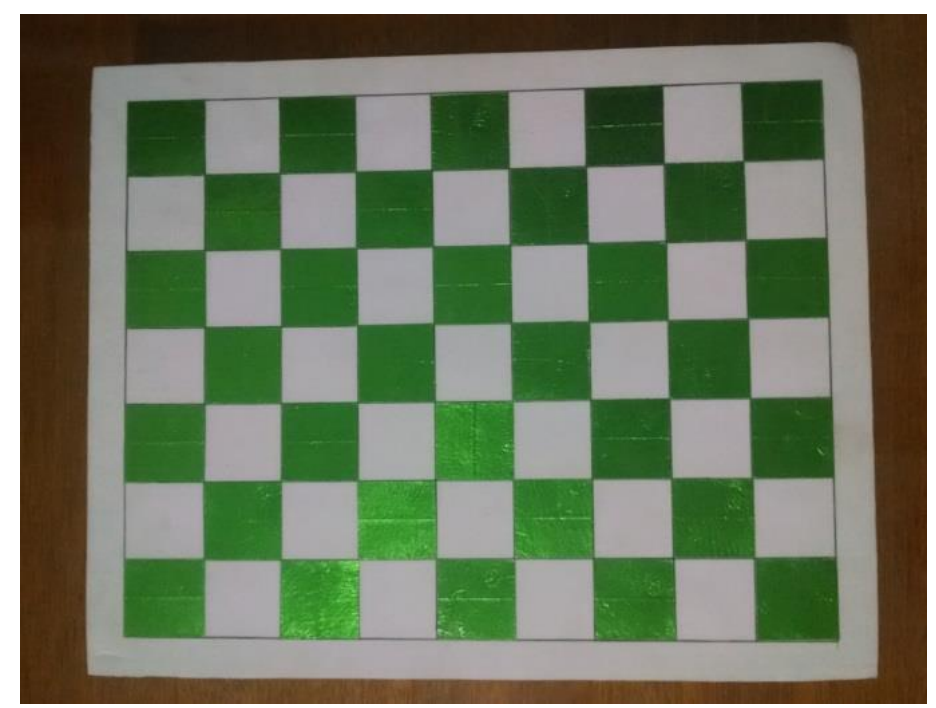

Figura 4.5 - Padrão xadrez utilizado na calibração das câmeras monocular e térmica.

O padrão xadrez é composto por 9 quadrados na horizontal e 7 quadrados na vertical, sendo que cada quadrado possui $4 \mathrm{~cm}$ de lado. Este padrão é capaz de gerar 48 features visíveis por ambas às câmeras. Com o auxilio da biblioteca gráfica OpenCV é possível fazer a correlação das 48 features uma a uma entre as câmeras (ver Figura 4.6) e aplicar métodos de mudança de perspectiva, ao final do processo é obtida a imagem térmica na perspectiva da imagem monocular. Com a imagem térmica em uma perspectiva próxima da imagem monocular é possível fazer a correlação aproximada entre os pixels e em um próximo passo, a fusão dos módulos de detecção. 


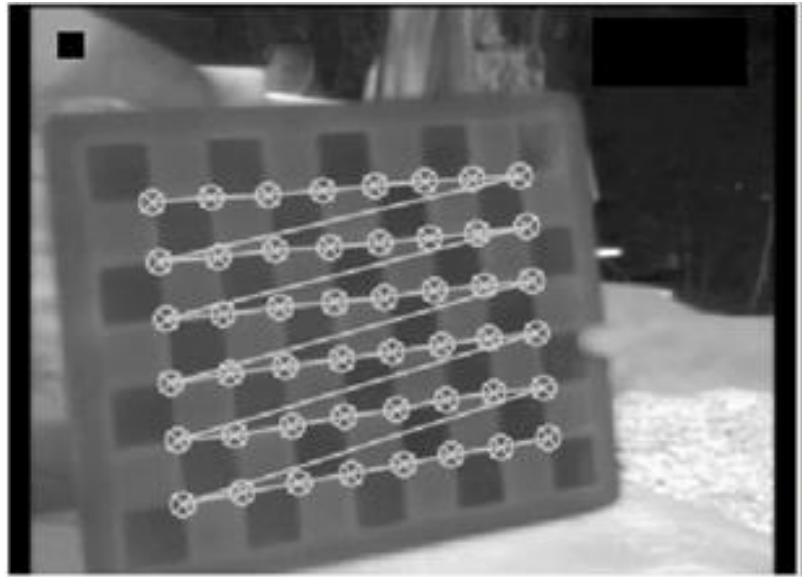

a)

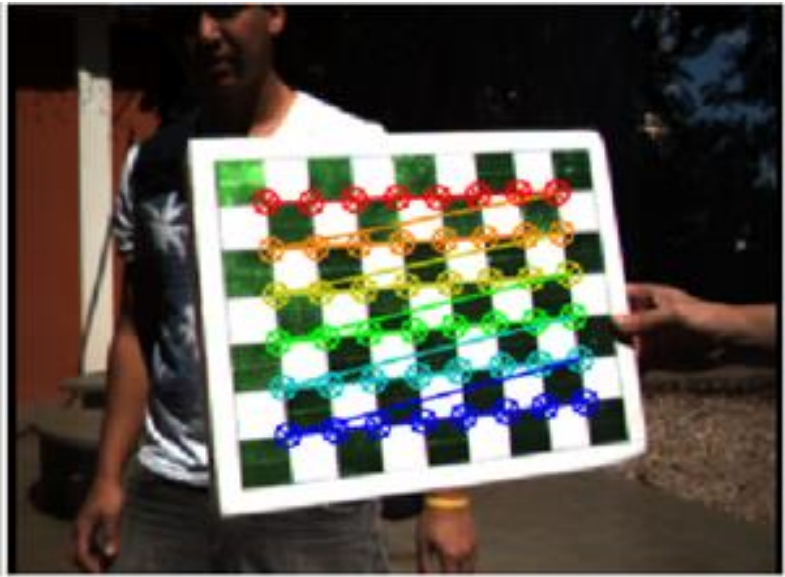

b)

Figura 4.6 - Detecção das features na imagem térmica a) e na imagem monocular b).

\subsection{Detecção de Obstáculos Utilizando Câmera de Vídeo Térmica}

Neste modulo de detecção de obstáculos será utilizada a câmera térmica FLIR PathFindIR. Através desta câmera é possível obtermos uma identificação de variação de temperatura podendo identificar objetos por suas diferentes assinaturas térmicas, porém não é possível a obtenção da temperatura exata dos objetos. Inspirado pelos trabalhos (NIN, 2011; CORREA, 2012), podemos complementar as informações obtidas através da câmera monocular identificando objetos que possam estar camuflados com cores semelhantes as do ambiente. É possível também detectar com mais facilidade a presença de pessoas, animais, implementos agrícolas, etc. devido à assinatura térmica particular que esses obstáculos emitem.

O método de detecção utilizando imagens térmicas foi escolhido baseado nos resultados obtidos pelo trabalho de Jadin (JADIN, 2012). Neste trabalho é demostrado como o método de Otsu, após ajustes da intensidade na imagem, é superior a outras técnicas no quesito segmentação de imagens utilizando câmera térmica. $O$ ajuste de intensidade na imagem térmica busca aumentar o máximo possível a diferença entre regiões quentes de regiões frias, o resultado deste processo pode ser visto pela Figura 4.7 na qual são mostrados componentes elétricos capturados com uma câmera térmica. 


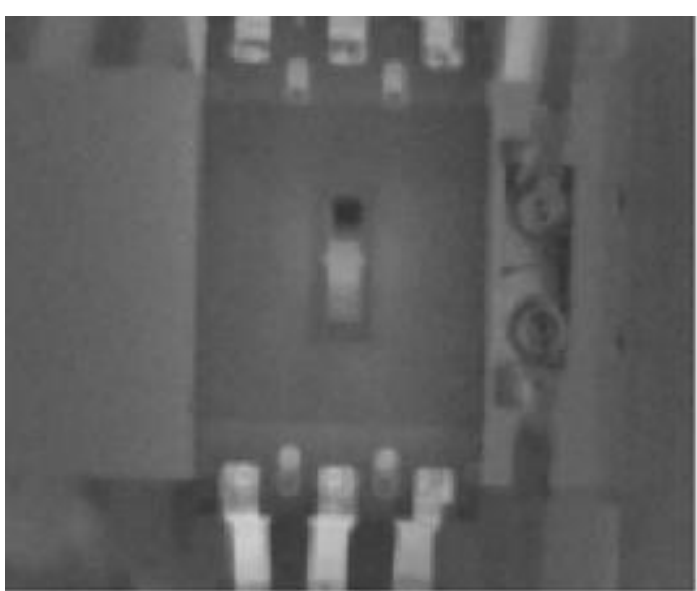

a)

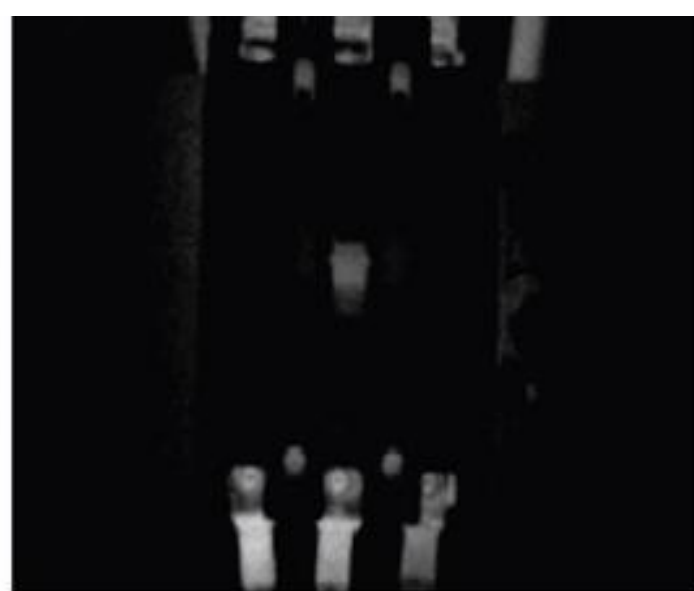

b)

Figura 4.7 - a) Imagem térmica. b) Imagem térmica com a intensidade corrigida. Fonte: (JADIN, 2012)

Com a imagem térmica gerada pelo procedimento de calibração descrito na seção 4.3, e considerando o método de Jadin para ajuste da intensidade na imagem, conseguimos obter pelo método de Otsu uma imagem com regiões quentes segmentadas que possui uma correlação aproximada com o mapa de profundidade. Desta forma, o módulo de detecção que utiliza imagens térmicas já pode ser fundido com os outros módulos descritos nas seções anteriores. Na seção 5.5 serão apresentados exemplos de segmentação das imagens térmicas utilizando o método de Otsu.

\subsection{Fusão de Dados dos Sensores}

O módulo de fusão de dados tem por responsabilidade correlacionar cada pixel das imagens resultantes dos três módulos de detecção de obstáculos de modo que ao final do processo seja criada uma nuvem de pontos onde cada célula possua uma probabilidade de haver um obstáculo. A nuvem gerada representará o ambiente onde o veículo será inserido e será através dela e das probabilidades relacionadas a cada célula que o veículo utilizará como um auxílio para se movimentar de forma autônoma e segura pelo ambiente.

Um exemplo de navegação baseada em células que indicam a probabilidade de ocupação foi implementado por (KLASER, 2014), usando Octomaps para representar a ocupação espacial gerada a partir de uma nuvem de pontos obtida unicamente a partir dos dados de uma câmera estereo. Neste trabalho aqui proposto, é realizada a fusão de múltiplas imagens, onde o resultado final pode ser aplicado diretamente no sistema de controle e navegação implementado em (KLASER, 2014), contribuindo para melhorar a percepção e detecção dos obstáculos presentes no ambiente. 
Cada pixel das três imagens capturadas e processadas pelos módulos de detecção de obstáculos será classificado em navegável ou não navegável, esta classificação não leva em conta o mapa de profundidade gerado pela câmera estéreo, apenas o resultado dos módulos de detecção descritos nas seções anteriores. Feitas as classificações, estas são finalmente fundidas ao mapa de profundidade que indicará além da probabilidade de presença de obstáculos no ambiente, sua distância em relação ao veículo/câmeras.

A fusão das imagens classificadas será realizada utilizando a Teoria de Dempster-Shafer. Cada pixel de uma imagem será uma evidência que ao ser somado aos outros pixels correlacionados a este, permite obter um grau de crença, ou seja, se o pixel é navegável e o veículo pode avançar, ou, se o pixel não é navegável por conter um obstáculo. O obstáculo será detectado na cena apenas se o grau de crença proporcionado pela soma das evidências das grades das três imagens for aceitável para a hipótese.

Na Figura 4.8 pode ser visto um exemplo de como os pixels das três imagens vindas de cada um dos sensores (monocular, estéreo e térmica) seriam classificados, onde está destacado em vermelho os possíveis obstáculos detectados por cada método (Histograma de Cor, Stixel e Método de Otsu). A grade resultante da fusão utilizando o método de Dempster-Shafer como proposto e descrito acima, indica a presença de obstáculos com diferentes graus de confiança, células com maiores probabilidades estão coloridas em vermelho e células com menor probabilidade em amarelo. 


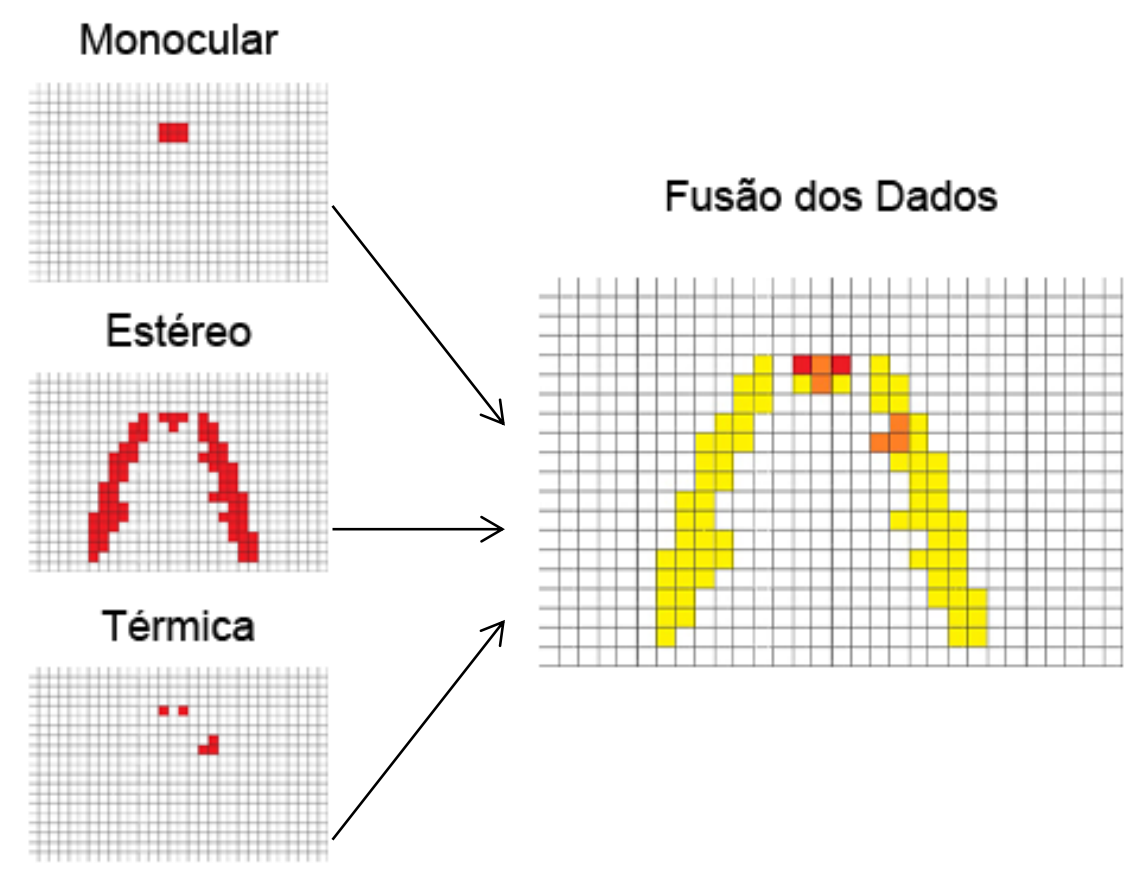

Figura 4.8 - Resultado da fusão em $2 D$ das informações dos módulos de deteç̧ão de obstáculos. As cores mais fortes representam uma probabilidade maior em existir um obstáculo.

Vale ressaltar que o resultado da fusão pode variar dependendo da importância dada a cada módulo de detecção de obstáculos. Na Figura 4.8 foram dadas importâncias iguais entre os módulos, mas é possível atribuir uma importância maior a um determinado módulo que seja mais confiável ao ambiente ou situação a que o veículo será exposto, desta forma, um possível obstáculo detectado por certo módulo poderá ser mais relevante em relação aos demais, e o resultado da fusão será diferente do mostrado na figura. Neste trabalho a importância de cada módulo pode ser alterada manualmente, pois não foram desenvolvidas técnicas que façam essa calibragem automaticamente considerando a qualidade da deteç̧ão ou eficiência do sensor no ambiente em que o veículo foi inserido.

Por exemplo, em um cenário noturno, a detecção pelo sensor de calor pode ser mais relevante que a detecção por cor (prejudicada pela falta de iluminação), e vice-versa, pois se os elementos do ambiente estiverem em uma temperatura próxima a do corpo humano, isto poderá dificultar a detecção de pessoas, reduzindo a importância do sensor térmico.

O passo seguinte a fusão 2D das imagens processadas pelos módulos, é a fusão com o mapa de profundidade gerado pela câmera estéreo. Ao final deste procedimento obtemos uma nuvem de pontos com informações da probabilidade da existência de obstáculos e sua distância do veículo. 


\subsection{Considerações}

Neste capítulo foi apresentada a metodologia a ser adotada para o desenvolvimento do sistema proposto através da apresentação dos módulos e procedimentos envolvidos e da relação entre eles. Buscou-se adotar técnicas de detecção de obstáculos que se completassem, isto é, cada uma das três câmeras destaca uma informação diferente e que podem se complementar para uma melhor precisão na detecção dos obstáculos e navegação do veículo autônomo.

Além disso, foi proposto um procedimento de calibração necessário para que possam ser correlacionados os pixels das duas câmeras e foi proposta a adoção de uma técnica de fusão dos sensores que permite aumentar ou diminuir a confiança de um determinado sensor dependendo das condições que o meio oferece. No capítulo 5 serão apresentados os resultados obtidos neste projeto de mestrado com as técnicas descritas neste capítulo. 


(5)

\section{Experimentos e Resultados}

Para avaliar e validar a metodologia proposta para este projeto de mestrado, diversas implementações foram realizados usando dados reais capturados com as câmeras em ambientes externos (outdoor). Foram registrados arquivos de log (os bags usados junto a plataforma ROS), de situações "controladas", e estes foram processados off-line. Porém, é importante destacar que foi levada em consideração a possibilidade de execução desta aplicação em tempo real (soft real-time constraints).

Este capítulo se divide em 6 seções apresentadas em ordem cronológica de desenvolvimento. A seção 5.1 descreve a configuração dos sensores utilizados e as condições de captura das imagens para os experimentos. Em seguida, a seção 5.2 apresenta o primeiro experimento de detecção de obstáculos, este utilizando a câmera monocular em ambiente outdoor. Na seção 5.3 é descrito outro experimento outdoor de detecção de obstáculos, mas desta vez utilizando a câmera estéreo. $\mathrm{Na}$ seção 5.4 é apresentado o experimento de calibração das câmeras térmica e monocular. Na seção 5.5 é descrito o experimento de deteç̧ão de obstáculos que utiliza a câmera térmica. Por fim, na seção 5.7 é discutido o experimento que realiza a fusão das detecções obtidas e apresentadas nas seções 5.2, 5.3 e 5.5 .

\subsection{Configuração dos Experimentos Realizados}

Nesta seção serão apresentados os detalhes das configurações dos experimentos realizados durante e ao final deste projeto de mestrado. Para auxiliar 
no desenvolvimento e teste dos módulos foram utilizados dois grupos de logs, um contendo aproximadamente 5 minutos (8814 quadros) e o outro contendo aproximadamente 2 minutos (3880 quadros). Chamaremos no decorrer dos experimentos o primeiro grupo de logs de $\log 1$ e o segundo grupo de logs de log 2. O log 1 contém apenas dados capturados pela câmera estéreo, este foi utilizado durante o desenvolvimento e é composto por registros capturados em uma plantação de laranja com o auxilio de membros da empresa Máquinas Agrícolas Jacto e integrantes do LRM-ICMC/USP. O log 2 contém dados capturados pelas câmeras estéreo e térmica, foram utilizados ao final do processo de desenvolvimento e início dos experimentos e validação do sistema.

A correta fixação das câmeras no veículo é muito importante para que, após o processo de calibração das câmeras, estas não percam a calibragem durante a movimentação do veículo por vias irregulares. Através da Figura 5.1 podemos ver a fixação das câmeras no veículo através de um suporte de metal e a fixação entre as câmeras feitas com presilhas que não permitem movimentação e transformam as duas câmeras em uma única peça. A disposição das câmeras com a câmera térmica mais próxima e acima da câmera monocular esquerda foi escolhida por maximizar a intersecção das áreas capturadas pelas duas câmeras.

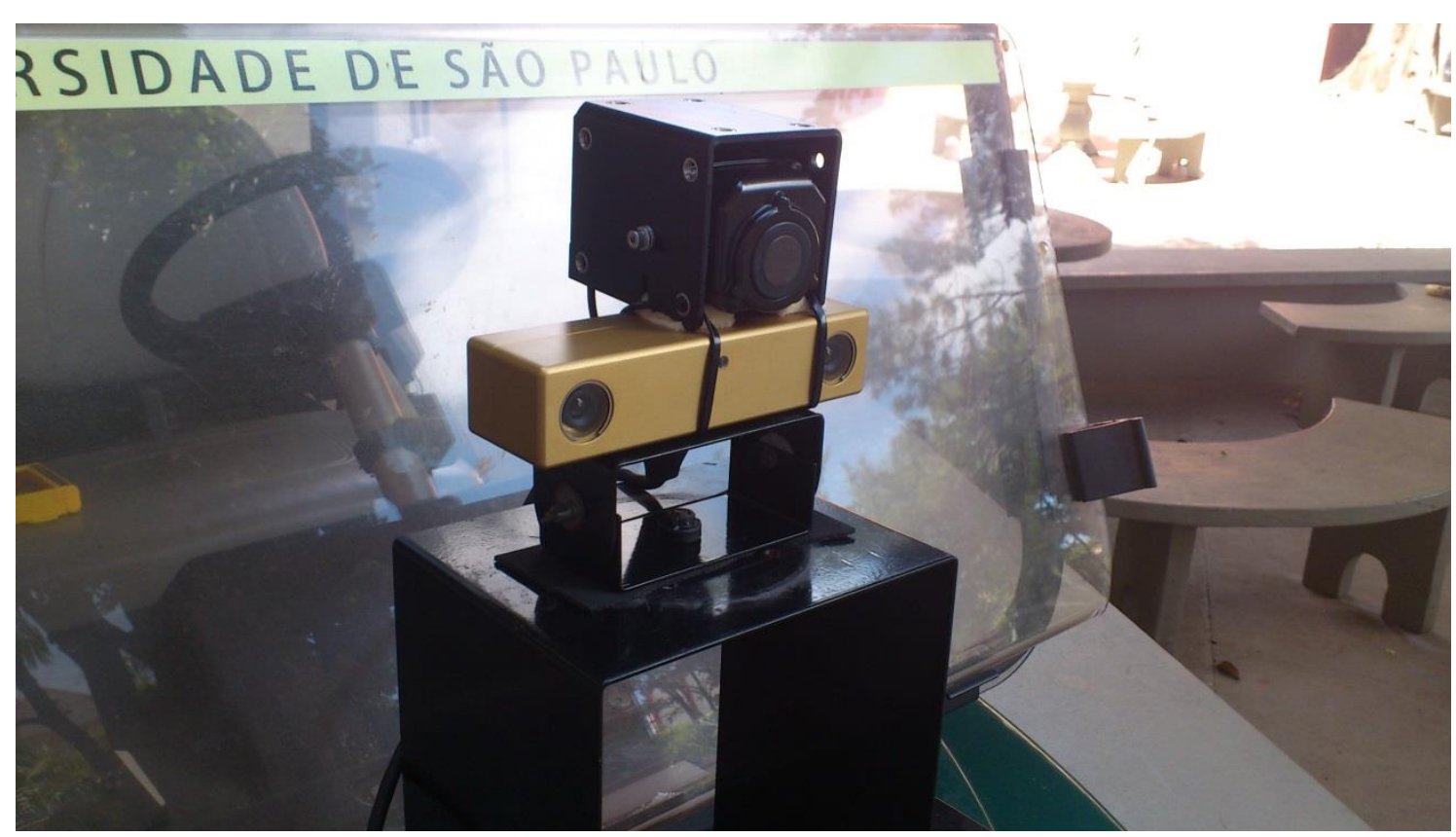

Figura 5.1 - Fixação e disposição das câmeras estéreo e térmica durante os experimentos.

Os logs utilizados contém capturas de imagens com a resolução de $320 \times 240$ pixels gerados pela câmera estéreo BumbleBee2 e pela câmera térmica FLIR PathFindIR a uma frequência de 30fps e 10fps respectivamente. Os logs foram registrados através das funcionalidades que o ROS fornece (como discutido na seção 2.9.2). Foi utilizado um módulo já desenvolvido no trabalho (MENDES, 2012) que 
calcula e disponibiliza o mapa de profundidade e sua nuvem de pontos gerada a partir do conjunto de imagens capturadas pela câmera estéreo.

A plataforma utilizada para os experimentos varia de acordo com o conjunto de logs. No primeiro grupo de logs feitos na plantação de laranja foi utilizado um trator que circulou pelas ruas da plantação em uma velocidade de $7 \mathrm{~km} / \mathrm{h}$. Já no segundo grupo de logs foi utilizado os veículos CaRINA I e CaRINA II, estes circularam em áreas do Campus I da USP que pudessem simular um ambiente rural. A velocidade máxima dos veículos durante a captura foi de $5 \mathrm{~km} / \mathrm{h}$ a $7 \mathrm{~km} / \mathrm{h}$.

Para avaliar os resultados obtidos para cada experimento, foi desenvolvido um software simples que permite, para cada quadro dos logs, definir diretamente sobre as imagens as áreas que contém obstáculos. É importante salientar que esta marcação permite avaliar apenas a detecção ou não de um obstáculo, porém sem uma maior precisão em relação a sua distância relativa ao veículo. Desta forma, é possível identificar a quantidade de detecções corretas e erradas (falso positivo e falso negativo) realizada pelos módulos de detecção ao executar os logs. Pela Figura 5.2 é possível ver o software criado com a demarcação manual dos obstáculos.

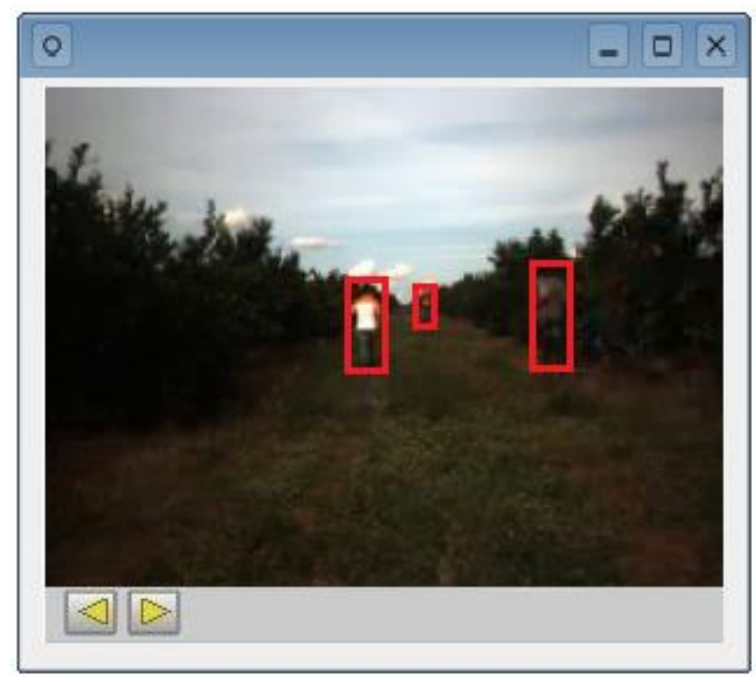

Figura 5.2 - Software de marcação manual de obstáculos.

Os casos de falso positivo são detectados quando uma detecção ocorre fora dos obstáculos demarcados (retângulo vermelho), já os casos de falso negativo ocorrem quando um obstáculo não possui nenhuma detecção. A imagem é considerada com detecção correta quando todos os obstáculos são detectados e nenhuma detecção ocorre fora dos obstáculos pré-definidos.

Todo o trabalho foi desenvolvido e implementado no sistema operacional Linux Ubuntu 11.04 utilizando a plataforma ROS Fuerte juntamente com a biblioteca de processamento de imagens OpenCV na linguagem de programação $\mathrm{C} / \mathrm{C}++$. 


\subsection{Módulo de Detecção de Obstáculos Utilizando Câmera Monocular}

Como já discutido na seção 4.1, este módulo de detecção de obstáculos tem por finalidade identificar o aparecimento de novidades no ambiente onde o veículo autônomo está se movendo. Para tanto, foi utilizada a imagem RGB esquerda capturada pela câmera estéreo Bumblebee2, onde as novidades buscadas são cores e texturas que podem evidenciar a presença de um obstáculo, visto que um ambiente agrícola não apresenta grande diversidade de cores entre a plantação.

O módulo desenvolvido pode ser dividido em três importantes etapas, a primeira é a remoção de áreas não interessantes, isto é, áreas que podem ser removidas, de modo geral, por não possuírem obstáculos que possam expor o veículo a algum dano. Estas áreas foram definidas como sendo o céu. Buscamos através disto diminuir a área que deverá ser processada na busca de identificar o aparecimento de novidades na imagem.

No processo de remoção do céu é utilizado o método de Otsu (OTSU, 1979) que busca na imagem um limiar ótimo que divida os pixels da imagem em dois grupos, os pertencentes e não pertencentes ao fundo da imagem (céu). Diferentemente do convencional, que é sua aplicação na imagem em tons de cinza, o método de Otsu foi aplicado na componente azul do espaço de cor RGB da imagem, pois desta forma é possível a remoção do céu independente de sua tonalidade (branco, azul e vermelho).

A técnica apresentada possui o inconveniente de que partes claras da imagem (por exemplo, roupas brancas) são removidas, perdendo assim informações importantes sobre obstáculos (ver Figura 5.3, em branco, áreas da imagem removidas pelo método de Otsu). Para recuperar essa informação perdida, partimos da suposição que o céu é a área removida de maior tamanho, desta forma, todas as áreas menores são reintegradas na imagem, removendo assim apenas o céu. $\mathrm{Em}$ preto está o resultado do processo descrito e que pode ser visto pela Figura 5.4. 

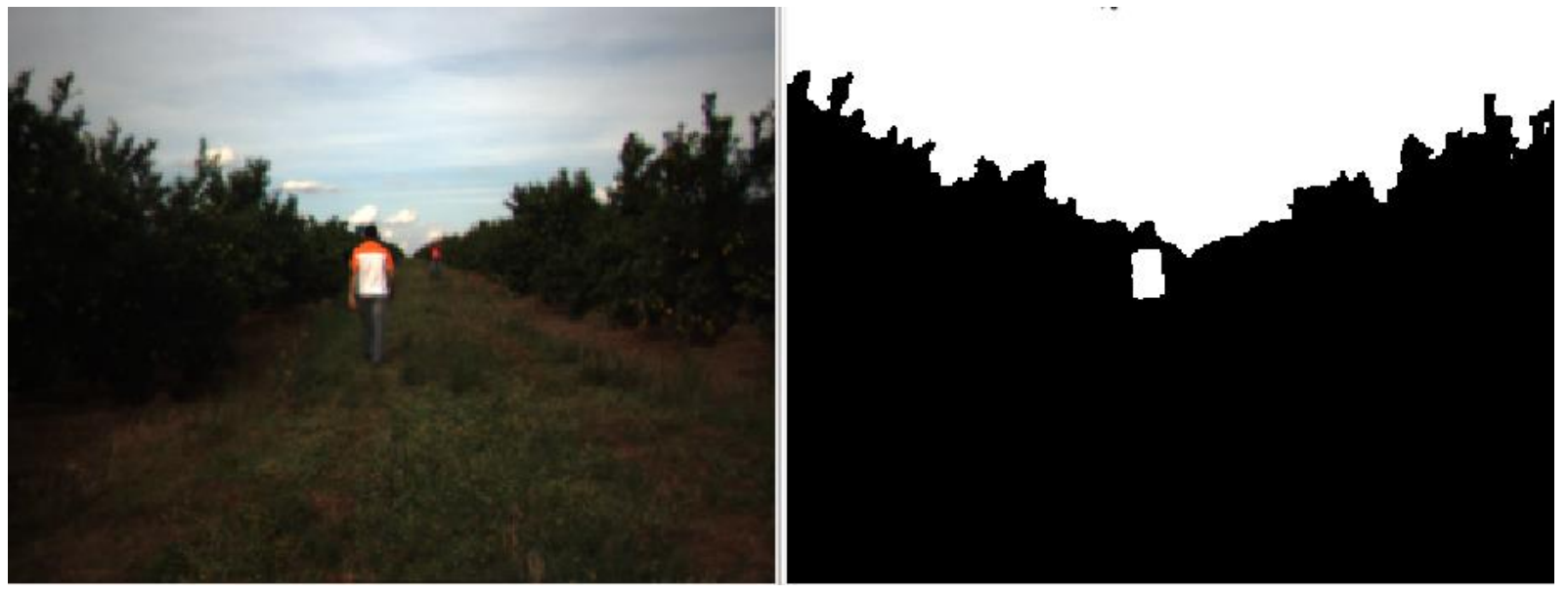

Figura 5.3 - Remoção do céu da imagem com perda de informação de obstáculo.
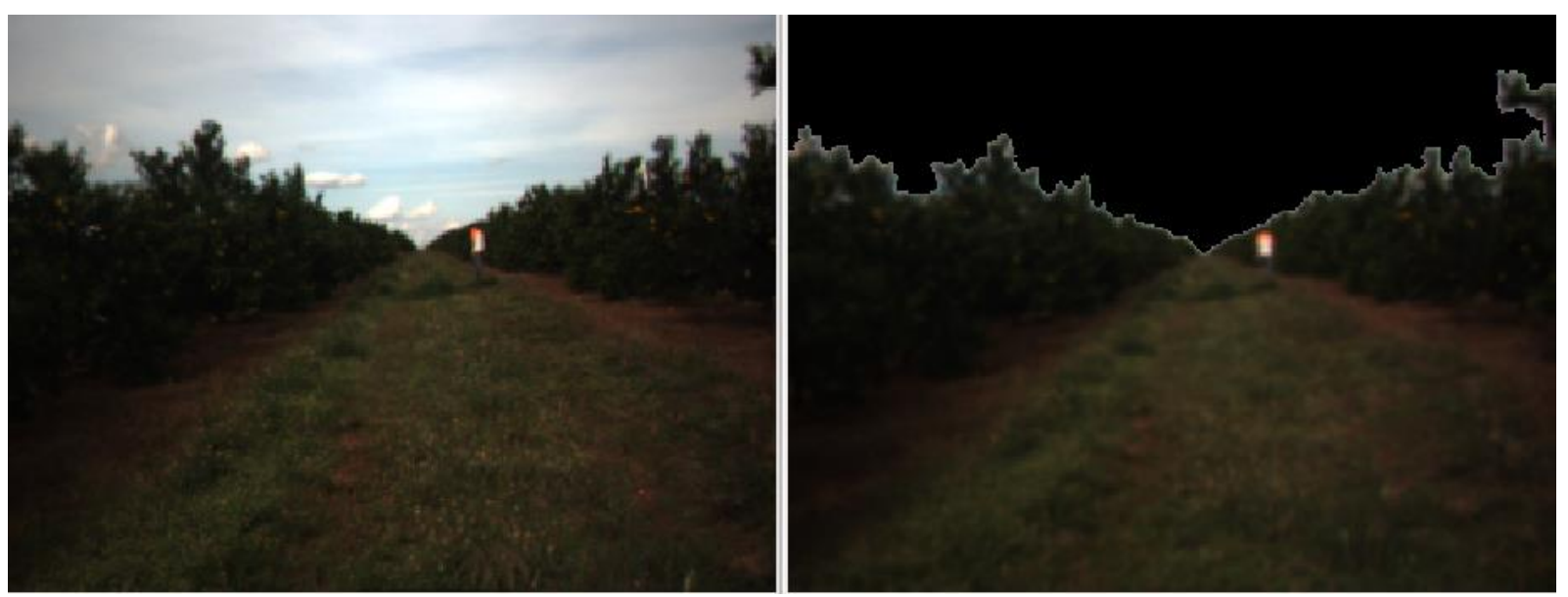

Figura 5.4 - Remoção do céu da imagem sem perda de informações adicionais.

A segunda etapa do módulo é a diminuição da quantidade de cores da imagem. Cores que forneçam pouca informação como: cinza e preto são desconsideradas e tons que se assemelham são aproximados para uma única cor, desta forma podemos identificar com maior precisão o aparecimento de novas cores na imagem.

Primeiramente é definida a quantidade máxima de cores que será permitida na imagem, quanto maior a quantidade melhor a qualidade da detecção dos objetos, porém é necessário um maior gasto computacional. No módulo desenvolvido foram utilizadas 93 diferentes cores, sendo três delas tons da cor branca. A imagem é então convertida para o espaço de cor HSV, este passo foi adotado para facilitar na definição e aproximação das cores. Utilizando limiares dependentes da quantidade de cores, este definido inicialmente, é feita a aproximação das cores da imagem. Através da Figura 5.5 podemos ver o resultado da aproximação das cores, é importante lembrar que tons de preto e cinza foram desconsiderados buscando eficiência no método. 

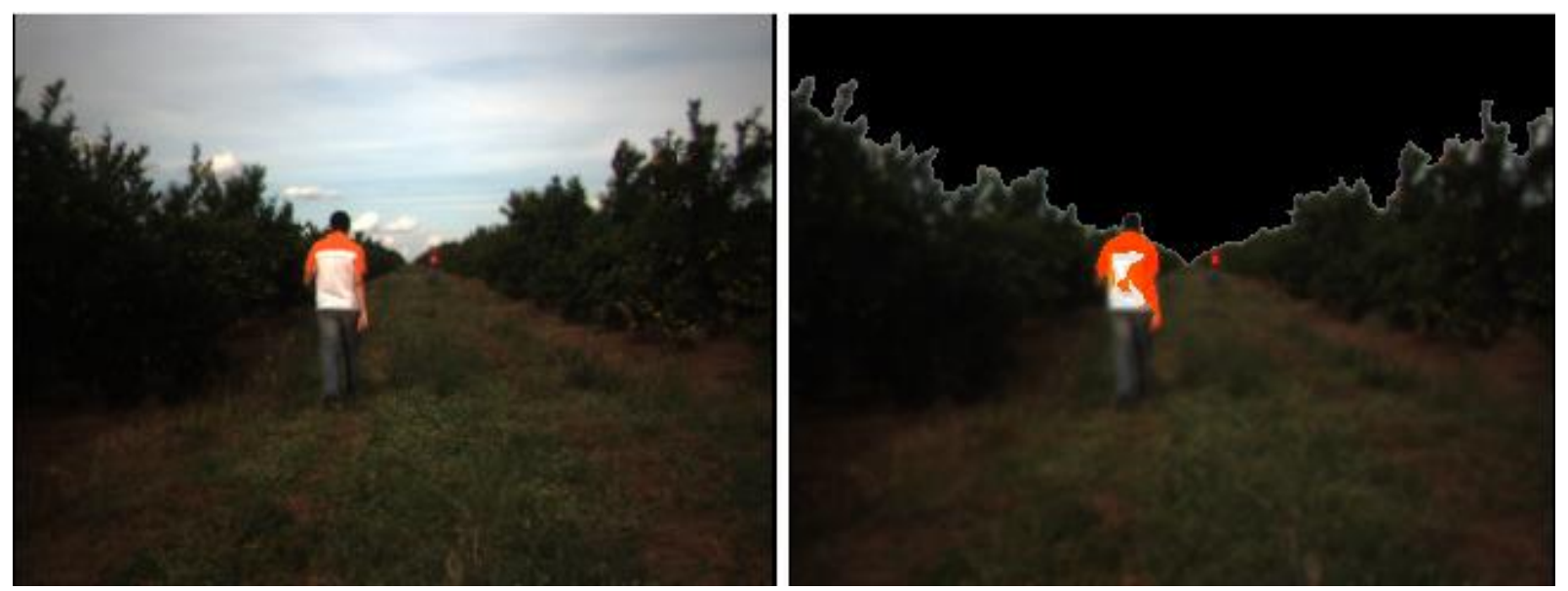

Figura 5.5 - Resultado da redução da quantidade de cores da imagem.

A última etapa realizada pelo módulo é a geração do histograma da imagem atual e sua comparação com o histograma gerado na iteração anterior. O resultado da comparação quantifica as cores definidas, permitindo que sejam identificadas novas cores que não estavam presentes na iteração anterior. Caso uma nova cor apareça, esta é classificada como obstáculo e só deixa de ser classificada desta forma após não ser mais encontrada na cena (por exemplo, obstáculo é removido) ou após um aumento exagerado de sua quantidade, sugerindo uma troca de ambiente (por exemplo, o veículo passa de um ambiente com grama para um ambiente com terra). Pela Figura 5.6 pode ser visto em preto o resultado da identificação dos obstáculos no ambiente.

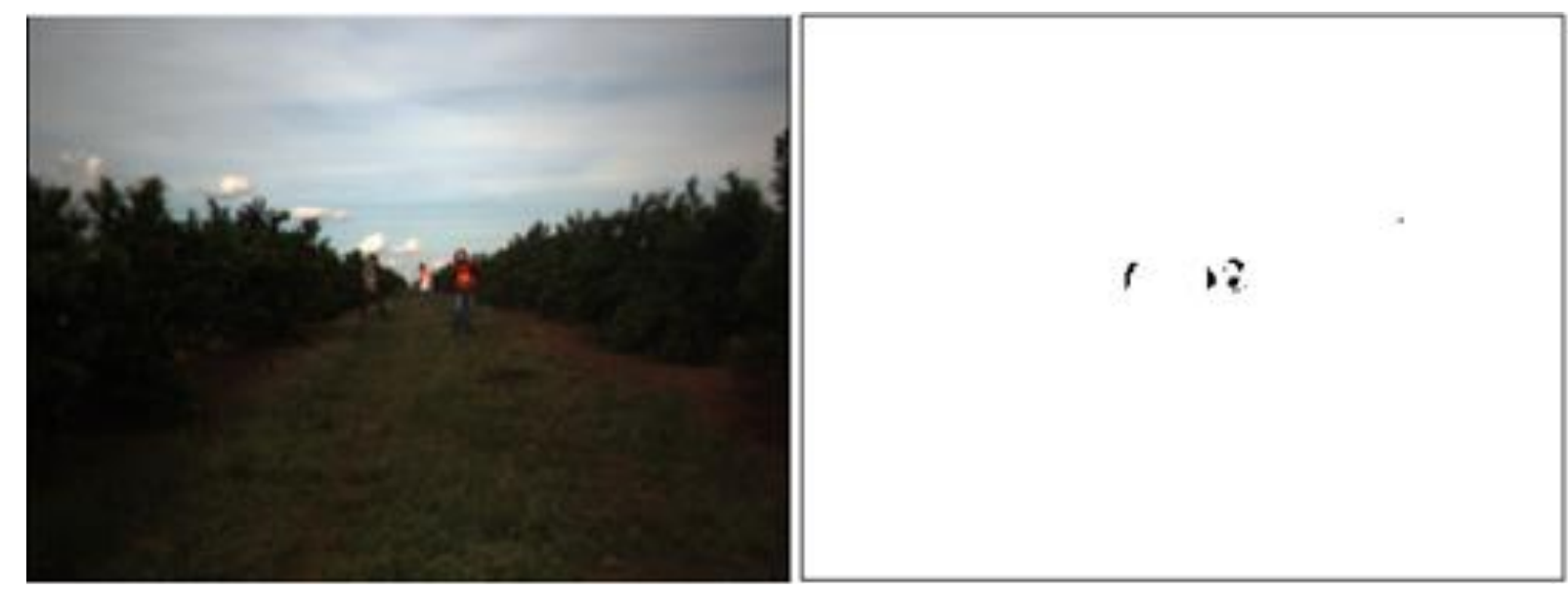

Figura 5.6 - Resultado da detecção de obstáculos utilizando câmera monocular.

Os resultados obtidos ao executar o módulo de detecção de obstáculos que utiliza a câmera monocular nos dois grupos de logs obtiveram um bom desempenho, identificando como esperado totalmente ou parcialmente os obstáculos. Devido à abordagem adotada, obstáculos que se camuflem no ambiente não foram identificados corretamente, porem espera-se que através da fusão de todos os módulos nenhum obstáculo que ameace a segurança do veículo autônomo deixe de 
ser detectado. Podemos ver através da Tabela 5.1 os resultados do módulo de detecção de obstáculos ao final dos dois experimentos.

Tabela 5.1 - Resultados da detecção de obstáculos utilizando a câmera monocular.

\begin{tabular}{|c|c|c|c|c|}
\hline \multirow{2}{*}{ Detecção } & \multicolumn{2}{|c|}{ Número de Quadros } & \multicolumn{2}{c|}{ Porcentagem Total } \\
\cline { 2 - 5 } & Log 1 & Log 2 & Log 1 & Log 2 \\
\hline Falso Positivo & 990 & 1015 & $11,3 \%$ & $26,1 \%$ \\
\hline Falso Negativo & 1386 & 100 & $15,7 \%$ & $2,6 \%$ \\
\hline Acertos & 6588 & 2865 & $74,7 \%$ & $73,8 \%$ \\
\hline
\end{tabular}

\subsection{Módulo de Detecção de Obstáculos Utilizando Câmera Estéreo}

O desenvolvimento deste módulo, como discutido na seção 4.2, utilizou a câmera estéreo Bumblebee2 para capturar as imagens do ambiente. O módulo foi inspirado no trabalho de Badino (BADINO, 2009) e baseado no trabalho de Rodrigo Benenson (BENENSON, 2012). O trabalho completo desenvolvido por Benenson realiza a detecção de pedestres utilizando a técnica Stixel desenvolvida por Badino, porém, para este módulo será necessário apenas a delimitação da área de interesse pela técnica Stixel.

A implementação deste módulo exigiu três importantes etapas, a primeira delas foi a obtenção dos parâmetros intrínsecos e extrínsecos da câmera estéreo. Sua importância deve-se ao fato de que através destes parâmetros de calibração embutidos no hardware da câmera é possível realizar o cálculo da disparidade entre as imagens e a determinação do plano do chão. Para sua obtenção foi necessário desenvolver uma pequena aplicação que através de funções contidas na biblioteca Triclops SDK (TRICLOPS, 2014), desenvolvida pela fabricante da câmera estéreo, fosse possível obter da câmera os parâmetros necessários para a técnica funcionar corretamente. Os parâmetros das câmeras esquerda e direita podem ser vistos abaixo:

- Câmera esquerda.

$$
\begin{gathered}
\text { Parâmetros Internos }=\left[\begin{array}{cccc}
412,312439652 & 0,0 & 160,0 \\
0,0 & 411,768076093 & 120,0 \\
& 0,0 & 0,0 & 1,0
\end{array}\right] \\
\text { Rotação }=\left[\begin{array}{ccc}
0,9999895020 & -0,0032427085 & -0,0032373937 \\
0,0032434896 & 0,9999947120 & 0,0002360459 \\
0,0032366111 & -0,0002465439 & 0,9999947317
\end{array}\right]
\end{gathered}
$$


Translação $=\left[\begin{array}{l}0,0 \\ 0,0 \\ 0,0\end{array}\right]$

Distorção Radial $=\left[\begin{array}{c}-0,447691524095981 \\ 0,255046440083257 \\ 0,00106243885765522\end{array}\right]$

- Câmera direita.

$$
\begin{aligned}
& \text { Parâmetros Internos }=\left[\begin{array}{ccc}
417,712845359 & 0,0 & 160,0 \\
0,0 & 417,113451923 & 120,0 \\
0,0 & 0,0 & 1,0
\end{array}\right] \\
& \text { Rotação }=\left[\begin{array}{ccc}
0,9999720703 & 0,0071262536 & 0,0022528005 \\
-0,0071257098 & 0,9999745807 & -0,00024932389 \\
-0,0022545200 & 0,0002332640 & 0,9999974313
\end{array}\right] \\
& \text { Translação }=\left[\begin{array}{c}
0,119988 \\
0,0 \\
0,0
\end{array}\right] \\
& \text { Distorção Radial }=\left[\begin{array}{c}
-0,452669644267157 \\
0,286808493717294 \\
0,00155237764677938
\end{array}\right]
\end{aligned}
$$

Tendo os parâmetros da câmera definidos corretamente, a segunda etapa do desenvolvimento do módulo foi a mudança de arquitetura do trabalho de Benenson para a plataforma ROS. Esta etapa foi necessária, pois toda a comunicação entre os processos e módulos e obtenção das imagens pela câmera é feita através do ROS. As mudanças feitas foram:

- As imagens passaram a ser capturadas e publicadas pelo módulo da câmera estéreo e o módulo de detecção assina estas publicações e as converte para a estrutura de dados padrão do OpenCV, estas imagens são então disponibilizadas dentro do módulo para qualquer método que as necessite.

- A imagem de saída (resultado do processamento) não é mais apresentada na tela através de uma janela, agora esta imagem é publicada, ficando disponível para quaisquer outros módulos.

- Desenvolvimento de classes genéricas de configuração dos parâmetros de calibração da câmera, facilitando assim a troca da câmera caso seja necessário. 
- Mensagens de informação, aviso, erro e exceção foram convertidas para o padrão ROS.

- Ciclo principal de execução da aplicação foi modificado para o padrão ROS.

- Desenvolvimento da troca de mensagens entre as classes utilizando o padrão ROS.

- Troca da biblioteca de manipulação de imagens pela biblioteca OpenCV. Assim, foi possível uma padronização entre os tipos de imagens utilizados neste projeto de mestrado.

Através deste grande número de mudanças foi possível conhecer mais detalhadamente o trabalho de Benenson, podendo assim, adequá-lo ao trabalho aqui proposto. Com o método já funcionando na plataforma ROS foi possível realizar diversos testes preliminares de desempenho e confiabilidade da técnica utilizando os logs gravados durante um trabalho de campo em uma plantação de laranja. Através da Figura 5.7 pode ser vista a técnica sendo executada na aplicação rviz, visualizador pertencente ao ROS.

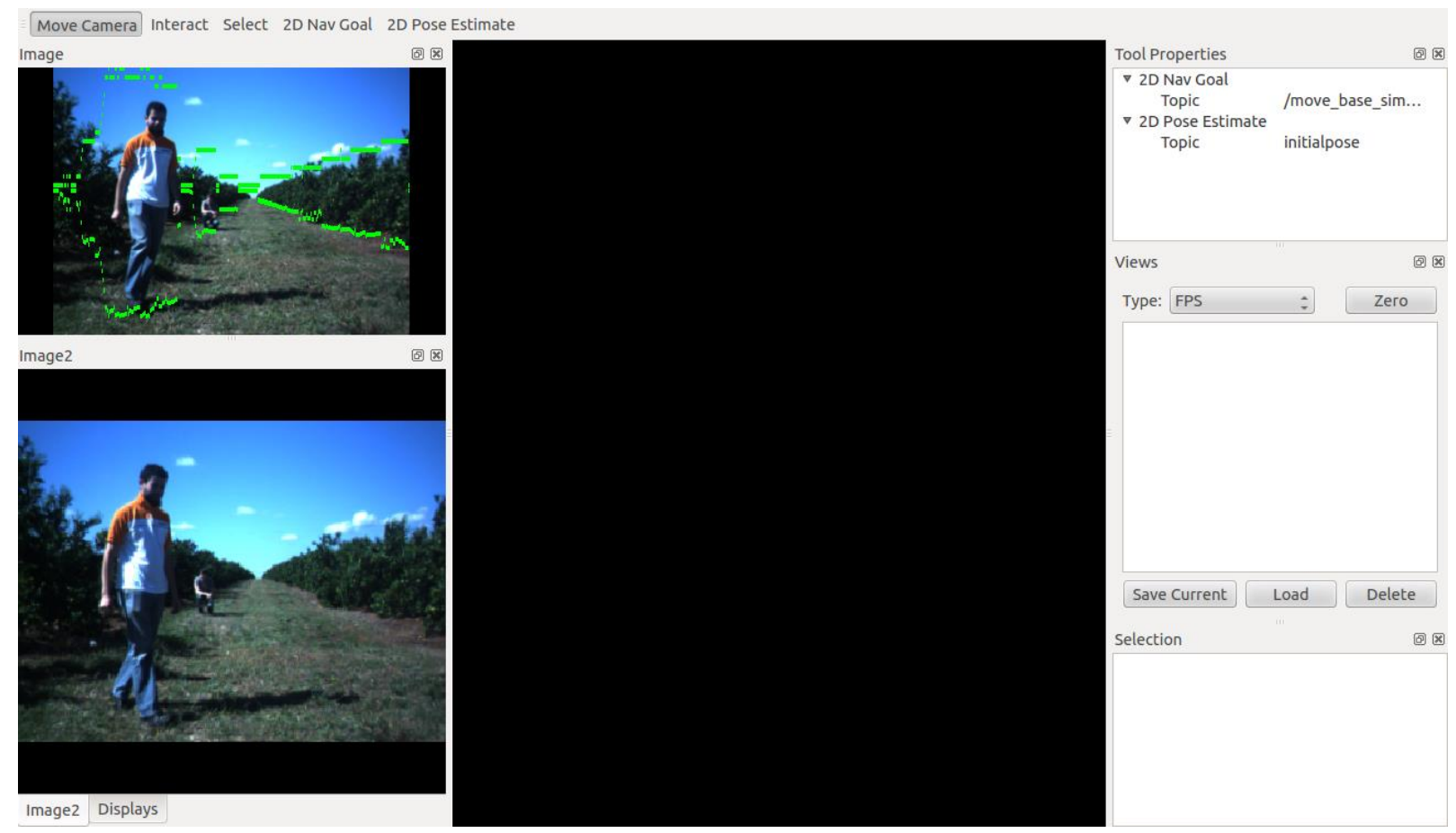

Figura 5.7 - Interface da aplicação rviz executando a técnica Stixel.

A terceira e última etapa realizada para o desenvolvimento deste módulo foi a simplificação do código. Diversas funcionalidades como filtros, métodos de aquisição de imagens, diferentes meios de se calcular a disparidade entre as imagens e outros métodos foram removidos do código buscando diminuir sua complexidade e 
aumentar seu desempenho. Portanto, o código final desenvolvido é dedicado à técnica Stixel utilizando o método desenvolvido por Benenson que não usa o mapa de profundidade para estimar os stixels e sim uma altura dos obstáculos pré-definida, no caso dos testes aqui realizados, 2,5 metros.

Os resultados obtidos durante os testes foram, apesar de pouco estáveis ao localizar um obstáculo, muito bons e em tempo real. Apesar de sua instabilidade, o obstáculo é sempre detectado totalmente ou parcialmente e isto já basta para que uma determinada região seja classificada como contendo um obstáculo. Inicialmente os testes foram feitos em um ambiente agrícola, onde o resultado da detecção dos obstáculos pode ser visto na Figura 5.8 entre os retângulos verdes.
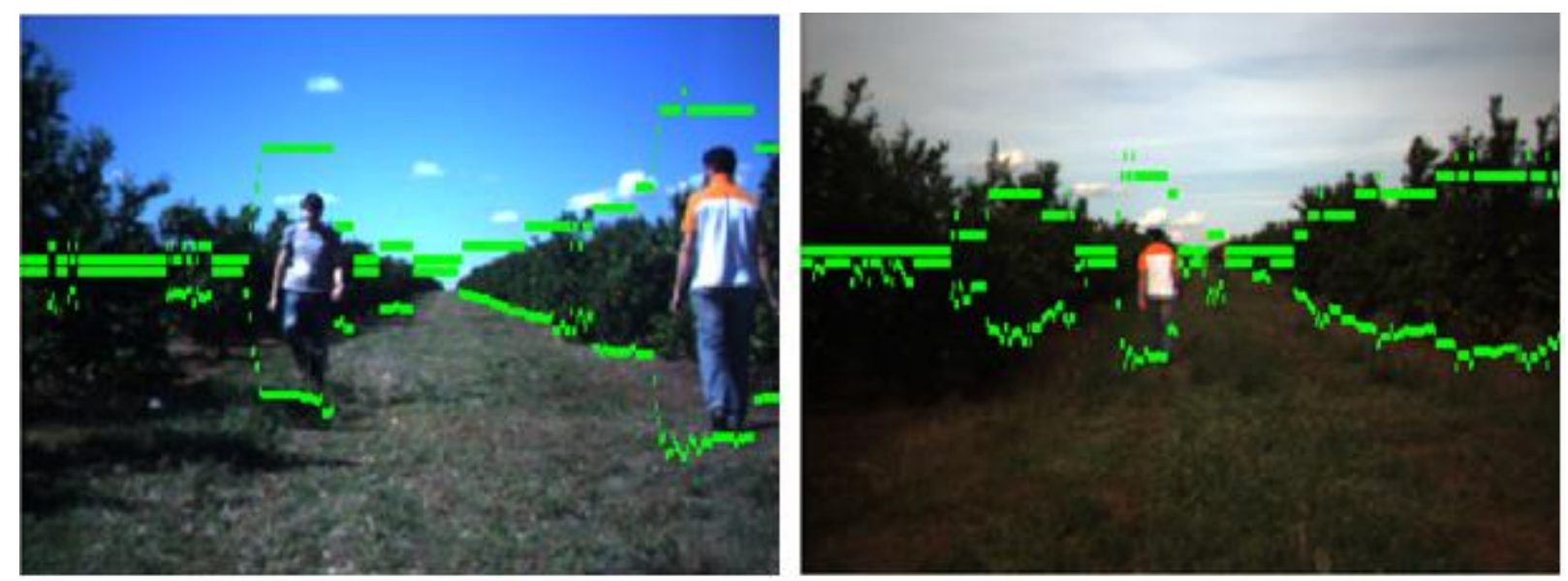

Figura 5.8 - Detecção de obstáculos em ambiente agrícola utilizando a técnica Stixel.

Apenas com o intuito de testar a versatilidade do método, foram realizados novos experimento, agora em um ambiente urbano com diferentes luminosidades. A técnica obteve novamente um bom resultado, detectando automóveis, guias, placas, muros, pessoas, etc. Através deste experimento, podemos estender seus resultados para um ambiente rural com baixa iluminação (operações noturnas), tendo como fonte de luz apenas a iluminação artificial gerada pelo veículo autônomo. O experimento foi realizado dentro e no entorno do Campus 1 da USP de São Carlos, o resultado pode ser visto através da Figura 5.9. 

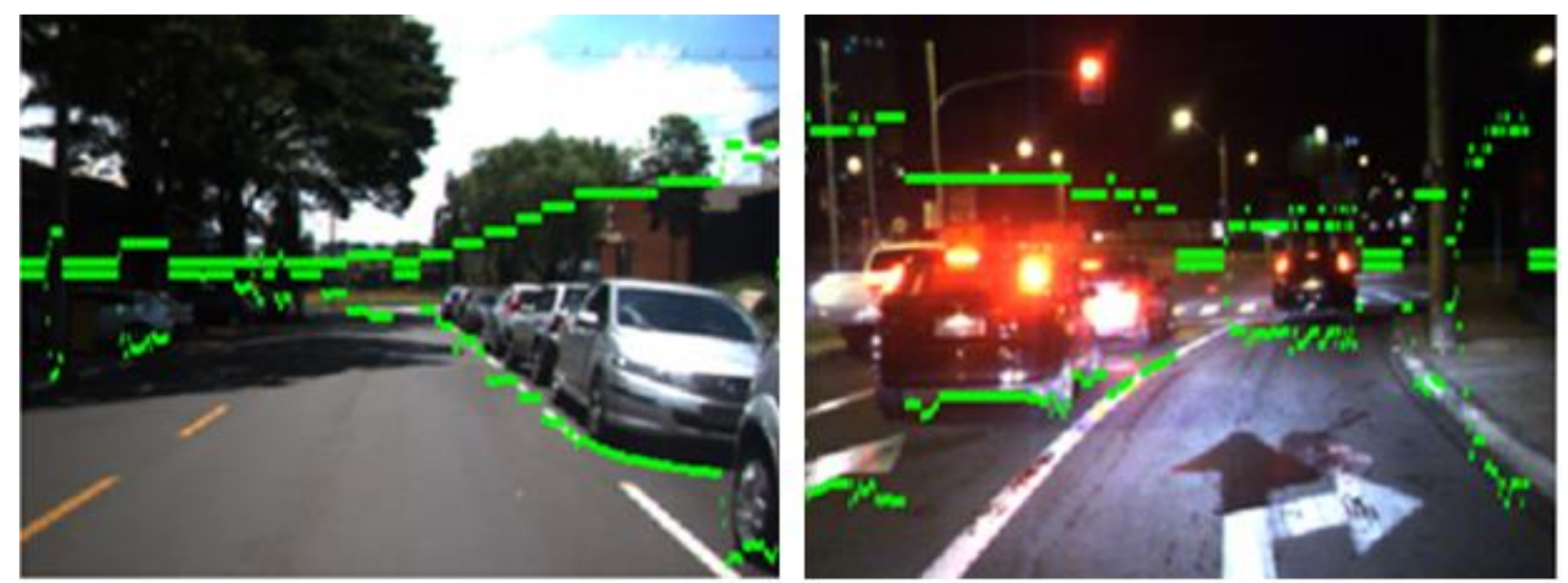

Figura 5.9 - Detecção de obstáculos em ambiente urbano com diferença de luminosidade utilizando a técnica Stixel.

O módulo de detecção de obstáculos desenvolvido mostrou-se muito robusto a mudanças de luminosidade e ambiente, detectando obstáculos tanto estáticos como dinâmicos. Além disso, pode ser executado em tempo real sem perda de quadros. A Tabela 5.2 mostra os resultados dos dois experimentos realizados utilizando os dois grupos de logs. Apesar de os resultados obtidos por este método serem encorajadores, é importante ressaltar que a detecção realizada por ele apenas demarca áreas que possam conter obstáculos, não localizando com precisão a posição do obstáculo na cena. Apenas a detecção de obstáculos que estão acima do solo não é suficiente para possibilitar manobras de evasão e garantir a segurança do veículo, pois isto requer a localização precisa do obstáculo.

Tabela 5.2 - Resultados da detecção de obstáculos utilizando a câmera estéreo.

\begin{tabular}{|c|c|c|c|c|}
\hline \multirow{2}{*}{ Detecção } & \multicolumn{2}{|c|}{ Número de Quadros } & \multicolumn{2}{c|}{ Porcentagem Total } \\
\cline { 2 - 5 } & Log 1 & Log 2 & Log 1 & Log 2 \\
\hline Falso Positivo & 330 & 388 & $3,8 \%$ & $10,0 \%$ \\
\hline Falso Negativo & 247 & 176 & $2,8 \%$ & $4,5 \%$ \\
\hline Acertos & 8277 & 3376 & $94,0 \%$ & $87,0 \%$ \\
\hline
\end{tabular}

\subsection{Calibração entre as Câmeras Térmica e Monocular}

O experimento de calibração entre as câmeras térmica e monocular descrito na seção 4.3 utilizou o segundo grupo de logs descrito na seção 5.1 deste capítulo. $O$ método de calibração foi escolhido devido a sua simplicidade e rapidez. Durante 0 experimento o padrão foi aquecido deixando-o ao Sol durante alguns segundos, ao ser apresentado já aquecido às câmeras foi possível fazer a calibração. 
A Figura 5.10 apresenta o resultado da detecção do padrão e a calibração realizados durante 0 experimento. Os itens a) e b) são imagens das câmeras monocular e térmica, respectivamente, com a detecção das 48 features que serão utilizadas para alterar a perspectiva da imagem térmica para a perspectiva da imagem monocular, assim, obtemos a imagem do item c) que é o resultado da calibração entre as duas câmeras.

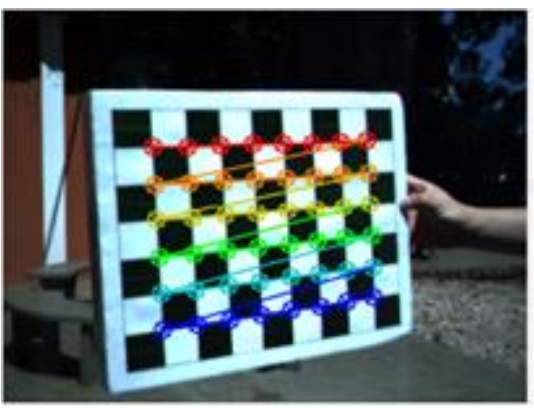

a)

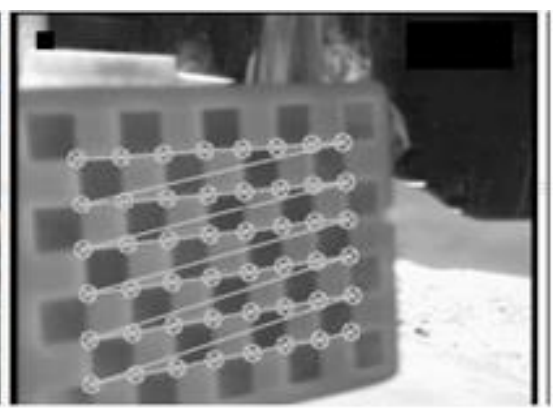

b)

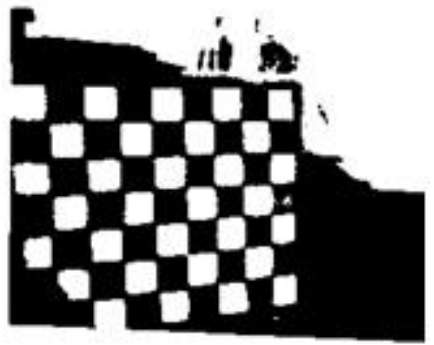

c)

Figura 5.10 - a) Padrão capturado pela câmera monocular. b) Padrão capturado pela câmera térmica. c) Imagem resultante da calibração.

Analisando o resultado da calibração durante toda a captura foi possível perceber que apesar do veículo passar por diversos terrenos irregulares, a correlação aproximada entre os pixels das duas imagens (térmica e monocular) se mantiveram durante todo o experimento. Também foi possível notar que devido ao método de calibração ser apenas uma mudança de perspectiva, o tamanho do pixel da imagem térmica comparado com o tamanho do pixel da imagem monocular é maior, desta forma, obstáculos a grandes distâncias possuem um pequeno deslocamento entre as imagens, ou seja, a correlação entre os pixels não se manteve muito precisa em todas as distâncias.

Buscando minimizar o resultado desta constatação, a calibração nos experimentos foi feita em uma distância média de 3 metros do conjunto de câmeras. Utilizando a distância acima citada, provocamos o mesmo deslocamento entre os objetos das imagens a curta distância, mas diminuímos seu deslocamento a grandes distâncias de uma forma que esta diferença apresentada entre as imagens possui baixa relevância no resultado final, visto que apenas uma correlação aproximada já é o bastante para o sucesso da fusão entre os módulos.

\subsection{Módulo de Detecção de Obstáculos Utilizando Câmera Térmica}

O experimento realizado para o teste do módulo de detecção de obstáculos utilizando a câmera térmica tem por finalidade identificar o aparecimento de assinaturas térmicas no ambiente agrícola onde o veículo autônomo estará se 
movendo. Para tanto, foi utilizada a imagem térmica capturada pela câmera FLIR PathFindIR resultante do processo de calibração descrito na seção 5.4 deste capítulo.

O módulo desenvolvido pode ser dividido em duas importantes etapas, a primeira é a intensificação das áreas quentes e frias da imagem. $O$ objetivo deste filtro é melhorar consideravelmente a distinção entre uma área mais clara (quente) de uma área mais escura (fria), com isso procuramos facilitar a segunda etapa que é a segmentação das áreas quentes que podem indicar a presença de pessoas, animais ou maquinários agrícolas. Na Figura 5.11 pode-se ver o resultado do método proposto por Jadin (JADIN, 2012) para ajustar a intensidade dos pixels da imagem térmica.

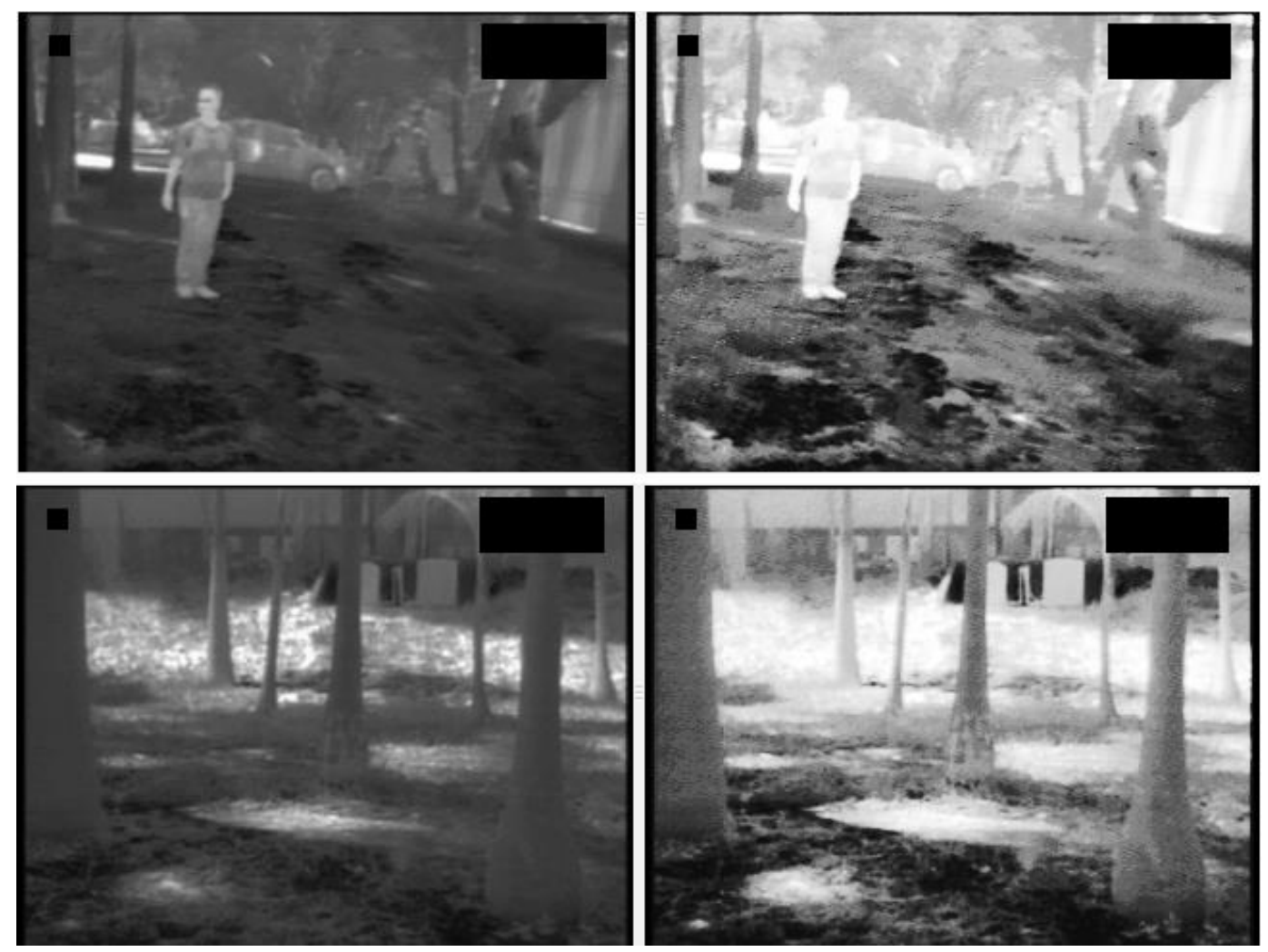

Figura 5.11 - Imagem térmica com ajuste de intensidade.

Em uma segunda etapa, é feita a segmentação das regiões da imagem com maior assinatura térmica. A segmentação da imagem é realizada utilizando o método de Otsu, que é uma técnica de threshold adaptativo. Ao final do processamento, o resultado obtido é uma imagem preto e branca na qual as regiões em preto são áreas quentes que podem evidenciar algum obstáculo. $O$ resultado do módulo de detecção de obstáculos utilizando uma câmera térmica pode ser visto pela Figura 5.12. 


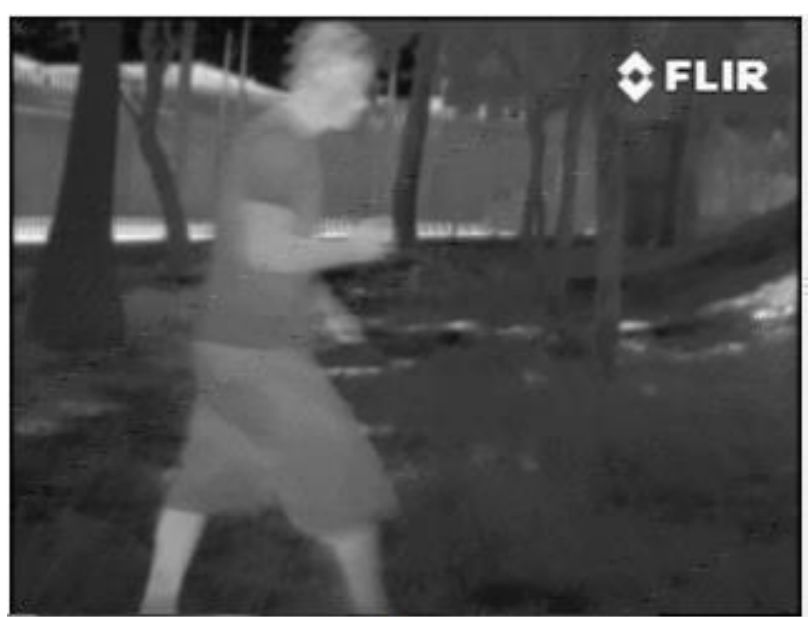

a)

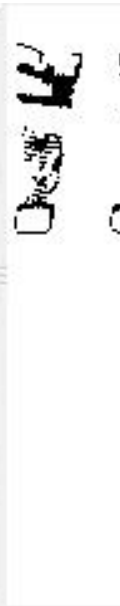

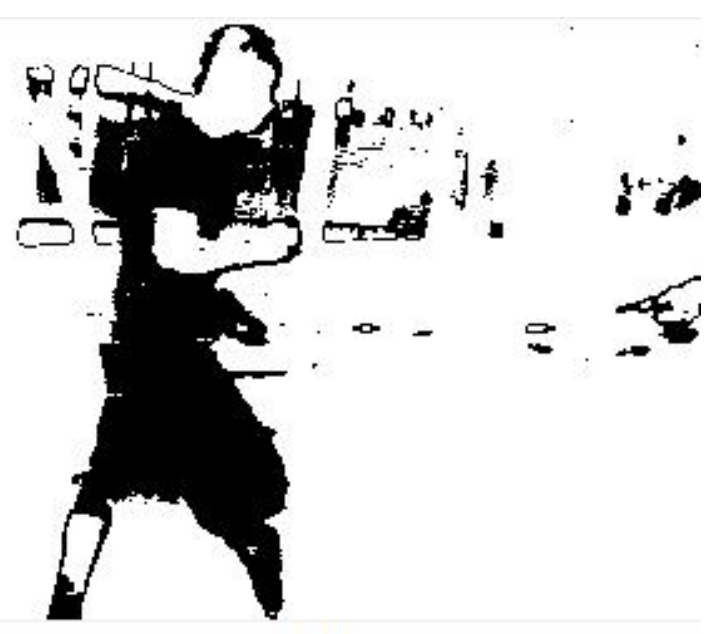

b)

Figura 5.12 - a) Imagem térmica. b) Imagem segmentada pelo método de Otsu.

A segmentação em ambientes fechados ou com pouca incidência de Sol apresentou um resultado muito bom, pois foi possível fazer a detecção de pessoas e carros que possuíam uma assinatura térmica mais elevada que os objetos do ambiente. Porém, em ambientes com muita incidência de Sol (ambiente agrícola), o método se mostrou problemático devido ao aquecimento que este provoca em árvores e no chão, superando ou se igualando a temperatura das pessoas e carros. Pela Figura 5.13 podemos ver o efeito da incidência do Sol na grama ao fundo da imagem.

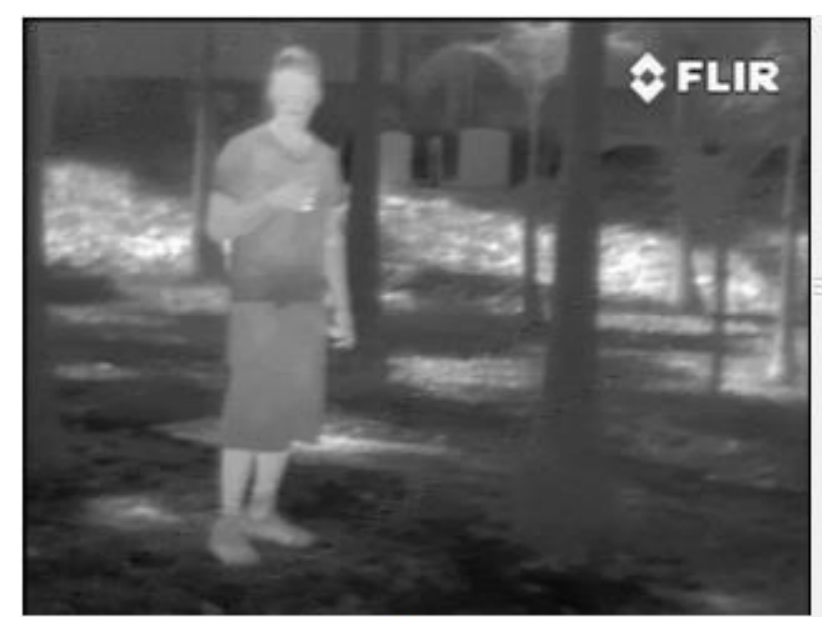

a)

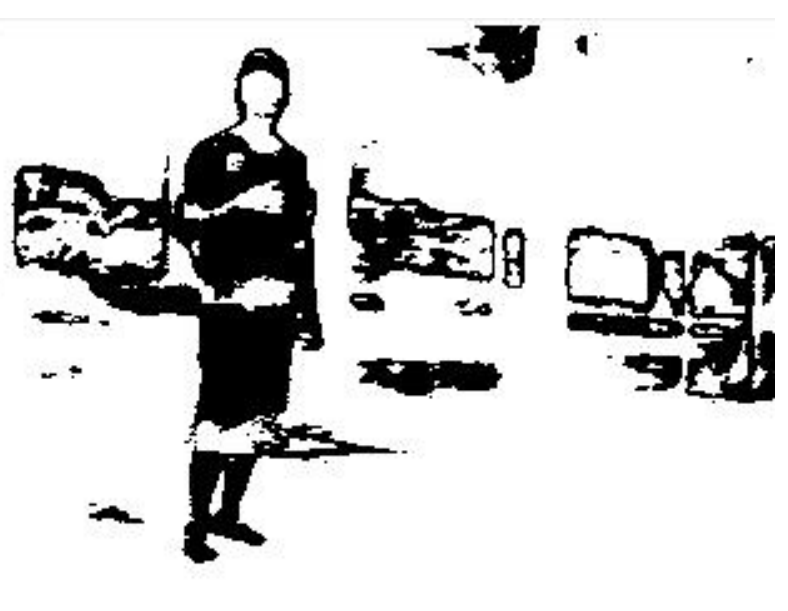

b)

Figura 5.13 - a) Imagem térmica com regiões expostas ao Sol. b) Imagem segmentada pelo método de Otsu.

A interferência do aquecimento do Sol em objetos que não oferecem risco ao veículo pode ser muito prejudicial no resultado final da fusão dos três módulos. $O$ problema torna-se de difícil resolução, pois a câmera térmica utilizada neste projeto fornece imagens com correção de intensidade (ajuste automático do contraste das 
imagens), ou seja, a mesma temperatura em duas imagens podem ter cores diferentes, assim, a segmentação de uma temperatura que possa evidenciar uma pessoa, por exemplo, torna-se difícil. A utilização de uma câmera térmica que forneça imagens com a temperatura absoluta dos objetos poderia melhorar os resultados obtidos neste experimento.

Apesar dos resultados ruins em ambientes com alta incidência de Sol, os resultados foram motivadores em ambientes noturnos ou sem a incidência de Sol, desta forma, o módulo pode ser utilizado nestas condições onde as câmeras monoculares e estéreos são pouco ou totalmente ineficientes.

Pela Tabela 5.3 pode ser visto o resultado do experimento feito apenas com o $\log 2$, este contendo imagens sincronizadas da câmera térmica com a câmera estéreo. A grande quantidade de falso positivo mostrada pela tabela deve-se a grande incidência do sol na grama presente no ambiente, fazendo com que a temperatura destas áreas fosse por vezes superior à temperatura das pessoas, gerando falsos negativos. O não acerto da detecção em nenhum quadro é devido aos falsos positivos, que pela regra adotada por este método de avaliação, um acerto é contabilizado apenas se o quadro não possui falsos positivos e nem falsos negativos.

Tabela 5.3 - Resultados da detecção de obstáculos utilizando a câmera térmica.

\begin{tabular}{|c|c|c|}
\hline Detecção & Número de Quadros & Porcentagem Total \\
\hline Falso Positivo & 3880 & $100,0 \%$ \\
\hline Falso Negativo & 474 & $12,2 \%$ \\
\hline Acertos & 0 & $0 \%$ \\
\hline
\end{tabular}

\subsection{Detecção de Obstáculos Utilizando Câmera Térmica Durante a Noite}

Buscando evidenciar a contribuição da câmera térmica em um módulo de detecção de obstáculos, um novo experimento realizado em condições mais adequadas ao sensor (à noite e com o ambiente em uma temperatura inferior a temperatura corporal humana) foi realizado. Neste experimento foi utilizada apenas a câmera térmica, pois devido à ausência de uma fonte luminosa o uso da câmera estéreo foi impossibilitado.

O experimento foi realizado durante a noite, com temperatura em cerca de $20^{\circ} \mathrm{C}$ dentro de uma área arborizada. As capturas utilizadas no experimento possuem aproximadamente 5 minutos de duração (8640 quadros). Este experimento tem por objetivo detectar obstáculos que possuem assinatura térmica alta (pessoas) a diferentes distâncias. As distâncias utilizadas entre a câmera e os obstáculos foram 
de 5, 20 e 30 metros. A Figura 5.14 mostra os diferentes cenários do ambiente onde o experimento foi realizado.

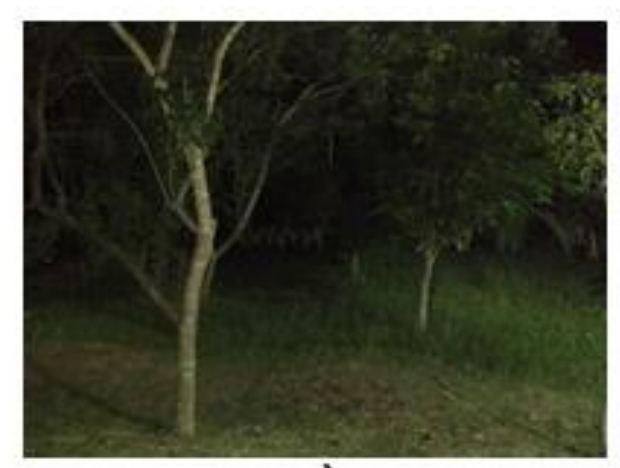

a)

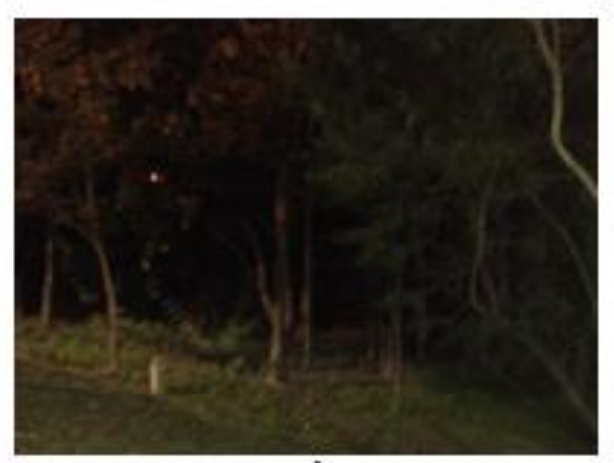

c)

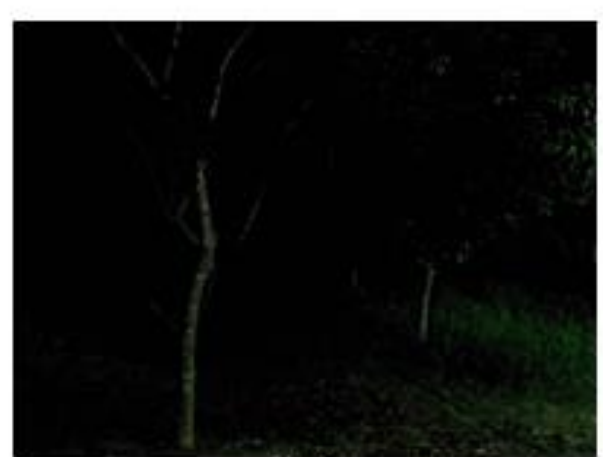

b)

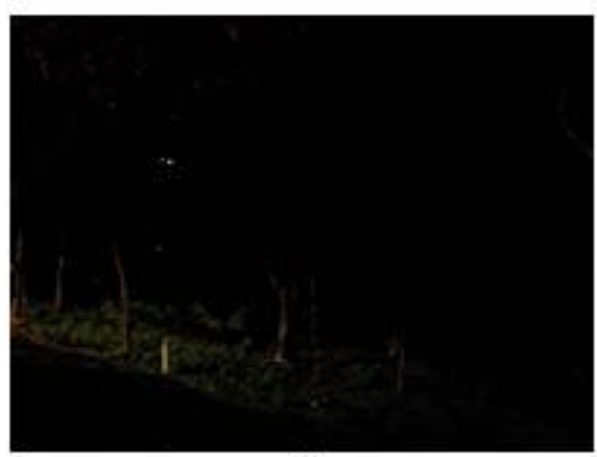

d)

Figura 5.14 - a) e c) Ambiente do experimento com iluminação artificial. b) e d) Ambiente do experimento sem iluminação artificial.

Aplicando os mesmos métodos utilizados no experimento da seção 5.5, obtivemos resultados completamente diferentes. Devido às distintas assinaturas térmicas do ambiente e das pessoas (consideradas obstáculos), foi possível realizar a perfeita segmentação e detecção de pessoas na cena. Com isso, foi possível mostrar que o ambiente tem grande influencia nos métodos de detecção de obstáculos que serão escolhidos para compor o sistema como um todo.

A Figura 5.15 mostra a imagem térmica capturada pela câmera e sua segmentação baseada na técnica apresentada na seção 4.4. As pessoas presentes na cena foram detectadas a diferentes distâncias e em situações em que elas estava parcialmente cobertas pela vegetação. 

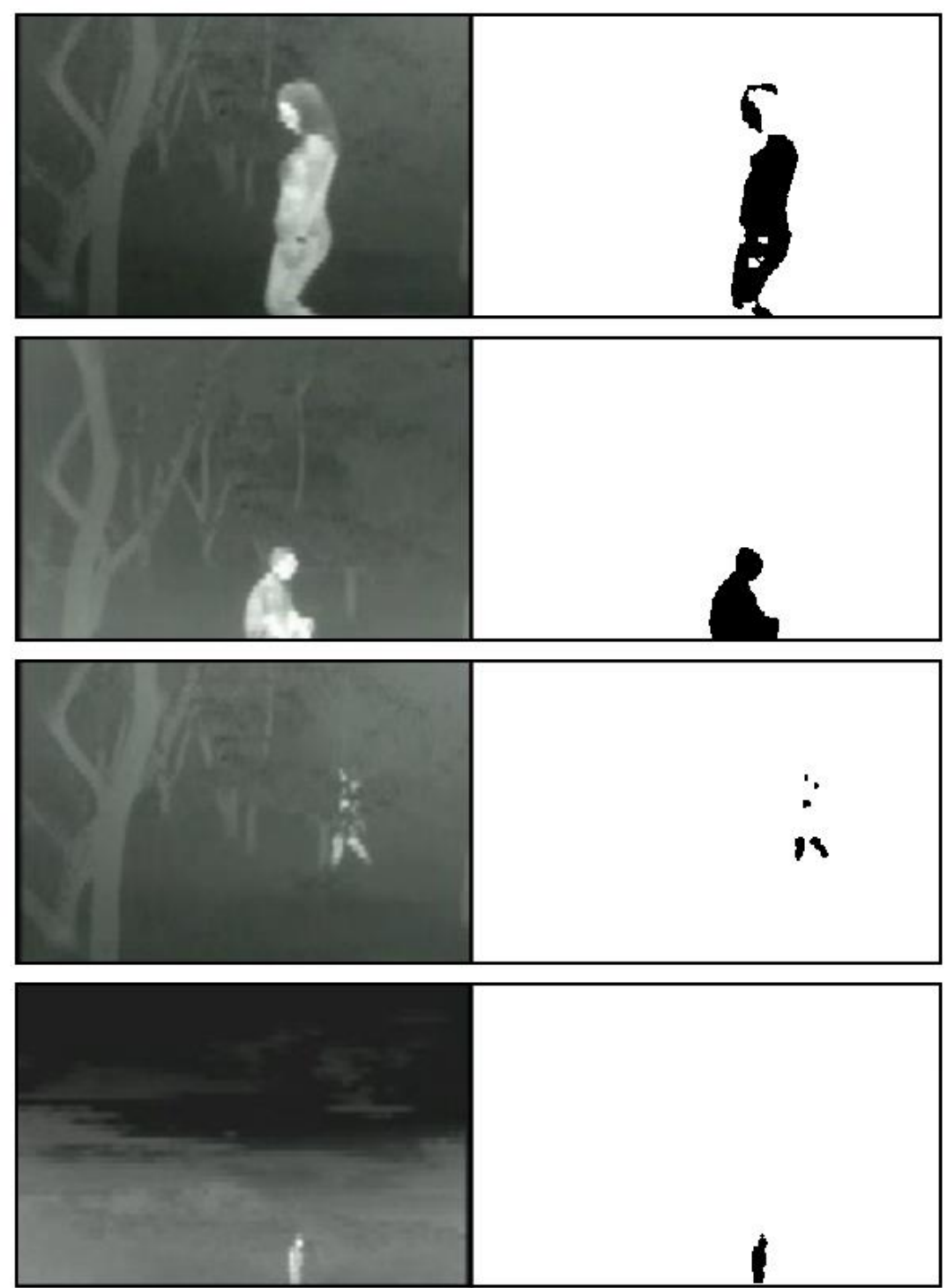

Figura 5.15 - Segmentação da imagem térmica em diferentes situações e distâncias.

Pela Tabela 5.4 pode ser visto o resultado da detecção de obstáculos (pessoas). Através destes resultados podemos concluir que o uso de câmera térmica em ambientes com baixa luminosidade e razoável diferença de temperatura entre o ambiente e seus obstáculos traz grande contribuição ao sistema de detecção de obstáculos.

Tabela 5.4 - Resultados da detecção de obstáculos utilizando a câmera térmica durante a noite.

\begin{tabular}{|c|c|c|}
\hline Detecção & Número de Quadros & Porcentagem Total \\
\hline Falso Positivo & 345 & $4,0 \%$ \\
\hline Falso Negativo & 0 & $0,0 \%$ \\
\hline Acertos & 8295 & $96,0 \%$ \\
\hline
\end{tabular}




\subsection{Fusão dos Módulos de Detecção de Obstáculos}

Foram realizados dois experimentos para analisar o resultado do módulo de fusão de sensores descrito na seção 4.5. O primeiro experimento utiliza as imagens do segundo grupo de logs. Neste experimento será avaliado como o mau resultado do módulo que utiliza a câmera térmica influencia no resultado da fusão com os outros dois detectores (monocular e estéreo). Já no segundo experimento, também será utilizado o segundo grupo de log, porém sem o módulo que utiliza a câmera térmica. Ao final os resultados serão comparados e analisados.

Nos experimento foram utilizados pesos iguais para cada imagem, ou seja, todos os módulos de deteç̧ão terão a mesma contribuição no resultado final. Além disso, as diferentes probabilidades de existência de obstáculos foram destacadas na nuvem de pontos de forma que, quanto mais escuro (preto) maior a probabilidade e quanto mais claro (branco) menor a probabilidade.

A Figura 5.16 mostra em preto (alta probabilidade) circundado em vermelho a detecção de uma pessoa em um ambiente rural simulado. Temos também na figura as imagens resultantes do processamento feito pelos módulos de detecção das câmeras estéreo, térmica e monocular, respectivamente.

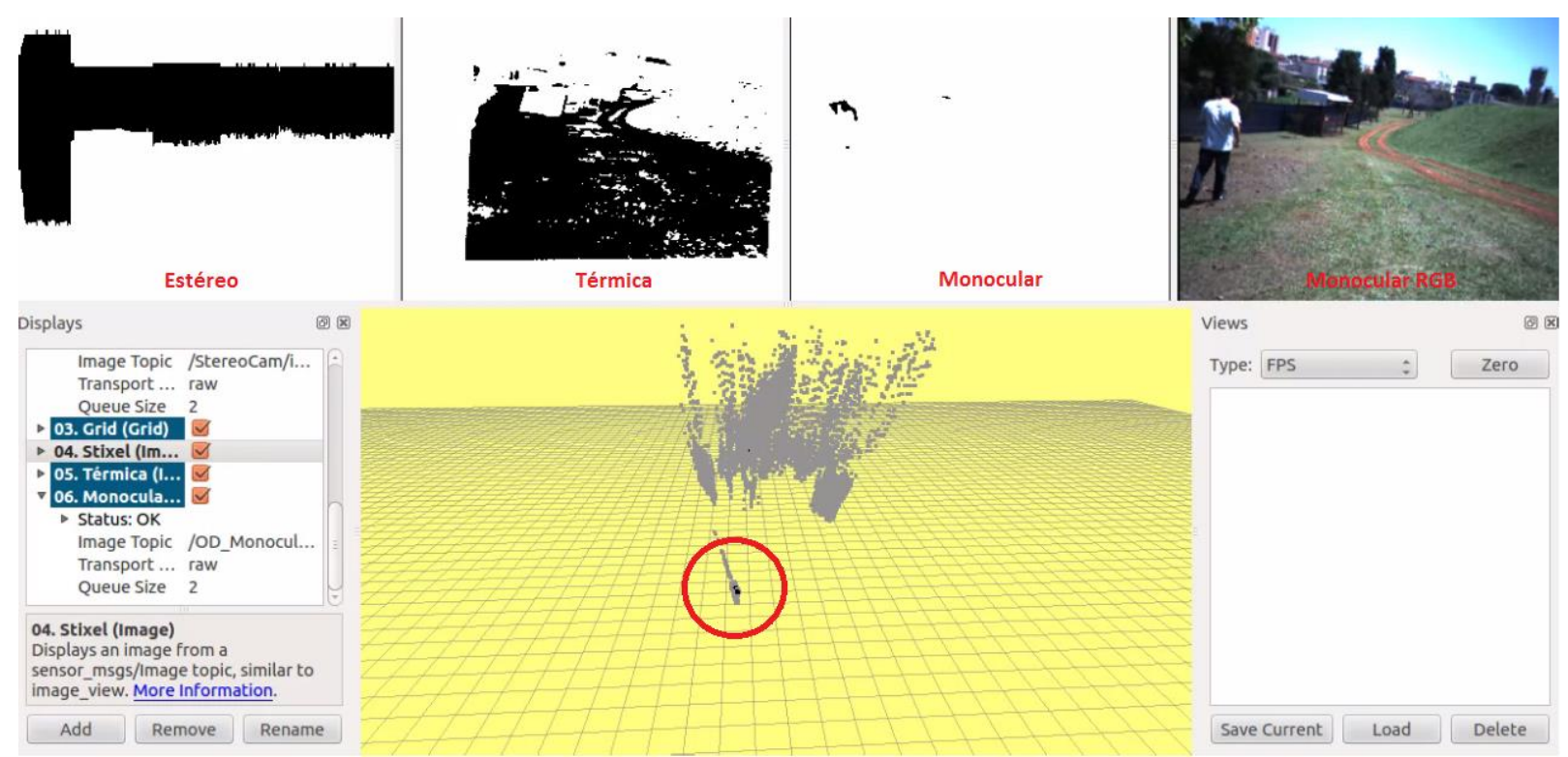

Figura 5.16 - Fusão dos módulos de detecção.

O ambiente utilizado para o experimento foi escolhido baseado em sua semelhança com o ambiente rural para o qual este projeto foi desenvolvido. As imagens foram capturadas durante um dia com muita incidência de Sol e em um local onde o chão possuísse irregularidades, terra e grama. Analisando os resultados é possível observar que o módulo que utiliza a câmera térmica não obteve um bom resultado devido à elevada temperatura que grande parte do chão apresentou devido 
à sua longa exposição ao Sol. Mesmo com o mau resultado de um dos módulos de detecção, o experimento mostrou que a técnica de fusão de sensores utilizada é robusta o bastante para compensar este mau resultado com os bons resultados dos outros dois módulos de detecção, fazendo assim, a detecção da pessoa em cena.

Sabendo a priori do mau desempenho do módulo de deteç̧ão que utiliza a câmera térmica, o segundo experimento foi feito utilizando as mesmas imagens capturadas do ambiente "rural" sob as mesmas circunstâncias (incidência de Sol, terreno irregular composto por terra e grama), porém, atribuindo a este módulo que apresentou um mau resultado um peso que anulasse sua contribuição no resultado final da fusão. Assim, temos apenas dois módulos de deteç̧ão cada um com $50 \%$ de contribuição. Através da Figura 5.17 é possível ver o resultado obtido em um ambiente contendo uma pessoa como obstáculos e na Figura 5.18 um ambiente livre de obstáculos.

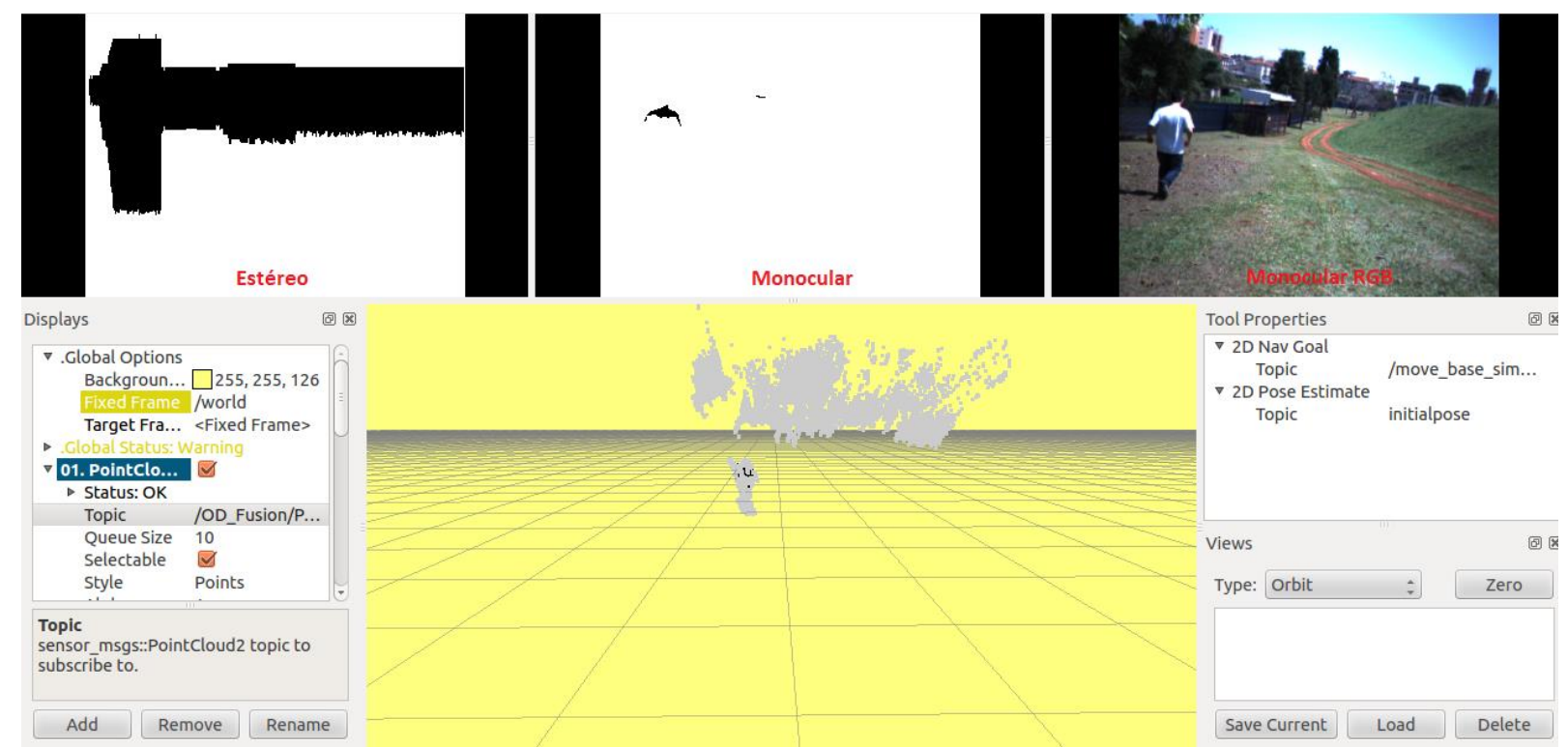

Figura 5.17 - Resultado da fusão dos sensores com a presença de obstáculo a frente do veículo. 


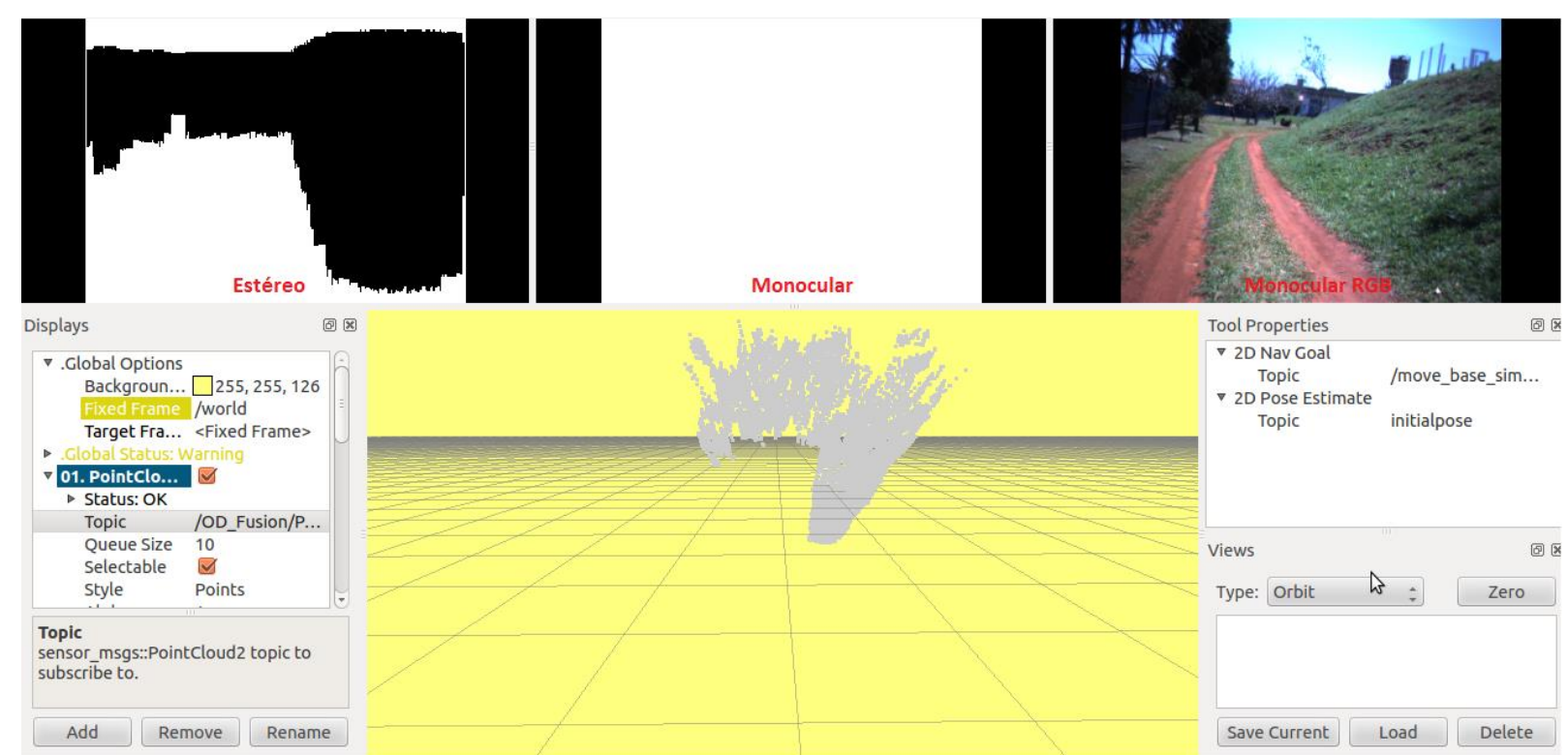

Figura 5.18 - Resultado da fusão de sensores sem a presença de obstáculos logo a frente do veículo.

Alterando os pesos dos módulos de detecção foi possível melhorar o resultado mantendo a detecção da pessoa com uma alta probabilidade de ser um obstáculo e diminuindo a probabilidade de existência de obstáculos em locais do ambiente que não são prejudiciais a segurança do veículo autônomo. Através da Tabela 5.5 é possível comparar os resultados dos dois experimentos do módulo de fusão. A contagem de falso positivo e acerto considerou apenas o resultado da fusão com probabilidade de $100 \%$. Já o falso negativo considerou qualquer probabilidade abaixo de $100 \%$.

Tabela 5.5 - Resultados da fusão dos módulos de detecção.

\begin{tabular}{|c|c|c|c|c|}
\hline \multirow{2}{*}{ Detecção } & \multicolumn{2}{|c|}{ Número de Quadros } & \multicolumn{2}{c|}{ Porcentagem Total } \\
\cline { 2 - 5 } & $\begin{array}{c}\text { Log 2 com } \\
\text { Térmica }\end{array}$ & $\begin{array}{c}\text { Log 2 sem } \\
\text { Térmica }\end{array}$ & $\begin{array}{c}\text { Log 2 com } \\
\text { Térmica }\end{array}$ & $\begin{array}{c}\text { Log 2 sem } \\
\text { Térmica }\end{array}$ \\
\hline Falso Positivo & 887 & 271 & $22,9 \%$ & $7,0 \%$ \\
\hline Falso Negativo & 266 & 266 & $6,9 \%$ & $6,9 \%$ \\
\hline Acertos & 2765 & 3383 & $71,3 \%$ & $87,2 \%$ \\
\hline
\end{tabular}

\subsection{Considerações}

Foram desenvolvidos diferentes métodos de detecção baseados em técnicas utilizadas para diferentes sensores do tipo câmera (monocular, estéreo e térmica). Devido às diferentes abordagens utilizadas para detectar obstáculos, a utilização de um método de fusão de dados permitiu que as características positivas de cada método pudessem ser adicionadas para maximizar a qualidade e fornecer uma 
detecção completa do ambiente, aumentando a segurança de navegação pelo veículo autónomo.

A execução dos experimentos descritos neste capítulo possibilitou a avaliação dos módulos de detecção e a implementação incremental de aprimoramentos no sistema proposto. Os resultados apresentados mostraram que os métodos de detecção de obstáculos propostos são adequados, mas devem ser cuidadosamente escolhidos levando em consideração algumas características do ambiente, como luminosidade, temperatura, etc.

O método de avaliação escolhido para quantificar os resultados obtidos pelos módulos de deteç̧ão de obstáculos mostrou-se razoavelmente efetivo, pois em sua avaliação considera apenas detecções em um único quadro e não em um conjunto de quadros. Um método de avaliação que levasse em consideração mais de um quadro apresentaria os resultados deste sistema de detecção com maior precisão, pois a avaliação de acerto ou erro em relação à existência de um obstáculo não deve ser pontual (quadro a quadro), mas sim global (sequência de quadros). 


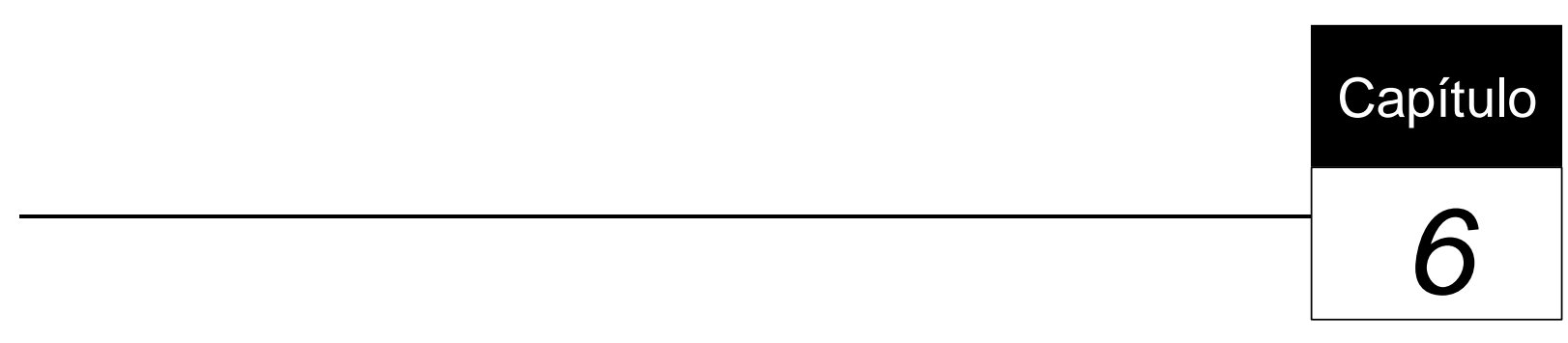

6. Conclusão

Esta dissertação apresentou uma análise de três métodos de detecção de obstáculos nos quais foram utilizados diferentes sensores do tipo câmera e apresentou um método de fusão de sensores que estima a probabilidade de existência de obstáculos. Para o desenvolvimento destes métodos, foi realizado um estudo sobre diferentes abordagens de processamento e diferentes características de imagens a fim de escolher uma forma de se processar uma sequência de imagens obtida por cada uma das câmeras utilizadas.

Os experimentos referentes aos métodos de detecção de obstáculos ilustraram as limitações de ambiente, luminosidade, custo computacional, desempenho, etc. que os sensores possuem. Os resultados obtidos com a câmera térmica mostraram que alguns tipos de sensores muito eficientes em um determinado ambiente podem se tornar muito ineficientes em outros. O experimento de fusão de sensores mostrou a vantagem de unir informações de deteç̧ão de obstáculos de diferentes fontes possibilitando a estimação da probabilidade de existência de obstáculo de forma mais segura.

Foi possível observar que combinar diferentes métodos, além de possibilitar uma maior precisão na localização de um obstáculo, eleva a capacidade de detecção em diferentes condições de iluminação e ambiente. Também foram determinados alguns parâmetros muito importantes que devem ser considerados ao escolher os 
métodos de detecção, como o horário (diurno ou noturno) e as condições climáticas (chuva, sol, etc...) onde o veículo estará atuando.

Por fim, este trabalho procurou maneiras inovadoras e relativamente baratas de realizar a deteç̧ão de obstáculos em ambiente rural utilizando sensores do tipo câmera, tendo como contribuição, o estudo e desenvolvimento de técnicas de segmentação e processamento de imagens e nuvens de pontos buscando a detecção de obstáculos em ambientes rurais em tempo real. Além disso, este trabalho contribuiu para o projeto do Laboratório de Robótica Móvel do ICMC-USP e o projeto JAV da empresa Máquinas Agrícolas Jacto S/A que tem como proposta o desenvolvimento de um sistema de auxílio à navegação de um veículo autônomo.

\subsection{Trabalhos Futuros}

Como trabalhos futuros, podem ser desenvolvidos e integrados a este sistema novos métodos de detecção de obstáculos que utilizem outros tipos de sensores, como por exemplo, laser, câmera trinocular, sonar etc. Esta integração permitirá ao sistema a capacidade de auxiliar a navegação do veículo com maior robustez. $\mathrm{Na}$ mesma linha de pesquisa em visão computacional, este sistema pode ser ampliado para operar em condições de baixa ou nenhuma luminosidade e chuva.

Buscando a diminuição de ruídos na fusão dos dados de detecção, pode ser implementado métodos que sejam capazes de detectar a má operação ou a baixa qualidade dos resultados de determinados métodos de detecção. Desta forma, o sistema poderá escolher entre desconsiderar por completo o resultado destas detecções ou atribuir um menor peso a seus resultados. Além disso, o sistema pode ser capaz de escolher os melhores métodos de detecção dependendo das características do ambiente ao qual o veículo estará inserido.

Como cada método de detecção de obstáculo processa porções de imagem de forma independente, é possível sua paralelização visando maior desempenho e menor tempo de resposta. Recomenda-se o uso de GPU ou a utilização de programação concorrente. Todas essas possibilidades de implementação tem como objetivo analisar e melhorar a velocidade de processamento do sistema, fornecendo ao veículo informações do ambiente em tempo real. 


\section{Referências Bibliográficas}

ALVES, E. G. (2007). Desenvolvimento de Algoritmos de Calibração de Câmeras para Aplicação em Robótica. Dissertação de Mestrado, UEL - Londrina. 2007.

AZEVEDO, E.; CONCl, A. (2003). Computação Gráfica - Teoria e Prática, Editora Campus, 2003.

BADINO, H.; FRNAKE, U.; PFEIFFER, D. (2009). The Stixel World - A Compact Medium Level Representation of the 3D-World. In DAGM, 2009.

BEKEY, G. A. (2005). Autonomous Robots: From Biological Inspiration to Implementation and Control. MIT Press.

BENENSON, R.; TIMOFTE, R.; GOOL, L. V. (2011). Stixels Estimation Without Depth Map Computation. Belgium. Katholieke Universiteit Leuven. 2011.

BENENSON, R.; MATHIAS, M.; TIMOFTE, R.; GOOL, L. V. (2012). Fast Stixel Computation for Fast Pedestrian Detection. Belgium. Katholieke Universiteit Leuven. 2012.

BLACKMORE, S.; GRIEPENTROG, H.W.; NIELSEN, H.; NØRREMARK, M.; RESTING-JEPPESEN, J. (2004). Development of a deterministic autonomous tractor. CIGR INTERNATIONAL CONFERENCE, 2004, Beijing: International Commission of Agricultural Engineering. 8 p.

BLACKMORE, S.; STOUT, B.; WANG, M.; RUNOV, B. (2005). Robotic agriculture the future of agricultural mechanisation. In: EUROPEAN CONFERENCE ON PRECISION AGRICULTURE, 8, 2005, Uppsala. Proceedings. Wageningen Academic Publishers, 2005. 621-628 p. 
BOVIK, A. C.; GIBSON, J. D.; BOVIK, A. (2000). (Ed.) Handbook of Image and Video Processing. Orlando, FL, USA: Academic Press, Inc. 2000.

BRADSKI, G.; KAEHLER, A. (2008). Learning opencv: Computer vision with the opencv library. Cambridge, MA, USA: O'Reilly, 2008.

BRÄUNL, T. (2008). Embedded Robotics: Mobile Robot Design and Application with Embedded Systems. Third Edition. Springer: Austrália. 2008.

BUMBLEBEE2 (2014). Bumblebee2 - $\quad$ PointGray. http://www.ptgrey.com/products/bumblebee2/bumblebee2_stereo_camera.asp. Acesso em 2 de setembro de 2014.

CIFTCIOGLU, O.; BITTERMANN, M. S.; SARIYILDIZ, I S. Sensor Data Fusion in Autonomous Robotics. Innovative Computing, Information and Control, 2007. ICICIC '07. Second International Conference. pp. 26,26, 5-7. 2007.

CORREA, D. S. O; (2012). Navegação autônoma de robôs móveis e detecção de intrusos em ambientes internos utilizando sensores 2D e 3D. Qualificação de mestrado. ICMC/USP, São Carlos - SP. 2011.

CROB (2014). Centro de Robótica de São Carlos. http://www.eesc.usp.br/crob/. Acesso em 2 de setembro de 2014.

DEMPSTER, A. P. (1967a). Upper and Lower Probabilities Induced by a Multivalued Mapping. Annals Mathematics Statistics, 38, 1967, p. 325-339.

DEMPSTER, A. P. (1967b). Upper and Lower Probability Inferences Based on a Sample from a Finite Univariate Population. Biometrika, 54, 1967, pp. 515-528.

DIAS, M. A.; OSÓRIO, F. S. (2011). Hardware/Software Co-design for Image Cross-Correlation. In: INTECH 2011 - International Conference on Integrated Computer Technology, 2011, São Carlos, SP. Proceedings of INTECH 2011 Integrated Computing Technology. Berlin / Heidelberg: Springer Verlag, 2011. v. 165. p. 161-175.

DICKENS, J. S.; GREEN J. J.; VAN WYK M. A. (2011). Human detection for Underground Autonomous Mine Vehicles Using Thermal Imaging. University of the Witwatersrand, Faculty of Engineering and the Built Environment. Johannesburg, South Africa. 2011.

DUDEK, G. e JENKIN, M. (2000). Computational principles of mobile robotics. Cambridge University Press. 
EMMI, L.; GONZALEZ, M.; PAJARES, G.; GONZALEZ, P. New Trends in Robotics for Agriculture: Integration and Assessment of a Real Fleet of Robots. The Scientific World Journal, vol. 2014, Article ID 404059, 21 pages, 2014.

FACELI, K. (2001). Combinação de métodos de inteligência artificial para fusão de sensores. Dissertação de mestrado. ICMC/USP, São Carlos - SP. 2001. Disponível online em: http://www.teses.usp.br/teses/disponiveis/55/55134/tde03052006-093513/pt-br.php. Acesso em 2 de setembro de 2014.

FERNANDES, R. G.; SILVEIRA, R. W.; DÓRIA NETO, A. D. (2004). On Disparity Matching in Stereo Vision via a Neural Networks Framework, Departamento de Engenharia de Computação e Automação - UFRN. 2004.

FISCHLER, M. A.; BOLLES, R. C. (1981). Random sample consensus: a paradigm for model fitting with applications to image analysis and automated cartography. In Commun. ACM, volume 24, pages 381-395, New York, NY, USA. ACM. 1981.

FLIR (2014). FLIR PathFindIR Camera (Thermal Infrared Camera). http://www.flir.com/uploadedFiles/Brochure_PathFindIRTrucking.pdf. Acesso em 2 de setembro de 2014.

GARCIA, A. C. B.; SICHMAN, J. S. (2003). Agentes e sistemas multiagentes. In Sistemas Inteligentes - Fundamentos e Aplicações, chapter 11, p. 269-306. Solange O. Rezende (Org.) Manole.

GIBSON, J.; MARQUES O. (2008) Stereo depth with a Unified Architecture GPU. pp.1-6, 2008 IEEE Computer Society Conference on Computer Vision and Pattern Recognition Workshops, 2008. Disponível online em: http://www.computer.org/portal/web/csdl/doi?doc=doi/10.1109/CVPRW.2008.4563092 . Acesso em 2 de setembro de 2014.

GONÇALVES, P. C. T.; TAVARES J. M. R. S.; JORGE R. N. (2007). Segmentação de Objetos Representados em Imagens Segundo Princípios Físicos. Faculdade de Engenharia do Porto. Portugal. 2007. Disponível online em: http://repositorio-aberto.up.pt/bitstream/10216/395/2/13895.pdf. Acesso em 2 de setembro de 2014.

GOULERMAS, J. Y.; LIATSIS, P. (2002). Feature Based Stereo Matching via Coevolution of Epipolar Subproblems, vol. 1a edição, Seventh International Conference on Image Processing And Its Applications. 2002.

HATA, A. Y. (2010). Mapeamento de Ambientes Externos Utilizando Robôs Móveis. Dissertação de mestrado. ICMC/USP, São Carlos-SP. 2010. Disponível online em: http://www.teses.usp.br/teses/disponiveis/55/55134/tde-1307201014463.php. Acesso em 2 de setembro de 2014. 
INCT-SEC (2014). Instituto Nacional de Ciência e Tecnologia em Sistemas Embarcados Críticos. http://www.inct-sec.org/br/. Acesso em 2 de setembro de 2014.

JACTO (2014). Máquinas Agrícolas Jacto. http://www.jacto.com.br/. Acesso em 2 de setembro de 2014.

JADIN, M. S.; TAIB, S. (2012). Infrared Image Enhancement and Segmentation for Extracting the Thermal Anomalies in Electrical Equipment. Electronics and Electrical Engineering. - Kaunas: Technologija, 2012. - No. 4(120). - P. 107-112.

KAM, M.; XIAOXUM, Z.; KALATA, P. Sensor fusion for mobile robot navigation. Proceedings of the IEEE, vol.85, no. 1, pp. 108, 119. 1997.

KIRNER, C.; TORI, R. (2004). Realidade Virtual: Conceitos e Tendências. Editora SBC. 2004.

KLASER, R. Navegação de veículos autônomos em ambientes externos não estruturados baseada em visão computacional. Dissertação de mestrado. ICMC/USP, São Carlos-SP. 2013. Disponível on-line em: http://lrm.icmc.usp.br/wiki/images/0/08/KLASER-Mestrado2014.pdf. Acesso em 30 de setembro de 2014.

LEE, J.; GRANE, C. D.; KIM, S.; KIM, J. (2005). Road Following in an Unstructured Desert Environment using Monocular Color Vision as Applied to the DARPA Grand Challenge. Florida. University of Florida. 2005.

LI, G.; HE, Y. (2002). A hierarchical combined feature and area-based stereo matching algorithm, 2a edição, Circuits and Systems, 2002. ISCAS 2002. IEEE International Symposium.

LI, M.; IMOU, K.; WAKABAYASHI, K.; YOKOYAMA, S. (2009). Review of research on agricultural vehicle autonomous guidance. Int J Agric \& Biol Eng, 2009; 2(3): $1-16$.

LRM (2014). Laboratório de Robótica Móvel - ICMC - USP. http://lrm.icmc.usp.br/. Acesso em 2 de setembro de 2014.

MARAPANE, S. B.; TRIVEDI, M. M. (1989). Region-based stereo analysis for robotic applications, Systems, Man and Cybernetics, IEEE Transactions. 1989.

MATARIĆ, M. J. (2007). The Robotics Primer. The MIT Press: Cambridge, Massachusetts. 2007.

MAYBANK, S.; FAUGERAS, O. (1992). A theory of self-calibration of a moving camera. The International Journal of Computer Vision, 8(2):123-151. 
MENDES, C. C. T. (2012). Navegação de robôs móveis utilizando visão estéreo. Dissertação de Mestrado: USP - ICMC: São Carlos, 2012. Disponível em: http://www.teses.usp.br/teses/disponiveis/55/55134/tde-18062012-162436/pt-br.php. Acesso em 2 de setembro de 2014.

MURARKA, A.; SRIDHARAN, M.; KUIPERS, B. (2008). Detecting obstacles and drop-offs using stereo and motion cues for safe local motion. Intelligent Robots and Systems, 2008. IROS 2008. IEEE/RSJ International Conference on, pages 702 708. 2008.

MURPHY, R. R. (2000). Introduction to Al Robotics. The MIT Press: Cambridge, Massachusetts. 2000.

NIN, M. H. C. (2011). Integração de câmera térmica e sensor laser para detecção de pessoas. Trabalho de conclusão de curso (bacharelado em ciências de computação), Instituto de Ciências Matemáticas e de Computação - Universidade de São Paulo, São Carlos-SP, 2011.

OPENCV (2014). Open Source Computer Vision. http://opencv.willowgarage.com/wiki/. Acesso em 2 de setembro de 2014.

OTSU, N. (1979). A threshold selection method from gray-level histograms. In: N/A, 1979, p. 62-66.

PCL (2014). Point Cloud Library. http://pointclouds.org/about.html. Acesso em 2 de setembro de 2014.

ROS (2014). Robot Operating System. http://www.ros.org/wiki/. Acesso em 2 de setembro de 2014.

SALES, D. O.; SHINZATO, P. Y.; PESSIN, G.; OSÓRIO, F. S.; WOLF, D. F. (2010). Vision-Based Autonomous Navigation System Using ANN and FSM Control, IEEE Latin American Robotics Symp. - LARS, p. 85-90. 2010.

SALVI, J.; ALMANGUÉ, X.;BATLLE, J. (2002). A comparative review of camera calibrating methods with accuracy evalution. Pattern Recognition vol. 35,pg 16171635, 2002.

SCARAMUZZA, D.; SIEGWART, R.; NOURBAKHSH, I. (2011). Introduction to Autonomous Mobile Robots, Mit Press, 2011.

SHAFER, G. (1976). A mathemathical theory of evidence. Princeton, Princeton University Press, 1976.

SHINZATO, P. Y. (2010). Sistema de identificação de superfícies navegáveis baseado em visão computacional e redes neurais artificiais. Dissertação de Mestrado: 
USP - ICMC: São Carlos, 2010. 77 p. Disponível em: http://www.teses.usp.br/teses/disponiveis/55/55134/tde-16122010-162924/pt-br.php. Acesso em 2 de setembro de 2014.

SIEGWART, R. e NOURBAKHSH, I. R. (2004). Introduction to Autonomous Mobile Robots. The MIT Press.

SOUZA, J.; OSÓRIO, F.; PESSIN, G.; SHINZATO, P.; WOLF, D. Vision-based waypoint following using templates and artificial neural networks. Neurocomputing (Amsterdam), p. 77-86, 2013.

SOUZA, J. R.; SALES, D. O.; SHINZATO, P.; OSÓRIO, F. S.; WOLF, D. F. (2011) Template-based autonomous navigation and obstacle avoidance in urban environments. ACM Applied Computing Review, v. 11, p. 49-59, 2011.

SUNYOTO, H. W. V. D. Mark; GAVRILA, D. M. (2004). A comparative study of fast dense stereo vision algorithms, Intelligent Vehicles Symposium, 2004 IEEE. 2004.

TRICLOPS SDK. (2014). Stereo Vision Camera Control and Image Acquisition Software. http://www.ptgrey.com/products/triclopsSDK/index.asp. Acesso em 2 de setembro de 2014.

TSAI, R. Y. (1987). A Versatile Camera Calibration Technique for HighAccuracy 3D Machine Vision Metrology Using Off-the-Shelf Cameras and Lenses. IEEE Journal of Robotics and Automation, vol. RA-3, 1987.

WANG, J. H.; HSIAO, C. P. (1999). On Disparity Matching in Stereo Vision via a Neural Networks Framework, Natl. Sci. Counc. ROC. 1999.

WOLF, D.; OSÓRIO, F. S.; SIMÕES, E.; TRINDADE, O. (2009) Robótica Inteligente: Da Simulação às Aplicações no Mundo Real. In: JAI - Jornada de Atualização em Informática 2009 (Tutorial) - Congresso da SBC - Bento Gonçalves. SBC - Editora da PUC Rio: Rio de Janeiro-RJ. 2009.

YAGHOUBI, S.; AKBARZADEH, N. A.; BAZARGANI, S. S.; BAZARGANI S. S.; BAMIZAN, M.; ASL, M. I. Autonomous Robots for Agricultural Tasks and Farm Assignment and Future Trends in Agro Robots. International Journal of Mechanical \& Mechatronics Engineering. IJMME-IJENS, vol. 13, n. 03, Jun. 2013. 


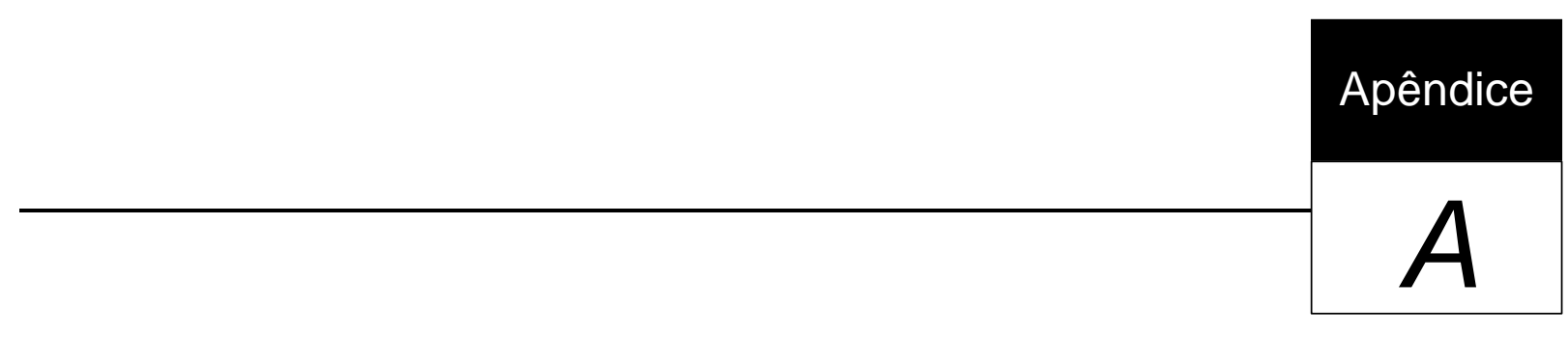

\section{Publicações Obtidas Como Resultado Deste Trabalho}

1 UTINO, V. M.; WOLF, D. F.; OSÓRIO, F. S. Data Fusion Obtained from Multiple Images Aiming the Navigation of Autonomous Intelligent Vehicles in Agricultural Environment. LARS-SBR 2014: Latin-American and Brazilian Robotics Symposium. IEEE Press, $2014 . \quad$ p.1-6. http://ieeexplore.ieee.org/xpl/articleDetails.jsp?tp=\&arnumber=7024274. Acesso em 4 de Fevereiro de 2015. 